\title{
The EPO/EPOR system in the brain: Search for mechanisms of action
}

\section{Dissertation}

\author{
for the award of the degree \\ "Doctor rerum naturalium" \\ Division of Mathematics and Natural Sciences \\ at the Georg August University Göttingen
}

submitted by

Liane Dahm

born in Wiesbaden

Göttingen 2013 


\section{Doctoral thesis committee}

Prof. Dr. Dr. Hannelore Ehrenreich (supervisor, first reviewer)

Clinical Neuroscience

Max Planck Institute of Experimental Medicine

Hermann-Rein-Straße 3

37075 Göttingen

Germany

Prof. Dr. Klaus-Armin Nave (second reviewer)

Department of Neurogenetics

Max Planck Institute of Experimental Medicine

Hermann-Rein-Straße 3

37075 Göttingen

Germany

Prof. Dr. Michael Müller

Department of Neuro- and Sensory Physiology

Georg-August-University

Humboldtallee 23

37073 Göttingen

Germany

Date of submission of the thesis: March 28, 2013

Date of oral examination: May 8, 2013 


\section{Declaration}

I hereby declare that the thesis "The EPO/EPOR system in the brain: Search for mechanisms of action" has been written independently and with no other sources and aids than quoted. 


\section{Acknowledgement}

I would like to thank my supervisor and first thesis committee member Prof. Hannelore Ehrenreich. I am sincerely grateful to Prof. Hannelore Ehrenreich for giving me the opportunity to work on very interesting projects in the amazing scientific atmosphere of the Max Planck Institute of Experimental Medicine in Göttingen. I would like to thank her for her continues support and guidance during my doctoral thesis and her open door whenever I needed advice.

I would like to thank my additional thesis committee members Prof. Klaus-Armin Nave and Prof. Michael Müller for their efforts and constructive discussions during my progress report meetings.

I would like to thank the present and past members of my research group, especially the lab team. It was a pleasure to work with Kathrin Hannke, Swetlana Sperling, Nora Hagemeyer, Sabrina Grube, Imam Hassouna, Kati Ostmeier, Christoph Ott, Mathieu Monnheimer and Niels Jensen. I am particularly grateful to Kathrin Hannke for her outstanding support during many cell culture experiments and to Swetlana Sperling for her continuous advice and our evening discussions. Furthermore, I would like to thank Kati Ostmeier for helping out whenever it was needed. I would like to thank the behavior team and particularly Daniela Winkler and Anja Ronnenberg for performing all behavior tests with the Viaat-HA-cEPOR mice, as well as Prof. Ekrem Dere and Martesa Tantra for their constructive discussions.

Many great collaborators within the institute as well as external ones have supported my work. I am especially thankful to Sonja Wojcik for her excellent scientific supervision during the creation of the transgenic mouse and Astrid Zeuch for her assistance during the cloning procedures. I would like to thank Christoph Bredack for recording the gamma oscillations of the transgenic animals and his patience in answering many questions. I would like to thank Prof. Michael Müller and Oliwia Jank for measuring the long term potentiation in the ViaatHA-cEPOR mice, Miso Mitkovski for his continuous advice during confocal microscopy, Richard Neher for his help in the analysis of the quadruple staining, and Prof. Anna-Leena Sirén and Nils Offen for providing many neurosphere cultures.

Last but not least I would like to express my deepest and warmest gratitude to my family and Andreas Wüstefeld for always being next to me, their support, encouragement and understanding during the time of my doctoral thesis. 


\section{Table of content}

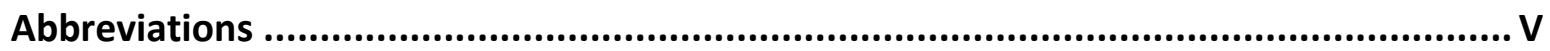

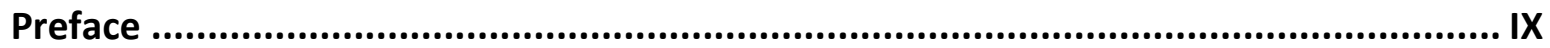

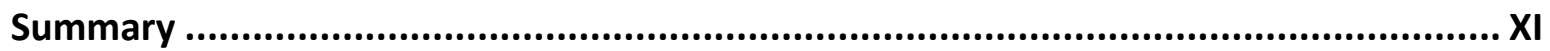

1 Introduction ...............................................................1

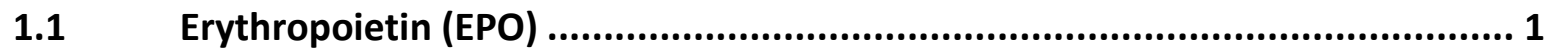

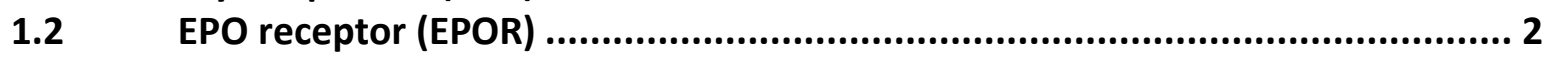

$1.3 \quad$ EPO/EPOR system in the brain.............................................................. 3

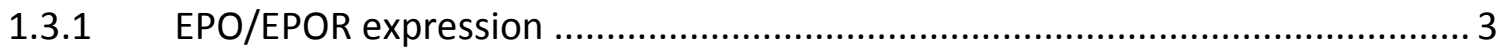

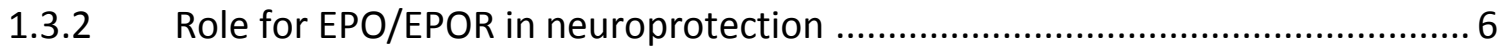

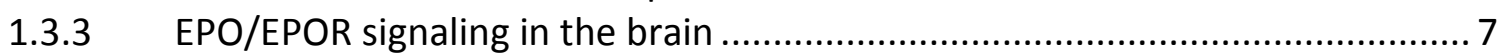

$1.4 \quad$ EPO/EPOR and cognition ...................................................................... 8

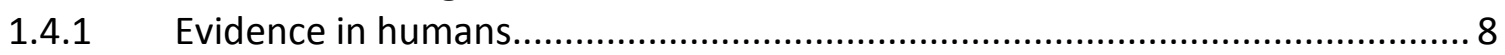

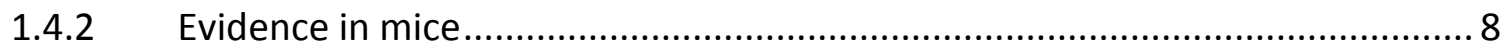

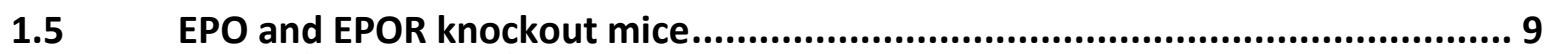

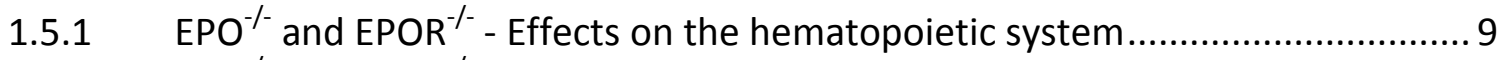

1.5.2 $\mathrm{EPO}^{-/}$and $\mathrm{EPOR}^{-/-}$- Effects on non-hematopoietic tissues .............................. 10

1.5.3 $\mathrm{EPOR}^{-1-}$ knockouts rescued for the hematopoietic lineage ............................ 11

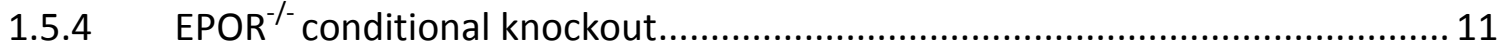

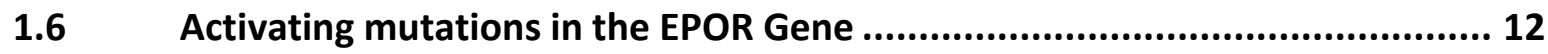

1.6.1 Natural occurring mutations in the human EPOR Gene ................................. 12

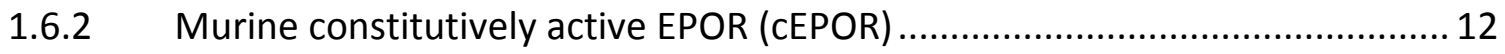

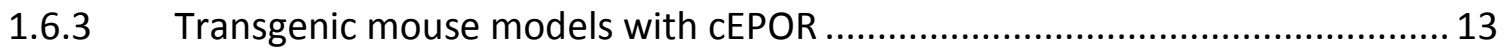

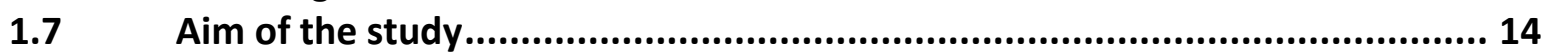

2 Methods...................................................................... 15

Methods Part I ...................................................................................15

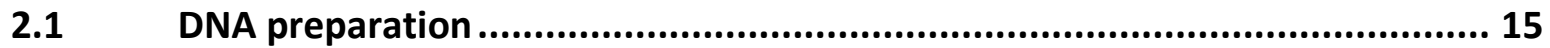

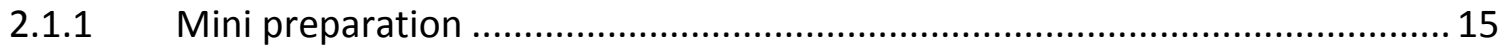

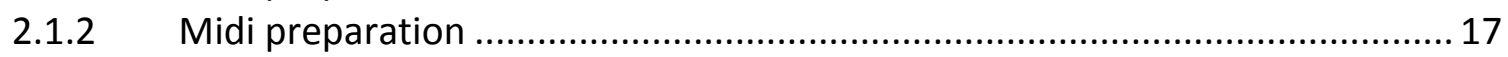

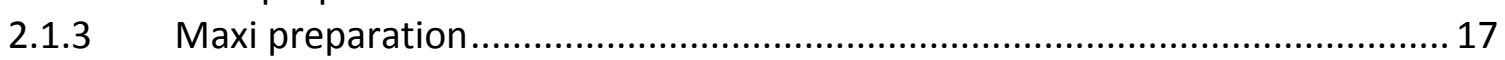

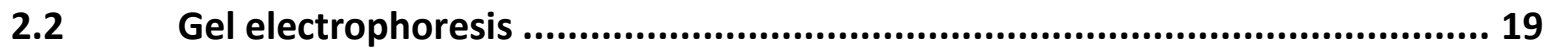

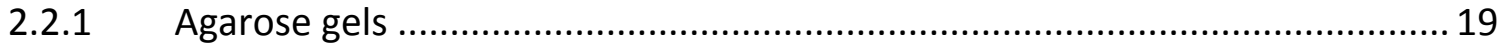

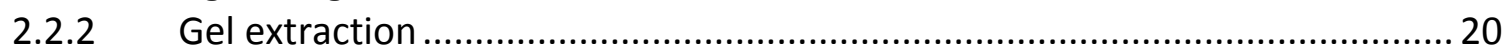

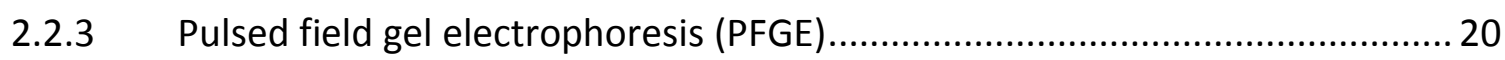

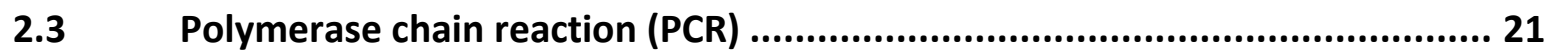

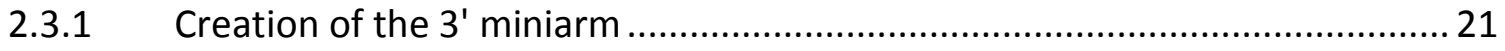

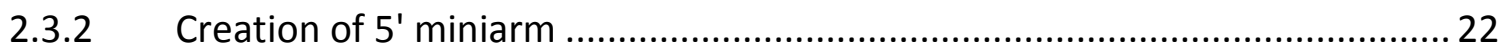

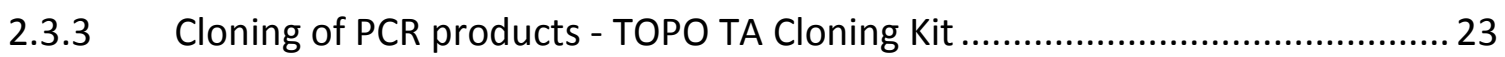

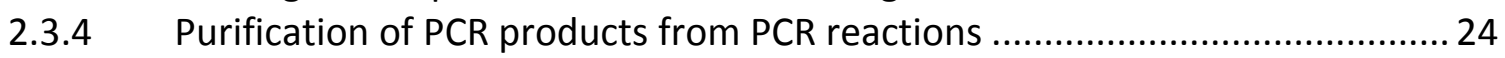

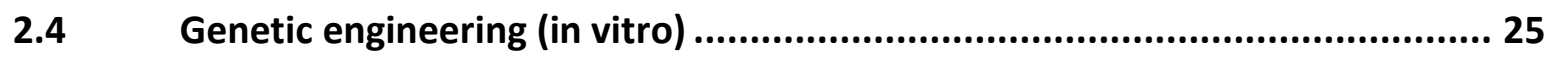

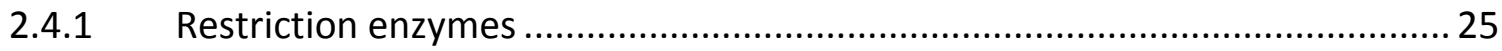

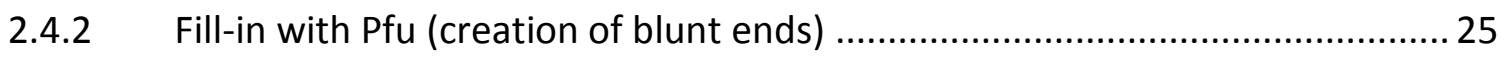

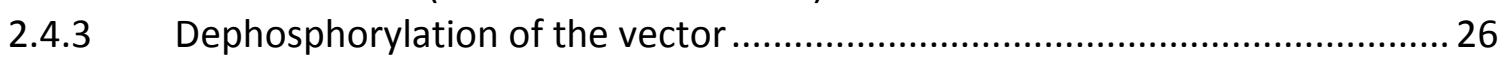

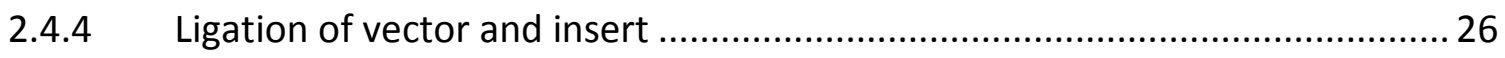




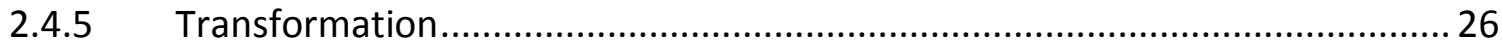

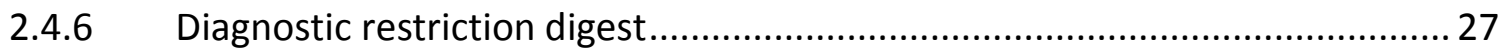

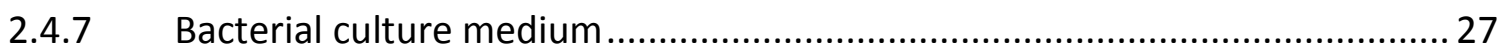

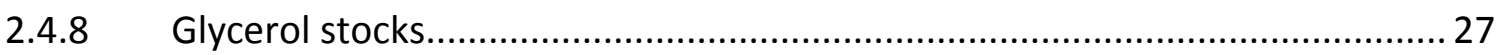

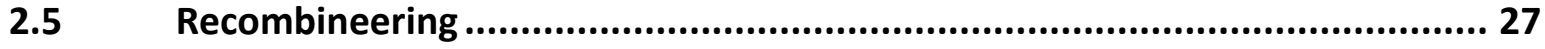

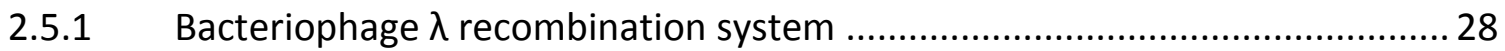

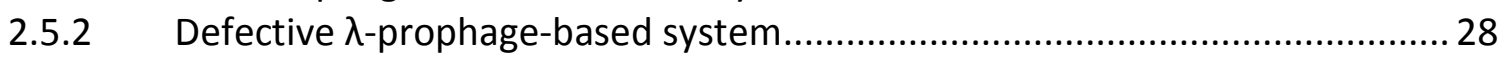

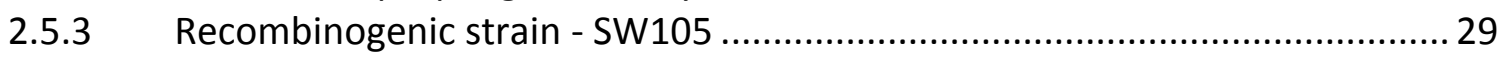

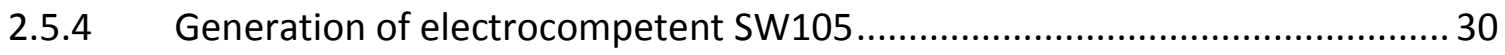

2.5.5 Transformation of the BAC into the recombinogenic strain SW105 .............. 30

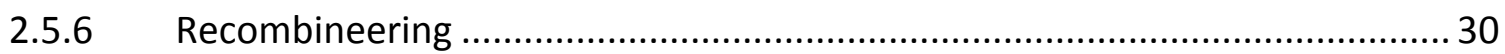

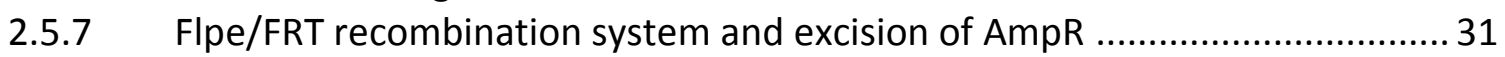

2.6 Linearization of the BAC and pronuclear injection .........................................33

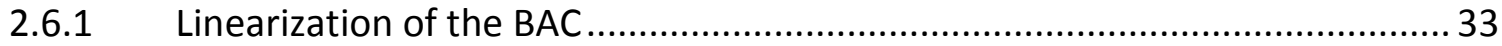

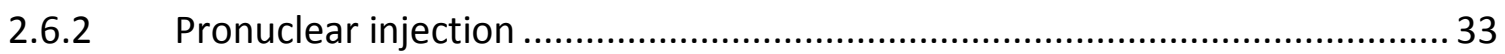

Methods Part II ......................................................................................35

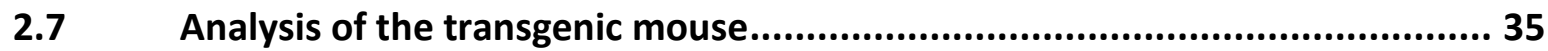

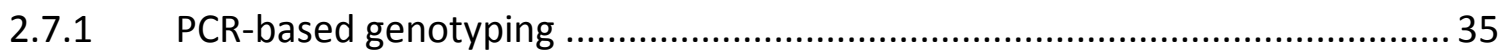

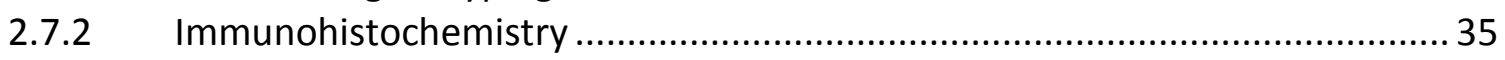

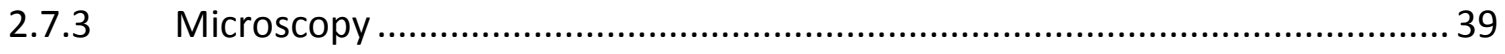

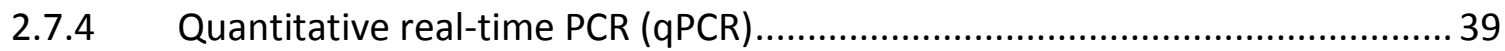

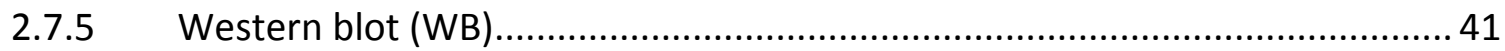

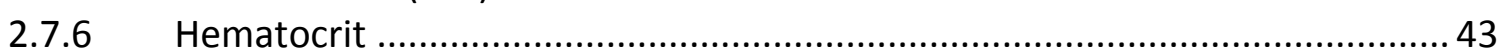

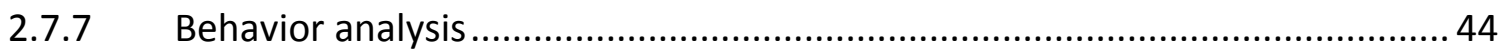

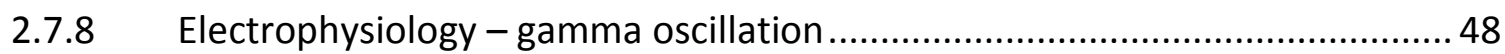

2.7.9 Electrophysiology - Long Term Potentiation (LTP) ....................................... 49

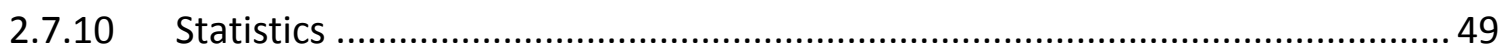

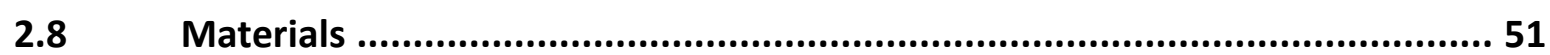

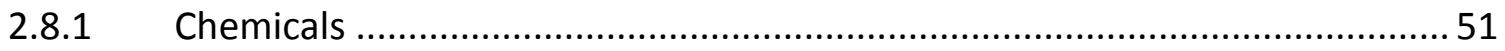

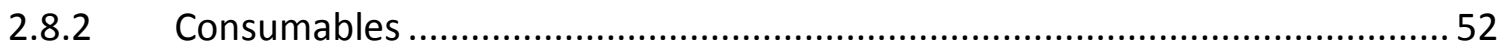

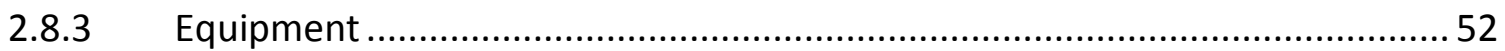

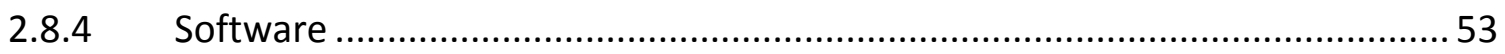

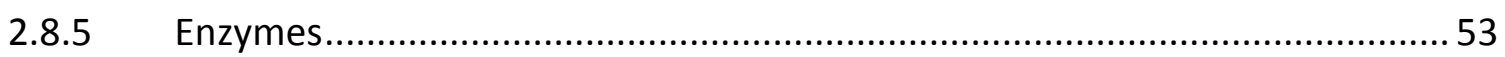

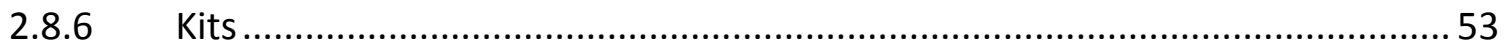

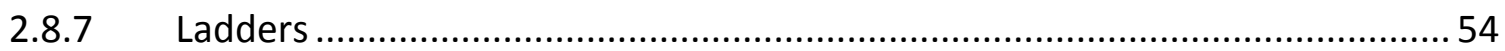

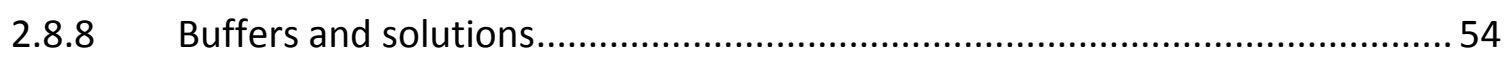

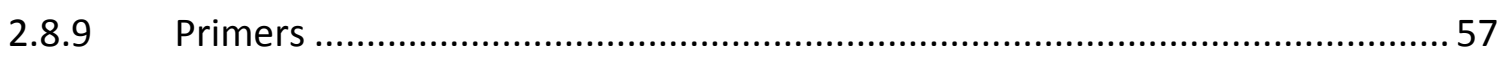

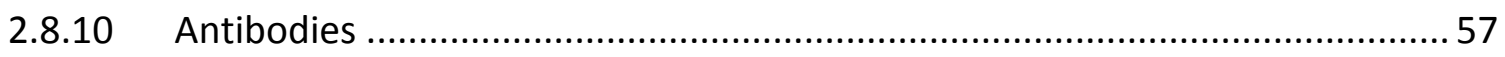

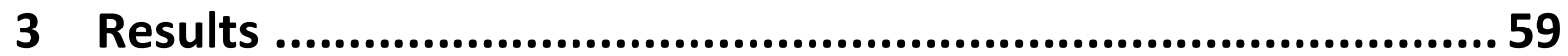

Results Part I .............................................................................59

3.1 Cloning of Viaat-HA-cEPOR ( \pm IRES-Venus) ........................................... 59

3.1.1 Step 1 - Validation of restriction cutting sites of alpha-CaMKII-HA-CEPOR ..... 59

3.1.2 Step 2 - Insertion of IRES-Venus into alpha-CaMKII-HA-CEPOR ....................... 61

3.1.3 Step 3 - Insertion of ampicillin resistance (AmpR) with FRT sites.....................62 62

3.1.4 Step 4 - Creation of 5' and 3' miniarms for recombineering ...........................63

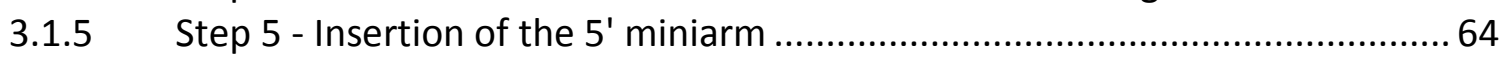

3.1.6 Step 6 - Insertion of the 3' miniarm and a kanamycin resistance (KanR) ........ 64 


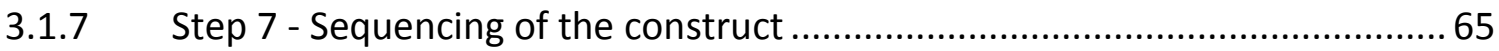

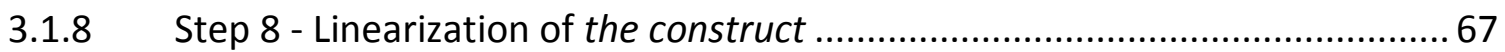

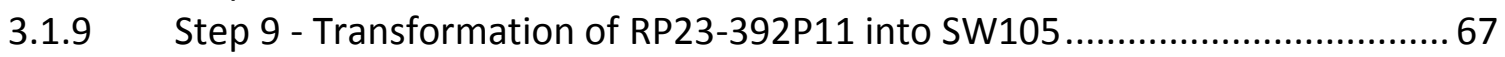

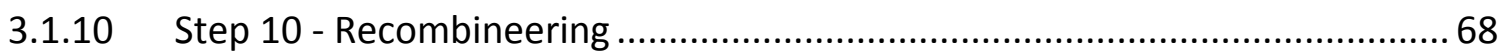

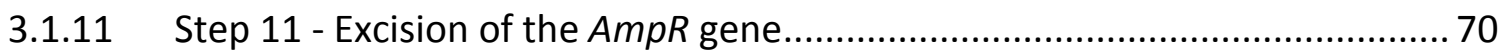

3.1.12 Step 12 - Linearization and purification of the BAC for pronuclear injection.. 71

Results part II ..........................................................................73

3.2 Analysis of Viaat-HA-cEPOR \pm IRES-Venus mouse lines................................... 73

3.2.1 Identification of transgenic offspring by genotyping PCR - FO generation ..... 73

3.2.2 Analysis of the construct expression by immunohistochemistry .................... 76

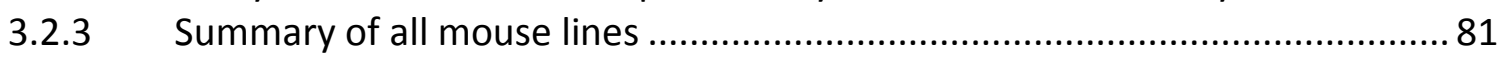

3.3 Analysis of mouse line D14-0023 (Viaat-HA-cEPOR) ................................ 82

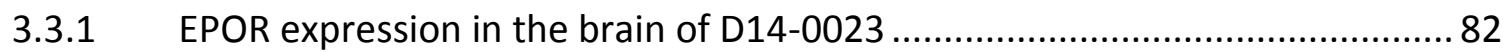

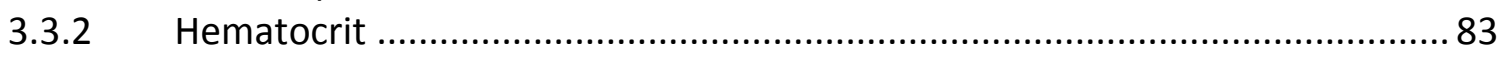

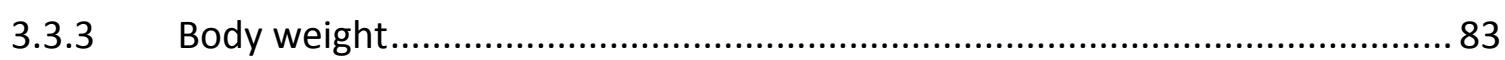

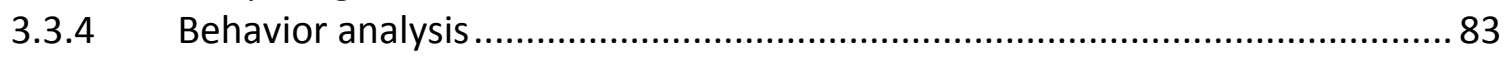

3.3.5 Electrophysiology - kainate induced gamma oscillation .............................. 87

3.3.6 Electrophysiology - short and long term potentiation (STP and LTP) .............88

4 Discussion ................................................................. 89

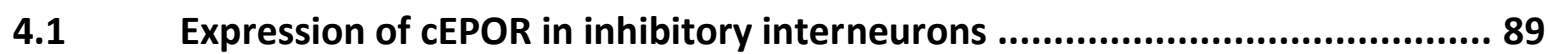

4.2 Analysis of the Viaat-HA-cEPOR line D14-0023.......................................... 91

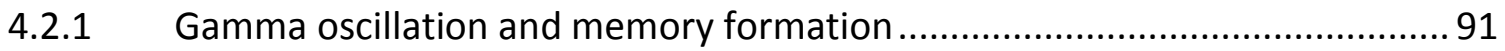

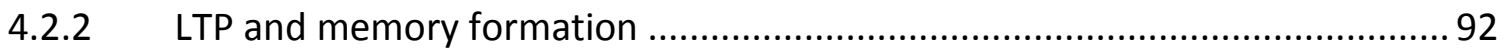

4.2.3 Comparison with EPO treated and with alpha-CaMKII-HA-cEPOR mice .......... 93

4.2.4 Body weight and metabolism................................................................. 94

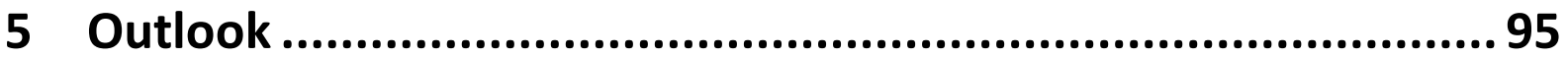

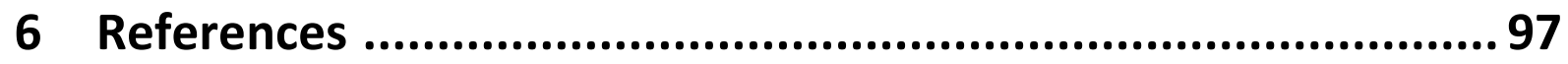

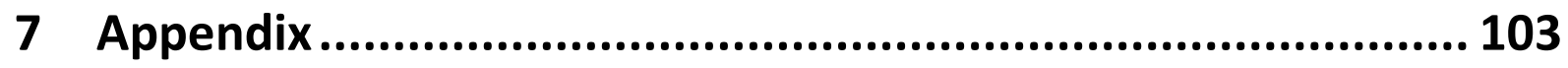

8 Curriculum Vitae.................................................................. 105 


\section{Abbreviations}

\begin{tabular}{|c|c|}
\hline $\mathrm{ABC}$ & Avidin-biotin complex \\
\hline ACSF & Artificial cerebrospinal fluid \\
\hline alpha-CaMKII & alpha-Ca2+/calmodulin-dependent protein kinase II \\
\hline AM & Ante meridiem \\
\hline Amp & Ampicillin \\
\hline AmpR & Ampicillin resistance \\
\hline ANOVA & Analysis of variance \\
\hline AKT & AKT8 virus oncogene cellular homolog/ protein kinase $B$ \\
\hline APS & Ammonium persulfate \\
\hline $\mathrm{AU}$ & Arbitrary units \\
\hline BAC & Bacterial artificial chromosome \\
\hline BBB & Blood-brain barrier \\
\hline BSA & Bovine serum albumin \\
\hline bp & Base pairs \\
\hline C & Cysteine \\
\hline${ }^{\circ} \mathrm{C}$ & Degrees Celsius \\
\hline CA1 & Cornu ammonis 1 \\
\hline $\mathrm{CB}$ & Cerebellum \\
\hline cDNA & Complementary DNA \\
\hline cEPOR & Constitutively active erythropoietin receptor \\
\hline ChAT & Choline acetyltransferase \\
\hline CHEF & Contour-clamped homogeneous electric field \\
\hline $\mathrm{Chl}$ & Chloramphenicol \\
\hline CT & Cycle threshold \\
\hline $\mathrm{CX}$ & Cortex \\
\hline DAPI & 4',6-diamidino-2-phenylindole \\
\hline $\mathrm{db}$ & Decibel \\
\hline $\mathrm{ddH}_{2} \mathrm{O}$ & Deionized water (Milipore quality $<0.055 \mu \mathrm{S} / \mathrm{cm}$ ) \\
\hline DNA & Deoxyribonucleic acid \\
\hline DTT & Dithiothreitol \\
\hline dNTPs & Desoxyribonucleoside triphosphate \\
\hline $\mathrm{E} 1, \mathrm{E} 2$ & Exon1, Exon2 \\
\hline$E 10,13,17, \ldots$ & Embryonic day $10,13,17, \ldots$ \\
\hline EDTA & Ethylenediaminetetraacetic acid \\
\hline EPO & Erythropoietin \\
\hline EPOR & Erythropoietin receptor \\
\hline ERK & Extracellular signal-regulated protein kinase \\
\hline $\mathrm{EtBr}$ & Ethidium bromide \\
\hline fEPSP & Field excitatory post-synaptic potential \\
\hline FA & Formaldehyde \\
\hline 5CSRTT & Five choice serial time task \\
\hline g & Gram \\
\hline GABA & Gammaaminobutyric acid \\
\hline GAPDH & Glyceraldehyde-3-phosphate dehydrogenase \\
\hline GATA-1 & Globin transcription factor 1 \\
\hline GFP & Green fluorescent protein \\
\hline GLUT-1 & Glucose transporter 1 \\
\hline h & Height \\
\hline
\end{tabular}




\begin{tabular}{|c|c|}
\hline $\mathrm{h}$ & Hour \\
\hline $\mathrm{HA}$ & Hemagglutinin \\
\hline HRP & Horseradish peroxidase \\
\hline hEPOR & Human erythropoietin receptor \\
\hline hGFAP & human glial fibrillary acidic protein \\
\hline HIF & Hypoxia inducible factor \\
\hline HRD & Hematopoietic regulatory domain \\
\hline HRE & Hypoxia response element \\
\hline $\mathrm{HP}$ & Hippocampus \\
\hline IL-3 & Interleukin-3 \\
\hline IT & Infratentorial \\
\hline IRES & Internal ribosome entry site \\
\hline JAK2 & Janus kinase 2 \\
\hline $\mathrm{kb}$ & Kilo base pairs \\
\hline $\mathrm{kg}$ & Kilogram \\
\hline $\mathrm{kHz}$ & Kilohertz \\
\hline Kan & Kanamycin \\
\hline KanR & Kanamycin resistance \\
\hline I & Length \\
\hline LB & Luria broth \\
\hline LTD & Long term depression \\
\hline LTP & Long term potentiation \\
\hline$M$ & Molar \\
\hline MAPK & Mitogen-activated protein kinase \\
\hline MAP2 & Microtubule-associated protein 2 \\
\hline MCAO & Middle cerebral artery occlusion \\
\hline $\min$ & Minutes \\
\hline MIMS & Multi-isotope imaging mass spectrometry \\
\hline $\mathrm{ml}$ & Mililiter \\
\hline $\mathrm{mm}$ & Milimeter \\
\hline $\mathrm{mM}$ & Milimolar \\
\hline $\mathrm{ms}$ & Miliseconds \\
\hline MS & Multiple sclerosis \\
\hline NF-KB & Nuclear factor $\mathrm{kB}$ \\
\hline mEPOR & Mouse erythropoietin receptor \\
\hline NHS & Normal horse serum \\
\hline no. & Number \\
\hline OD & Optical density \\
\hline PAGE & Polyacrylamide gel electrophoresis \\
\hline PBS & Phosphate buffered saline \\
\hline PCR & Polymerase chain reaction \\
\hline PFGE & Pulse field gel electrophoresis \\
\hline $\mathrm{pH}$ & $=-\lg \left[\mathrm{H}^{+}\right]$ \\
\hline $\mathrm{PI3K}$ & Phosphoinositol-3-kinase \\
\hline PM & Post meridiem \\
\hline PMSF & Phenylmethylsulfonyl fluoride \\
\hline POMC & Proopiomelanocortin \\
\hline PPI & Prepulse inhibition \\
\hline PV & Poliovirus \\
\hline$\overline{q P C R}$ & Quantitative polymerase chain reaction \\
\hline $\mathrm{R}$ & Arginine \\
\hline
\end{tabular}




\begin{tabular}{|l|l|}
\hline rhEPO & Recombinant human EPO \\
\hline RNase & Ribonuclease \\
\hline RT & Room temperature \\
\hline rpm & Revolution per minute \\
\hline sEPOR & Soluble EPOR \\
\hline S & Seconds \\
\hline SDS & Sodium dodecyl sulfate \\
\hline SEM & Standard error of the mean \\
\hline ST & Supratentorial \\
\hline STATs & Signal transducers and activators of transcription \\
\hline STD & Short term depression \\
\hline STP & Short term potentiation \\
\hline$U$ & Units \\
\hline TAE & Tris/acetate/EDTA \\
\hline TBE & Tris/borate/EDTA \\
\hline TBS & Tris buffered saline \\
\hline TBST & Tris buffered saline/Tween20 \\
\hline TE & Tris/EDTA \\
\hline TEMED & $N, N, N ', N '$-Tetramethylethylenediamine \\
\hline tg & Transgenic \\
\hline TSA & Tyramide signal amplification \\
\hline TUNEL & Terminal deoxynucleotidyl transferase dUTP nick end labeling \\
\hline TWEEN20 & Polyethylene glycol (20) sorbitan monolaurate \\
\hline rtPA & Recombinant tissue-type plasminogen activator \\
\hline UTR & Untranslated region \\
\hline V & Volt \\
\hline VEGF & Vascular endothelial growth factor \\
\hline VGAT & Vesicular GABA transporter \\
\hline Viaat & Vesicular inhibitory amino acid transporter \\
\hline Vs. & Versus \\
\hline w & Width \\
\hline wt & Wildtype \\
\hline$\mu g$ & Microgram \\
\hline$\mu \mathrm{l}$ & Microliter \\
\hline$\mu m$ & Micrometer \\
\hline & \\
\hline & \\
\hline
\end{tabular}




\section{Preface}

During my doctoral thesis I worked on three projects, investigating the function of erythropoietin (EPO) and its receptor (EPOR) in the brain. The projects aimed at a better understanding of the cellular and molecular basis of the previously described EPO-induced cognitive improvement found in mouse and man. These three projects were as following:

\section{1.) In vitro analysis of proliferation and differentiation}

in EPO-treated neurospheres and primary hippocampal cultures

Result: $\quad$ Erythropoietin reduces proliferation in neurospheres and accelerates differentiation of neural precursors in neurosphere and hippocampal cultures

2.) Creation and analysis of a transgenic mouse line expressing a constitutively active EPOR in GABAergic and glycinergic interneurons

Result: $\quad$ Constitutively active EPOR in GABAergic and glycinergic interneurons increases LTP but decreases acquisition learning

\section{3.) In vitro analysis of microglia motility after stimulation and examination of} underlying signaling pathways

Result: $\quad$ Erythropoietin reduces microglia motility and changes the phosphorylation kinetics of the ERK pathway

Project 1 shows for the first time that EPO is able to increase the number of neurons and oligodendrocytes in the hippocampus of juvenile mice. This publication is currently in the process of revision. The manuscript with a description of my contribution is presented in the appendix.

Project 2 includes the creation of a transgenic mouse line and its early analysis. The study is not ready to be submitted for publication yet. A plan of still to be performed experiments can be found in the outlook section.

Project 3 is still work in progress and therefore not included in this thesis. First results showed reduced migration of stimulated EPO-treated primary microglia cultures. Additionally, changes in the phosphorylation kinetics of the ERK pathway could be observed after EPO treatment. 


\section{Summary}

Erythropoietin (EPO) and its receptor (EPOR) are known to be essential for erythropoiesis. However, the EPO/EPOR system turned out to have additional important functions in nonhematopoietic tissue. The brain is one of the target areas and both, EPO and EPOR, are expressed in the brain. EPO has been shown to be neuroprotective and to improve the cognitive performance of patients suffering from schizophrenia and multiple sclerosis. Interestingly, the mechanism of cognitive enhancement is also present in healthy individuals and genetic common variants of EPO/EPOR can actually influence cognitive performance. The cellular and molecular basis of this phenomenon is not totally understood and by systemically administered EPO, it is difficult to separate the direct effect on neural cells from hematopoietic effects through enhanced tissue oxygenation. In this study, a transgenic mouse line was generated expressing a constitutively active EPOR (CEPOR) in GABAergic and glycinergic interneurons in order to enable us to specifically examine the impact of EPO/EPOR on cognition, when expressed in inhibitory neurons. For this purpose, the cEPOR construct was inserted into the Viaat bacterial artificial chromosome (BAC) RP23-392P11 and microinjected into fertilized eggs of $\mathrm{C} 57 \mathrm{BL} / 6 \mathrm{~N}$ females. Nine independent mouse strains were generated by breeding the founders with wildtype mice. The strains showed varying levels of construct expression and one strain actually had an insertion of different copy numbers in two different chromosomes. This relatively rare event in strain D14-0023 was further analyzed. Indeed, the offspring of D14-0023 segregated into low and high expressers, which was confirmed on the mRNA and protein levels. The phenotype of low and high expressers was then investigated in behavior and electrophysiological tests. Here, the basic behavior of the transgenic mice appeared to be comparable to wildtypes with respect to anxiety, olfaction, hearing, motor performance and pain perception. In the hole board working memory task, the transgenic mice showed a worse performance in rule learning in the acquisition phase, but no significant differences between the low and high expressers. Electrophysiological tests were conducted with the high expressers, measuring gamma oscillation and long term potentiation in the hippocampus. Whereas a significant influence of cEPOR could not be found in the gamma oscillation, short and long-term potentiation was increased. Hence, the study provides new information about the influence of the EPO/EPOR system on synaptic plasticity and cognitive performance. Importantly, the effects are pure neuronal effects, excluding hematopoietic side effects as confounding factors. 



\section{Introduction}

\subsection{Erythropoietin (EPO)}

Erythropoietin (EPO) is a hematopoietic growth factor and the main regulator of erythropoiesis. EPO is known to support the survival of erythroid progenitor cells by preventing their apoptosis and by inducing terminal differentiation (Jelkmann, 1992; Jelkmann and Metzen, 1996). Under normoxic conditions, the hormone's plasma levels are very low $\left(\sim 10^{-11} \mathrm{M}\right)$ which hindered the isolation and purification for a long time. Already in 1906, Carnot described a humoral factor, which stimulated the red blood cell production (Fisher, 2010). In 1948, Bonsdorff and Jalavisto gave the humoral factor the present name 'Erythropoietin'. It then took almost another 30 years before Miyake was able to purify EPO from the urine of aplastic anemia patients (Miyake et al., 1977). This was a milestone in the EPO research and important for its characterization, cloning (Jacobs et al., 1985; Lin et al., 1985) and in vitro expression (Davis et al., 1987; Sasaki et al., 1987). After the promising results of Eschbach, showing that recombinant EPO (rhEPO) increases the hematocrit in anemic patients with end stage renal disease (Eschbach et al., 1987), rhEPO was approved in June 1989 by the American Food and Drug Administration for the treatment of patients with chronic renal failure (Fisher, 2003). At that time, rhEPO was first produced and put on the market by Amgen.

Human EPO is a glycoprotein with a size of $\sim 30 \mathrm{kDa}$, although it appears with sizes of 30 38 kDA in SDS-polyacrylamide gels (Jelkmann, 2004; Noguchi et al., 2008) because of different carbohydrate contents. EPO is composed of about $60 \%$ protein and $40 \%$ carbohydrate; the protein core is important for binding to its receptor and the carbohydrates stabilize the hormone by preventing degradation. The human EPO gene is located on chromosome 7 (q11-22), it includes five exons and four introns, and codes for a single polypeptide with 165 amino acids. The sequence is highly conserved and the murine gene, located on chromosome 5 , shows $80 \%$ homology to the human protein.

The EPO expression in fetal liver and adult kidney can be upregulated under hypoxic conditions up to 1000-fold (Ebert and Bunn, 1999). The transcription of the EPO gene is enhanced by binding of the hypoxia inducible factor (HIF) to the hypoxia-responsive element (HRE), which was first found in the EPO mRNA 3' UTR of hepatocytes (Semenza and Wang, 
1992). Under normoxic conditions HIF1- $\alpha$ is hydroxylated by prolyl hydroxylases, which enables the binding of the von Hippel-Lindau factor, leading to ubiquitination and degradation in the proteasome. Under hypoxic conditions HIF1- $\alpha$ forms a dimer with HIF1- $\beta$, which bind to the HRE. However, the regulation of the EPO gene is cell-type specific. The utilization of the promoter varies between different cell types and another HRE was also found in the EPO 5' UTR (Haase, 2010). Additionally, it has to be noted that HIF2- $\alpha$ may be more important for EPO gene regulation than HIF1- $\alpha$, which might preferentially enhance VEGF and GLUT-1 transcription (Noguchi et al., 2008).

\subsection{EPO receptor (EPOR)}

With the availability of pure rhEPO, the search for its receptor and signaling pathways started, leading to the first publication in 1987, where the murine EPOR (mEPOR) was identified in primary erythroid progenitor cells by cross-linking studies with radiolabled ${ }^{125}$ IEPO (Sawyer et al., 1987). Only two years later, the mEPOR was cloned and isolated from a pMX expression library made from a murine erythroleukemia cell line (D'Andrea et al., 1989). In 1990, the human EPOR (hEPOR) was isolated from the human erythroleukemia cell line OCIM1 and fetal liver (Jones et al., 1990) and found to share around $82 \%$ homology with the mEPOR. The mEPOR gene spans around $5 \mathrm{~kb}$, contains eight exons, and produces a 507 amino acid protein with a predicted molecular weight of $55 \mathrm{kDa}$ (Youssoufian et al., 1990). Glycosylation of the EPOR causes the protein to appear with a size of $66 \mathrm{kDa}$ in SDSpolyacrylamide gels. Additional phosphorylation can shift the protein size even up to $72 \mathrm{kDa}$ (Youssoufian et al., 1993). The EPOR contains a single hydrophobic transmembrane domain, separating the extracellular from the intracellular domain. The extracellular domain contains 4 conserved cysteine residues and a Trp-Ser-X-Trp-Ser (WSXWS) motif, which classifies the EPOR as a cytokine class I receptor (Constantinescu et al., 1999a). The intracellular domain is divided into two functional regions. One is the membrane-proximal region, which contains two conserved domains, box1 and box2. Since the EPOR has no intrinsic kinase activity, this domain is of special importance, because it is the binding site for the Janus kinase 2 (JAK2). A deletion of 20 amino acids in this conserved area eliminates any mitogenic effect as well as the phosphorylation of the receptor (Miura et al., 1991). The second domain is the membrane-distal domain, which contains eight tyrosine residues acting as docking sites for 
several signaling molecules (Tilbrook and Klinken, 1999). In deletion models, it was found that the distal region can function as a negative regulator (D'Andrea et al., 1991) and is important for signal termination.

For a long time, it was thought that EPO binding induces homodimerization of the EPOR. But in 1999, crystallography gave evidence for a preformed EPOR homodimer (Livnah et al., 1999). Binding of EPO leads to conformational changes allowing the trans-phosphorylation by JAK2, which was discovered to be the protein tyrosine kinase transmitting the EPO activation signal (Witthuhn et al., 1993). The signaling pathways known to be activated by EPO include the signal transducers and activators of transcription (STATs), the mitogenactivated protein kinase (MAPK), the phosphoinositol-3-kinase (PI3K/AKT) and nuclear factor (NF)-кB. The protein tyrosine phosphatase SHP-1 was found to bind at Y429 and to play a major role in signal termination (Klingmüller, 1997; Klingmüller et al., 1995).

Similar to the expression of EPO, the expression of EPOR is cell-type specific. The promoter contains no TATA or CCAAT sequence, which is typical for genes that are regulated in a tissue specific manner. Early promoter-fusion studies showed that the -581 to -130 promoter element stimulates the expression of EPOR in erythroid cells but not in fibroblasts (Youssoufian et al., 1990). Later, it was proven that the hematopoietic transcription factor GATA-1 binds to this region of the promoter (Zon et al., 1991) and enhances the transcription of EPOR in hematopoietic cells. GATA-1 expression is known to be restricted to hematopoietic tissue. Therefore, EPOR under the GATA-1 promoter was used to rescue complete EPOR knockout mice and to analyze the effect of EPO/EPOR in non-hematopoietic tissues (see 1.5.3).

\subsection{EPO/EPOR system in the brain}

\subsubsection{EPO/EPOR expression}

EPO and the EPOR were first found to be important for erythropoiesis and it took some time until the first results indicated an additional role of the system in non-hematopoietic tissues, like the brain. In order for the EPO/EPOR system to play a role in other tissues, these cells would have to express EPO and/or the EPOR. This was difficult to prove for the EPOR. So far, there is no reliable antibody for the EPOR available on the market (Elliott et al., 2006; Kirkeby et al., 2007) and this causes confusion in the EPO field. Even though there are at 
least two independent methods to find EPOR expressing cells, both have their pitfalls. The first method is to measure the mRNA expression (which does not prove that the EPOR is translated into protein and that the receptor is located in the membrane) and the second method is to indirectly measure the existence of the receptor by ligand binding or signaling pathways (with this method, it cannot be excluded that EPO binds to another protein or receptor). There are many publications showing positive results of EPO and/or EPOR expression and effects in non-hematopoietic tissues (explained in detail on the following pages), but there is also a small fraction of researchers doubting functional EPOR expression and effects of the EPO/EPOR system in non-hematopoietic cells (Sinclair et al., 2010).

\section{EPO expression in non-hematopoietic cells}

One of the first indications for EPO expression in non-hematopoietic tissue was published in 1992. EPO mRNA was found to be increased after hypoxia, not only in the liver and kidney, but interestingly also in testis and brain of adult rats (Tan et al., 1992). Figure 1, a picture from that study, is of particular interest for two reasons. First, it shows that EPO is not only expressed in developmental stages, but also at low levels in the adult brain. Secondly, the expression can be increased with hypoxia, which is important with regard to ischemia and neuroprotection.

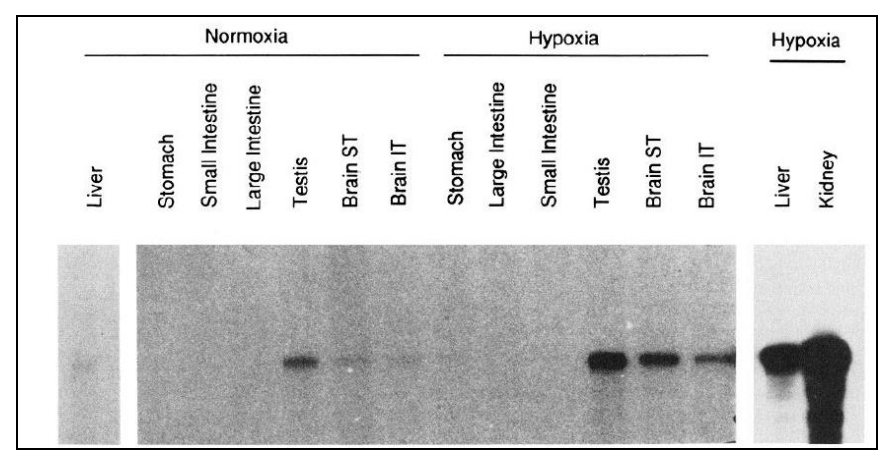

Figure 1: Detection of EPO mRNA with autoradiography (from Tan et al., 1992). ST = Supratentorial portion of the brain, IT = Infratentorial portion of the brain.

In 1994, in another study published by Masuda (Masuda et al., 1994), EPO protein was detected in cerebral rat cultures using enzyme linked immunoassays. Like in the previous study, EPO expression was stimulated under hypoxia. Analyses to detect the cell type producing EPO showed that astrocytes are the main source of EPO production, whereas no EPO production could be detected in microglia. Interestingly, the growth and differentiation of erythroid cells could be stimulated with EPO purified from cerebral cultures. In the end, 
the authors postulated a paracrine mechanism for EPO in the brain (in contrast to the endocrine mechanism in the hematopoietic system). Astrocytes produce EPO for direct communication with closely located neurons or other glial cells. Therefore, the lower binding affinity of the EPOR found in PC12 cells (Masuda et al., 1993) could be overcome through higher EPO concentrations. In 1999, EPO mRNA expression was found in cerebral mouse neuron cultures (Bernaudin et al., 1999) and in 2002, EPO mRNA was also found to be expressed at very high levels in rat oligodendrocyte cultures (Sugawa et al., 2002). So far, it is not clear if microglia are able to express EPO. Until today, EPO expression in the human brain was reported for astrocyte cultures, but was not detectable in neuron, oligodendrocyte or microglia cultures (Nagai et al., 2001).

\section{EPOR expression in non-hematopoietic cells}

In 1994, Liu et al. showed endogenous expression of the EPOR on mRNA level in embryonic mice (Liu et al., 1994). The expression at E10 was found to be relatively high. Remarkably, it was found to be higher than in adult bone marrow or spleen, and decreased with

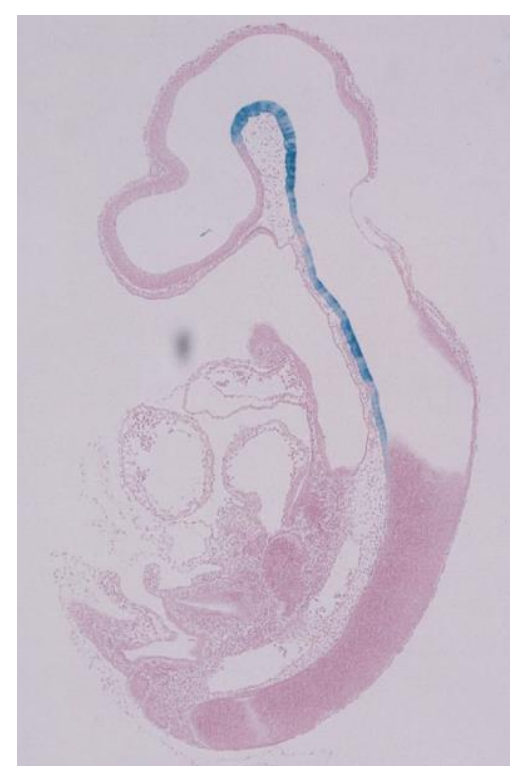
development to non-detectable values at day E16. Later, the same author published a second article with a transgenic mouse carrying a fusion product of the hEPOR promoter $(-1778$ to +1$)$ and a $\beta$-galactosidase reporter (Liu et al., 1997). At E9.5, the expression can be nicely visualized in the neural tube (Figure 2). As in the first study, the authors could not detect any expression of EPOR in the adult brain. However, the study did not include the application of hypoxia.

Figure 2: hEpoR/ $\beta$-galactosidase reporter gene expression at E9.5. The blue color shows the expression in the neural tube of the mouse embryo (from Liu et al., 1994).

A different study published in 1995, demonstrated an increase of EPO and EPOR mRNA in the adult mouse brain under hypoxic conditions (Digicaylioglu et al., 1995). Interestingly, radiolabeled ${ }^{125}$ I-EPO was shown to bind mainly in the capsula interna, the corpus callosum and the fimbria of the hippocampus, indicating the location of the EPOR expression in the adult brain for the first time. Later, our group was able to show hypoxia-induced mRNA expression of EPO and EPOR in hippocampal rat neuron cultures (Lewczuk et al., 2000) and 
additionally showed protective effects of EPO by reduced cell death. It is therefore likely that one role of EPO/EPOR in the adult brain is associated with ischemia and may be important for neuroprotection. Finally, a number of studies showed that the EPOR is not only expressed in neurons, but also in astrocytes, oligodendrocytes and even microglia (Marti et al., 1996; Nagai et al., 2001; Sugawa et al., 2002).

\subsubsection{Role for EPO/EPOR in neuroprotection}

There are many publications demonstrating the neuroprotective function of EPO and various reviews summarizing the most important findings (Brines and Cerami, 2005; Sargin et al., 2010). EPO was shown to be neurotrophic, angiogenic, anti-oxidative, anti-inflammatory, anti-apoptotic, and stem cell modulating. This line of research started in 1993 when EPO was shown for the first time to increase the survival of ChAT neurons after unilateral fimbriafornix dissection (Konishi et al., 1993). A few years later, a protective effect of EPO on neurons from glutamate neurotoxicity could be demonstrated (Bernaudin et al., 1999; Morishita et al., 1997; Sakanaka et al., 1998). One caveat, that needs to be considered with these in vitro studies, is that the EPO treatment has to be applied at least $8 \mathrm{~h}$ before the incubation with glutamate to be protective. Therefore, these in vitro data are not very helpful regarding the clinical implementation of EPO as a neurotherapeutic drug in acute stroke. However, the results of in vivo experiments done by Sakanaka et al. in 1998 are very impressive (Sakanaka et al., 1998). The authors implanted small minipumps for intracerebroventricular infusion of EPO or soluble EPOR (SEPOR) directly into the brain of gerbils. They then applied ischemia by middle cerebral artery occlusion (MCAO) for 3 min and showed improved learning abilities after EPO treatment. They also applied mild ischemia (2.5 min) which did not lead to significant cell death under normal conditions (Figure 3D). Interestingly, there was a significant reduction in the total number of pyramidal neurons in CA1 and increased cell death after infusion with SEPOR, which is able to neutralize endogenous EPO (Figure 3C). Taken together, these experiments provide conclusive evidence for the protective effect of endogenous EPO in the brain. As discussed by Brines and colleagues (Brines et al., 2000) intrathecal administration of EPO is not practical in most clinical contexts. Thus, the authors applied MCAO in male rats and injected EPO intraperitoneal before, simultaneously, or after the occlusion. EPO was able to reduce the necrosis volume if injected before, simultaneously or $3 \mathrm{~h}$ after the MCAO. The important 
question for applying EPO systemically is, whether and how EPO is transported over the blood-brain barrier (BBB) into the brain. Using biotinylated EPO they could demonstrate that EPO is able to cross the BBB within $5 \mathrm{~h}$ in healthy mice. This time frame is comparable to humans, where intravenously injected indium labeled EPO can be found in the cerebral spinal fluid after 5-7 $\mathrm{h}$ (Ehrenreich et al., 2004). However, the mechanism is still not clear, but is thought to be a receptor-mediated transport.

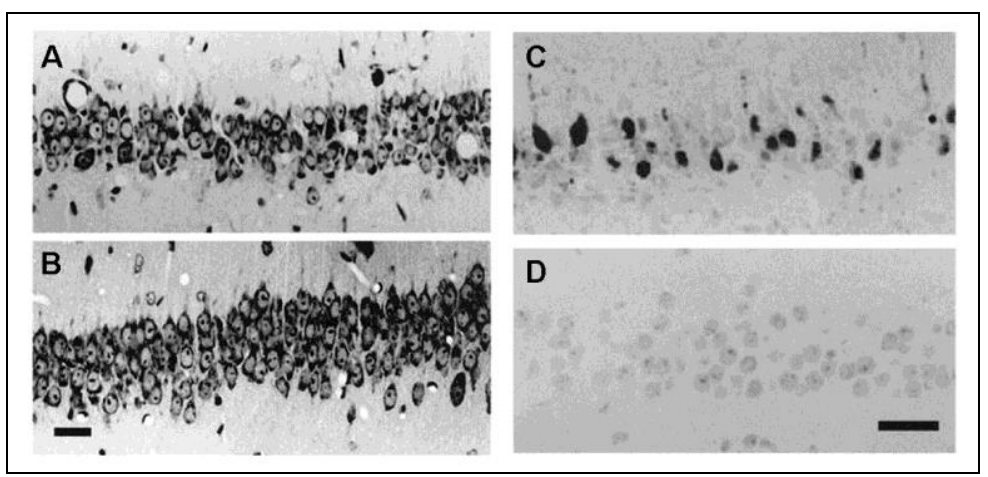

Figure 3: Effects of the intracerebroventricular infusion of $s E P O R$ in the pyramidal layer of CA1 in gerbils. (A) Cresyl violet staining of the hippocampal CA1 field after sEPOR infusion. (B) Cresyl violet staining of the hippocampal CA1 field after vehicle infusion. (C) TUNEL staining of the hippocampal CA1 field after sEPOR infusion. (D) TUNEL staining of the hippocampal CA1 field after vehicle infusion. (from Sakanaka et al., 1998).

\subsubsection{EPO/EPOR signaling in the brain}

In 2001 our group provided evidence that EPO/EPOR signaling in the brain is comparable to EPO/EPOR signaling in the hematopoietic system (Sirén et al., 2001). Hippocampal neuron cultures showed an activation of STAT5, MAPK, and PI3K/AKT after EPO treatment under hypoxic conditions. Afterwards, another article, published in Nature, identified the activation of NF-KB in neurons after EPO treatment (Digicaylioglu and Lipton, 2001). Thus, all major signaling pathways activated in erythrocytes can be found in neurons (Figure 4).

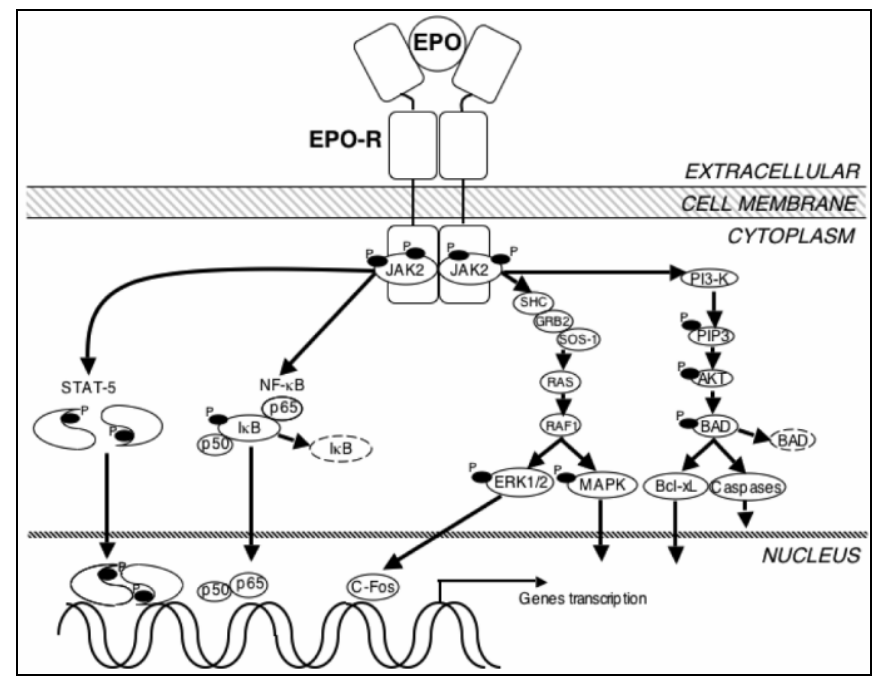

Figure 4: Signaling pathway of EPO/EPOR in neurons (from Noguchi et al., 2007). 


\subsection{EPO/EPOR and cognition}

\subsubsection{Evidence in humans}

With its promising neuromodulatory function, it seemed likely that rhEPO could be used as a neurotherapeutic drug for stroke and neurotrauma as well as neuroinflammatory and neurodegenerative diseases. The first human trials showed mainly positive outcomes. The first clinical study on stroke patients demonstrated improvement in outcome scales and reduced infarct sizes in rhEPO treated patients (Ehrenreich et al., 2002; Ehrenreich et al., 2011). This result was confirmed in the second trial, phase II/III for patients not receiving rtPA, but not for patients simultaneously receiving thrombolytic drugs (Ehrenreich et al., 2011; Ehrenreich et al., 2009). Nonetheless, the stroke study from 2002 is not the only clinical study in humans showing beneficial effects of rhEPO treatment. Multiple sclerosis (MS) as well as schizophrenia are medical conditions sharing neurodegenerative features and thus, human treatment trials for these disorders with rhEPO were initiated. Interestingly, rhEPO was able to improve the cognitive performance in chronic MS and schizophrenic patients (Bartels et al., 2008; Ehrenreich et al., 2007a; Ehrenreich et al., 2007b). In 2011, a study suggested a possible mechanism of EPO action in schizophrenic patients, showing that EPO counteracts the gray matter loss (Wüstenberg et al., 2011). Recently, a study was published showing that the genetic composition of common variants in the EPO and EPOR gene are associated with the cognitive performance of schizophrenic patients and healthy controls (Kästner et al., 2012). Studies from other groups expand the application range of rhEPO to mood disorders, by showing anti-depressant-like effects in humans and mice (Miskowiak et al., 2012).

To summarize, the EPO/EPOR system influences cognition, not only in disease conditions, but interestingly also in healthy subjects (Kästner et al., 2012; Miskowiak et al., 2007). The molecular mechanism behind is still not fully understood, but animal studies may offer further insight in the future.

\subsubsection{Evidence in mice}

Several animal studies were designed to examine the effects of rhEPO on cognition. In 2008, Adamcio et al. showed that a three week long rhEPO treatment in juvenile healthy mice increases the long term potentiation (LTP) and hippocampal memory (Adamcio et al., 2008). Another study used the Five Choice Serial Reaction Time Task (5CSRTT) to analyze explicit 
executive function and attention in healthy juvenile mice treated with EPO (El-Kordi et al., 2009). The 5CSRTT is challenging for mice and the study showed that EPO-treated animals have a higher probability to finish the task. In both studies, EPO was administered by i.p. injection. The question whether or not the positive effects are at least partially transmitted via the hematopoietic system and enhanced tissue oxygenation cannot be answered by such studies. Therefore, a transgenic mouse line with a constitutively active EPOR in pyramidal neurons was developed and analyzed in our group (Sargin et al., 2011). These mice show increased LTP as well as enhanced cognitive functions, but also increased impulsivity (see also 1.6.3).

\subsection{EPO and EPOR knockout mice}

\subsection{1 $\mathrm{EPO}^{-/}$and $\mathrm{EPOR}^{-/-}$- Effects on the hematopoietic system}

The first EPO and EPOR mouse models were complete knockouts (EPO ${ }^{-/}$or EPOR $^{-/}$) and primarily used to understand the role of EPO in the hematopoietic system. At almost the same time, three different groups generated and published $\mathrm{EPO}^{-/-}$or $\mathrm{EPOR}^{-/-}$knockout mice with comparable results (Kieran et al., 1996; Lin et al., 1996; Wu et al., 1995). All knockout animals were generated by disrupting the EPO or EPOR gene by homologous recombination. The heterozygous animals appeared normal, were viable and fertile, and showed no changes in hematocrit (Wu et al., 1995). The homozygous knockouts of EPO or EPOR exhibited identical phenotypes which are characterized by reduced primitive erythropoiesis and early death around E13 because of failure of definitive fetal liver erythropoiesis (severe anemia). Similar results were published for the EPOR knockout by Lin and Kieran (Kieran et al., 1996; Lin et al., 1996). All three labs analyzed the erythropoiesis of $\mathrm{EPOR}^{-/-}$mice in vivo and in vitro. In vivo, the peripheral blood of the wildtype (wt) mice included yolk sac-derived erythroid cells (mature erythrocytes with nucleus), normoblast (n), and mature enucleated erythrocytes (m) (Kieran et al. 1996; Figure 5B). The liver blood contained proerythroblast $(p)$, normoblasts $(n)$ and mature enucleated erythrocytes $(m)$ (Kieran et al. 1996; Figure 5C). But neither the peripheral blood nor the liver blood of the $\mathrm{EPOR}^{-/-}$mice revealed hemoglobinized normoblast $(n)$ or mature enucleated erythrocytes $(m)$. This demonstrates the importance of the EPO/EPOR system for the differentiation of proerytroblasts to further developmental stages in definitive fetal liver erythropoiesis. 


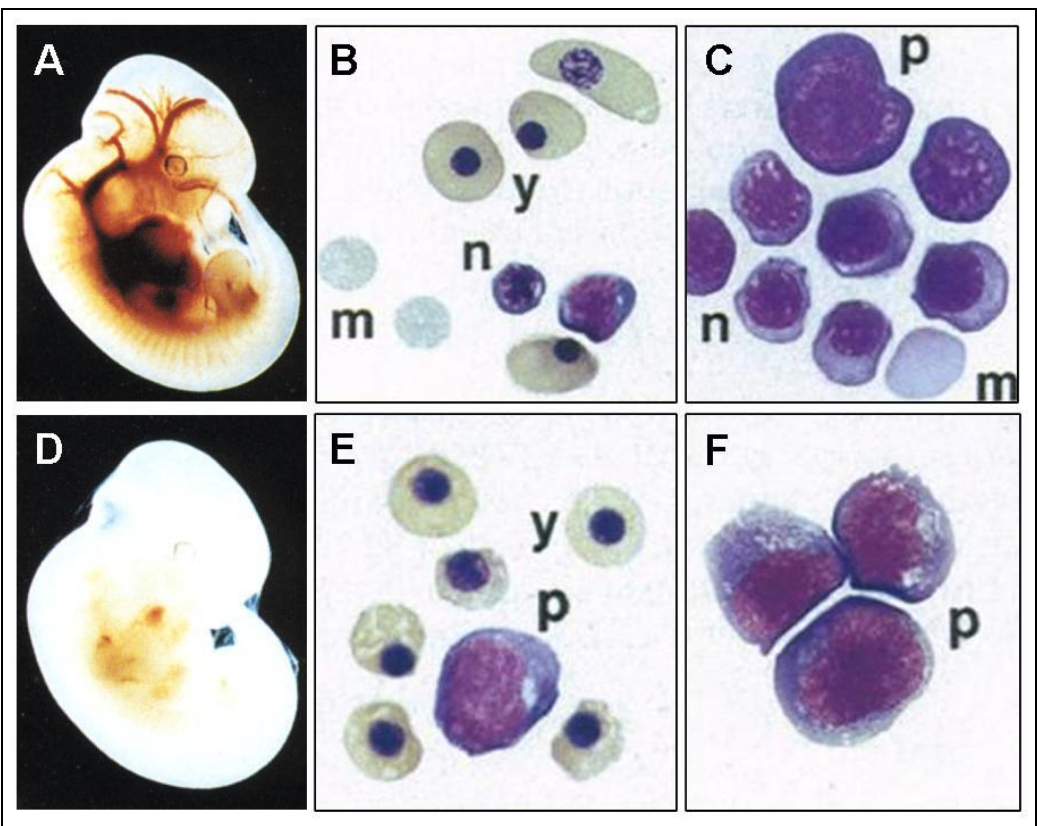

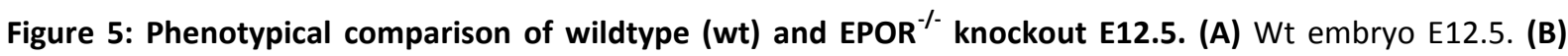
Peripheral blood cells of wt E12.5 (May-Grunwald-Geimsa staining). (C) Fetal liver blood cells of wt E12.5 (MayGrunwald-Geimsa staining). (D) EPOR ${ }^{-/}$embryo E12.5. (E) Peripheral blood of EPOR ${ }^{-/-}$E12.5 (May-GrunwaldGeimsa staining). (F) Fetal liver blood of EPOR ${ }^{-1-}$ E12.5. (May-Grunwald-Geimsa staining). Abbreviations: $y=$ primitive yolk sac-derived erythroid cells, $n=$ normoblasts, $m=$ mature enucleated red cells, $p=$ proerythroblasts. (A and D from Lin et al., 1996; B, C, E and F from Kieran et al., 1996).

\subsection{2 $\mathrm{EPO}^{-/-}$and $\mathrm{EPOR}^{-/-}$- Effects on non-hematopoietic tissues}

Based on the first indications that the EPO/EPOR system might play a role in many tissues, $\mathrm{EPO}^{-/-}$and $\mathrm{EPOR}^{-/-}$knockouts were analyzed again with regard to non-hematopoietic tissues. The first publication in 1999 showed impaired cardiac development and disrupted vascularization in $\mathrm{EPOR}^{-/-}$(Wu et al., 1999). The cardiac hypoplasia, evident from $\mathrm{E} 12.5$ on, was likely due to a reduction in proliferation of cardiomyocytes and not due to an increase in apoptosis. Interestingly, the mRNA of EPOR in wildtype mice was not found in the myocardium itself, but transient expression was detected in endo-, epi- and pericardium from E10.5 to E13.5. Therefore, the authors suggested a non-cell-autonomous mechanism of EPO on cardiomyocyte proliferation. In this study, no effect was found for brain tissue. However, in 2002, the first data showing effects in the developing brain of $\mathrm{EPOR}^{-1-}$ mice were published (Yu et al., 2002). As early as of E10.5, the authors found increased apoptosis in the cerebral cortex and neuroepithelium of the midbrain. In cortical cultures of E10.5 knockout mice, they detected less nestin positive progenitor cells and after four days less microtubuleassociated protein 2 (MAP2) positive mature neurons. Under normoxic conditions, no changes in cell death were seen. In contrast, significantly higher apoptosis rates were found 
in cell cultures of knockout animals under hypoxic conditions. The results from the complete knockout suggest that EPO/EPOR signaling is important for proliferation and survival of nonhematopoietic progenitor cells. However, it cannot be ruled out that the effects are caused indirectly by the general state of hypoxia, due to the reduction of mature erythrocytes.

\subsection{3 $\mathrm{EPOR}^{-/-}$knockouts rescued for the hematopoietic lineage}

To circumvent the issue that the effects found in non-hematopoietic tissues might be caused indirectly by a general state of hypoxia, an $\mathrm{EPOR}^{-/-}$knockout mouse was rescued for the hematopoietic system (Suzuki et al., 2002). This was achieved by using the EPOR ${ }^{-/}$knockout with transgenic expression of the EPOR under the control of the GATA-1 hematopoietic regulatory domain (GATA1-HRD-EPOR). The $\mathrm{EPOR}^{-/-} \mathrm{TgEPOR}_{\mathrm{E}}$ mice initially developed normally and were fertile, but later developed obesity and insulin resistance (Teng et al., 2011). The mice were also less active, had decreased energy expenditure, and increased fat mass. Interestingly, wt mice express high levels of EPOR in the hypothalamus, most likely in proopiomelanocortin (POMC) neurons and $\mathrm{EPOR}^{-/-} \mathrm{TgEPOR}_{\mathrm{E}}$ animals showed decreased mRNA levels of POMC. These results suggest a non-hematopoietic effect of EPO on energy homeostasis.

\subsection{4 $\mathrm{EPOR}^{-/-}$conditional knockout}

Conditional knockouts were generated by crossbreeding of EPOR ${ }^{\text {floxp/floxp }}$ mice with hGFAP$\mathrm{Cre}^{+}$mice (Tsai et al., 2006). The hGFAP promoter activity and specific expression in the central nervous system starting at E13.5 had been reported by an earlier study (Zhuo et al., 2001). The hGFAP ${ }^{+}$radial glial cells generate almost all cortical projection neurons during development (Malatesta et al., 2003) and are also known to constitute the stem cells in the adult brain. The conditional knockouts were viable and fertile, showing that the expression of EPOR after E13.5 is not essential for survival. However, the animals showed less proliferating cells in the subventricular zone, which was also reduced in total size. Furthermore, the animals showed an impaired post-stroke recovery with decreased numbers of doublecortin positive progenitors migrating into the peri-infarct area. 


\subsection{Activating mutations in the EPOR Gene}

\subsubsection{Natural occurring mutations in the human EPOR Gene}

Primary familial and congenital polycythemia, also known as familiar erythrocytosis, is caused by autosomal dominant mutations of the EPOR gene, causing elevated levels of red blood cells. So far, there are 16 mutations known in humans and 14 of them result in a truncated version of the EPOR (Huang et al., 2010). The first mutation, leading to a $70 \mathrm{C}$ terminal truncation (G6002A), was found 1993 in a Scandinavian family (de la Chapelle et al., 1993). This stirred a sensation, because one of the positive test subjects was Eero Antero Mäntyranta, the successful cross-country skier and multiple Olympic champion (Longmore, 1993). In 1991, it had already been shown that familiar erythrocytosis is coupled with hypersensitivity of erythroid progenitor cells to EPO (Juvonen et al., 1991) and that this form of erythrocytosis has no obvious effects on health or life-span. At the same time, it was reported that the cytoplasmic C-terminus of the murine EPOR contains negative growthregulatory domains (D'Andrea et al., 1991). C-terminal truncation of the receptor allowed $\mathrm{Ba} / \mathrm{F} 3$ cells to grow with $1 / 10$ of the normal required EPO concentration, which nicely mimics the human data. In 2001, a mouse model for congenital polycythemia was developed by replacement of the murine EPOR with the mutated human EPOR (Divoky et al., 2001). The mice were a phenocopy of the human disorder and showed increased hematocrit and higher sensitivity of erythroid progenitor cells to EPO.

\subsubsection{Murine constitutively active EPOR (cEPOR)}

The analysis of the truncated versions of the EPOR was initiated by Akihito Yoshimura, who developed a mutating cell-culture system for EPOR with Ba/F3 cells (Yoshimura et al., 1990). $\mathrm{Ba} / \mathrm{F} 3$ cells are naturally interleukin-3 (IL-3) dependent, but the expression of the EPOR allows the cells to grow in the presence of EPO without IL-3. Yoshimura infected the cells with a retrovirus expressing the murine wildtype EPOR, hoping that with replication and packaging spontaneous mutations would occur. By decreasing the concentrations of EPO, the authors selected two mutants, one with a C-terminal truncation and hypersensitivity for EPO and a second one with a point mutation leading to growth factor independent proliferation and survival. The point mutation, a transition from $\mathrm{C}$ to $\mathrm{T}$ at nucleotide 484 , causes a substitution in the exoplasmic domain from arginine $(R)$ to cysteine $(C)$ at codon 129 (R129C). The mutated EPOR was isolated and cloned into the mammalian expression 


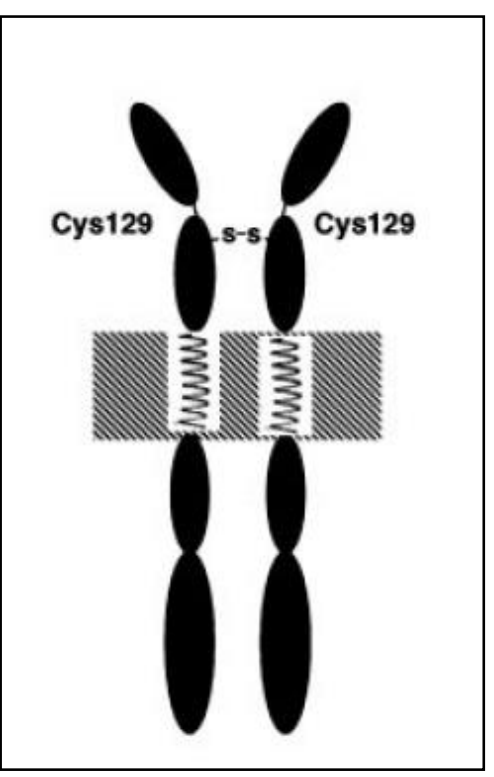

vector $\mathrm{pMX}$ for further analysis. In following experiments it was shown that not the loss of the arginine but the presence of the new cysteine is required for the constitutive activity (Watowich et al., 1992). Furthermore, it was observed that cEPOR was able to form disulfide-linked homodimers (Figure 6). It is thought that the covalent dimerization leads to conformational changes comparable to EPO binding, thereby inducing the constitutive activity of the receptor.

Figure 6: Illustration of the disulfide-linked homodimers of cEPOR (from Constantinescu et al., 1999b).

\subsubsection{Transgenic mouse models with cEPOR}

In a previous study of our group, CEPOR was expressed under the alpha-CaMKII promoter in pyramidal neurons (Sargin et al., 2011). The mice were viable and fertile, and showed no obvious neuropathology, no change in body weight, mating behavior, or hematocrit. However, compared to wildtype mice, they showed increased hippocampal-dependent learning, social memory and attention, but were also significantly more impulsive. In addition, an increase in LTP was reported. Therefore, the model proves that the EPO-EPOR system is able to enhance neuronal plasticity and cognition independently of the blood system. Furthermore, the study compares the phenotype of transgenic mice with the effects of systemically administered EPO (Table 1).

\begin{tabular}{|l|c|c|}
\hline \multicolumn{1}{|c|}{ Readout } & Systemically administered EPO & alpha-CaMKII-HA-cEPOR mice \\
\hline Spontaneous activity (Open field) & $=$ & $\uparrow$ (Hyperactive) \\
\hline Impulsivity (5CSRT/Marble burying) & $=$ & $\uparrow$ \\
\hline Social memory & $=$ & $\uparrow$ \\
\hline Spatial learning (Morris water maze) & $\uparrow$ & $\uparrow$ \\
\hline Cognition (5CSRTT-initial phase) & $\uparrow$ & $\boldsymbol{\uparrow}$ \\
\hline Cognition (5CSRTT-attentional performance) & $\uparrow$ & $\uparrow$ \\
\hline STP and LTP (Electrophysiology) & $\uparrow$ & $\uparrow$ \\
\hline
\end{tabular}

Table 1: Comparison of the effects of systemically administered EPO with the alpha-CaMKII-HA-cEPOR-mice. = no change, $\uparrow$ increase (from Sargin et al., 2011).

Interestingly, the transgenic animals show hyperactivity and impulsivity, which in contrast cannot be found after systemic EPO administration. This might be explained by an imbalance of the homeostasis of neuronal networks. Systemically administered EPO is able to activate 
signaling in excitatory and inhibitory neurons, whereas the transgenic mice are stimulated only in excitatory pyramidal neurons. This might lead to an imbalance and a relative deficit of inhibition, thereby explaining hyperactivity and impulsivity. This led to the interest in the role of the EPO/EPOR system in inhibitory neurons and their impact on cognition.

\subsection{Aim of the study}

In general, it is now widely accepted that EPO influences cognition, but there are many open questions as to how EPO is able to improve cognitive functions in mouse and man. There is still an ongoing debate as to whether or not the positive effects are caused via the hematopoietic system and enhanced tissue oxygenation. To date, it has been difficult to exclude the effect of the hematopoietic system, because the majority of the studies measuring cognitive performance are using rhEPO intravenously or intraperitoneally. Of course, cell culture models can exclude the effect of the hematopoietic system, but in this case it is difficult to make a connection to cognition. To analyze the role of the EPO/EPOR system in cognition, it is necessary to activate or inactivate the signaling in specific neuronal subpopulations. In the study mentioned above (Sargin et al., 2011), the constitutively active EPOR (cEPOR) was expressed in excitatory pyramidal neurons. The logical counterpart would be a transgenic mouse line with cEPOR in inhibitory interneurons.

Thus, the aim of the current study was to generate a transgenic mouse line expressing CEPOR in inhibitory interneurons and to analyze the impact of this genetic manipulation on cognition. The cEPOR was placed under the control of the vesicular inhibitory amino acid transporter (Viaat) promoter, which should lead to expression of cEPOR in all gammaamino butyric acid (GABA)ergic and glycinergic neurons.

This novel mouse model was used to investigate the function of the EPO/EPOR system in inhibitory neurons and to provide insight into the mechanism by which cEPOR expression modulates cognition. Importantly, all effects reported in this study are pure neural effects, excluding the hematopoietic system as a confounding factor. 


\section{Methods}

The methods section is divided into the following parts:

Part I - Cloning of the Viaat-HA-cEPOR construct

Part II - Analysis of the transgenic Viaat-HA-CEPOR mouse

\section{Methods Part I}

\subsection{DNA preparation}

Plasmid DNA preparation is a method to extract and purify plasmid DNA amplified in bacteria. Depending on the size of the bacterial culture, it is named mini, midi or maxi preparation.

\subsubsection{Mini preparation}

The mini preparation is mainly used to screen clones for correct DNA constructs. 12 clones were picked and grown overnight in $5 \mathrm{ml}$ culture medium at $37^{\circ} \mathrm{C}$. For plasmid DNA, $1.5 \mathrm{ml}$ were used for a crude plasmid isolation (boiling method) and a diagnostic restriction digest. The pellet of $3.5 \mathrm{ml}$ was stored at $-20^{\circ} \mathrm{C}$, until the results of the digest show clones with correct fragment sizes. The DNA from 2-4 positive clones was isolated and purified using a column based plasmid mini kit for sequencing and further processing.

\section{Plasmid mini preparation (boiling method)}

The boiling method is a crude and fast method. The resulting plasmid DNA is contaminated with proteins and bacterial genomic DNA. This is why the method is also called "dirty mini preparation". However, for the diagnostic restriction digest the purity is not important and the method is much cheaper compared to the column-based plasmid mini kit.

For the preparation of plasmid DNA, the pellet of the $1.5 \mathrm{ml}$ overnight culture was resuspended in $300 \mu \mathrm{l}$ STET buffer and shaken for $5 \mathrm{~min}$. The lysozyme solution was freshly prepared $(10 \mathrm{mg} / \mathrm{ml}-0.01 \mathrm{~g}$ in $1 \mathrm{ml} \mathrm{STET})$ and $25 \mu \mathrm{l}$ were added. After heating for $1 \mathrm{~min}$ at $100^{\circ} \mathrm{C}$, the preparation was cooled down on ice for $2 \mathrm{~min}$ and centrifuged for $10 \mathrm{~min}$ at $15,000 \mathrm{rpm}$ at room temperature (RT). The pellet was removed with a toothpick. For precipitation of the DNA, $100 \mu \mathrm{l} 7.5 \mathrm{M} \mathrm{NH}_{4} \mathrm{OAc}$ and $400 \mu \mathrm{l}$ isopropanol were added and the 
mixture vortexed. The centrifugation was started immediately for $30 \mathrm{~min}$ at 15,000 rpm at RT. The supernatant was discarded and the pellet dried. The dried pellet was dissolved in $50 \mu \mathrm{l} \mathrm{TE}$ for $30 \mathrm{~min}$ at $37^{\circ} \mathrm{C}$ on a shaker. For the diagnostic restriction digest $5 \mu \mathrm{l}$ were used.

\section{Plasmid mini preparation (Column based - Life Technologies)}

To obtain plasmid DNA with high purity, the PureLink Quick Plasmid Miniprep Kit (Life Technologies) was used. This is an alkaline/SDS based DNA isolation kit containing a silica membrane column. The preparation was done according to the manufacturer's protocol with minor modifications. The pellet of the $3.5 \mathrm{ml}$ overnight culture was resuspended in $250 \mu \mathrm{l}$ resuspension buffer (R3, containing RNaseA). After adding $250 \mu \mathrm{l}$ of the lysis buffer (L7), the solution was mixed carefully by 5 times inversion of the tube. The solution was incubated for $5 \mathrm{~min}$ at RT, $350 \mu$ of the precipitation buffer (N4) were added, and the tube was inverted immediately. The solution was centrifuged at $11,000 \mathrm{rpm}$ for $10 \mathrm{~min}$ at RT. The supernatant was loaded onto the spin column and centrifuged for $1 \mathrm{~min}$ at 11,000 rpm at RT. The flow-through was discarded and $700 \mu$ l washing buffer (W9) were added. After centrifugation at $11,000 \mathrm{rpm}$ at RT and discarding the flow-through, the column was dried by centrifugation for $1 \mathrm{~min}$ at 11,000 rpm at RT. The column was placed in a clean tube, $40 \mu \mathrm{l}$ EB buffer (preheated to $65^{\circ} \mathrm{C}$ ) was added and incubated for $1 \mathrm{~min}$, followed by elution by centrifugation at $11,000 \mathrm{rpm}$ at RT. It is important to use EB buffer or water for the elution and not TE buffer if the samples are to be sequenced. TE buffer contains ethylenediaminetetraacetic acid (EDTA) which chelates $\mathrm{Mg}^{2+}$ ions, which are important for the activity of the Taq polymerase during sequencing.

\section{BAC mini preparation (Qiagen)}

For the isolation of BAC DNA, the Plasmid Mini Kit (Qiagen) was used with a slightly modified protocol (Liu et al., 2003). An overnight culture of $5 \mathrm{ml}$ was centrifuged for $1 \mathrm{~min}$ at $15,000 \mathrm{rpm}$ at RT. The pellet was dissolved in $250 \mu \mathrm{l}$ of P1 buffer. Then, $250 \mu$ lysis buffer P2 were added. The tube was very carefully inverted 4-6 times and incubated for 5 min at RT. $350 \mu$ of the precipitation buffer N3 were added and the tube was again inverted 4-6 times. Especially for BAC DNA, the inversion is a critical step and has to be done very gently, since the risk of shearing the large molecule is very high. After centrifugation at $12,000 \mathrm{rpm}$ for 4 min the supernatant was transferred into a new tube and centrifuged again at $12,000 \mathrm{rpm}$ 
for $4 \mathrm{~min}$. Because the large BAC DNA would be difficult to elute from the silica membrane, the supernatant was not applied to a spin column. Instead, the DNA was precipitated by adding $750 \mu \mathrm{l}$ isopropanol. The tubes were again inverted carefully 4-6 times and incubated for $10 \mathrm{~min}$ at RT. After centrifugation at $15,000 \mathrm{rpm}$ for $10 \mathrm{~min}$ at RT, the pellet was washed with $70 \%$ ethanol, dried, and dissolved in $50 \mu \mathrm{LB}$ buffer.

\subsubsection{Midi preparation}

The plasmid midi preparation was done with the PureLink HiPure Plasmid Midiprep Kit (Life Technologies). The midi preparation was done according to the manufacturer's protocol with minor modifications. $50 \mathrm{ml}$ of an overnight culture were centrifuged for $15 \mathrm{~min}$ at 3,500 rpm and in parallel the column was equilibrated with $15 \mathrm{ml}$ of equilibration buffer (EQ1). The pellet was dissolved in $10 \mathrm{ml}$ resuspension buffer (R3) with RNase A. The cells were lysed with $10 \mathrm{ml} \mathrm{L7} \mathrm{buffer}$ and the Falcon tube was inverted 5 times before incubation for $5 \mathrm{~min}$ at RT. For precipitation, $10 \mathrm{ml}$ of $\mathrm{N} 3$ buffer were added and the Falcon tube was inverted 5 times. The suspension was loaded onto the column through a filtration cartridge and filtered by gravity flow. The cartridge and the flow-through were discarded and $20 \mathrm{ml}$ washing buffer (W8) were added and drained by gravity flow. The plasmid DNA was eluted with $5 \mathrm{ml}$ elution buffer (E4) again drained by gravity flow. In the following step, the eluted DNA was concentrated with an isopropanol precipitation. Therefore, $3.5 \mathrm{ml}$ isopropanol were added and mixed by vortexing. After 2 min of incubation the solution was centrifuged for 45 min with $3,500 \mathrm{rpm}$ at $4{ }^{\circ} \mathrm{C}$. The supernatant was discarded and the pellet was washed with $70 \%$ ethanol and dried for approximately $5 \mathrm{~min}$. The dried pellet was dissolved in $50 \mu \mathrm{L}$ EB buffer.

\subsubsection{Maxi preparation}

\section{Plasmid maxi preparation (Column based - Life Technologies)}

For the plasmid maxi preparations, the PureLink HiPure Plasmid Maxiprep Kit (Life Technologies) was used. This kit enables the isolation and purification 500-850 $\mu \mathrm{g}$ plasmid DNA. The preparation was done according to the manufacturer's protocol with minor modifications. $200 \mathrm{ml}$ of the overnight culture was distributed in $4 \times 50 \mathrm{ml}$ Falcon tubes and centrifuged $15 \mathrm{~min}$ at 3,500 rpm. With starting the centrifugation step, the temperature was reduced to $4{ }^{\circ} \mathrm{C}$. During centrifugation, the column was equilibrated with $30 \mathrm{ml} \mathrm{EQ1}$. After centrifugation, the pellet was dissolved in $10 \mathrm{ml}$ resuspension buffer (R3) and $10 \mathrm{ml}$ lysis buffer $\mathrm{L7}$ were added. The Falcon tubes were inverted 5 times and incubated for 5 min at RT. 
For precipitation, $10 \mathrm{ml}$ of $\mathrm{N} 3$ buffer were added and the Falcon tubes were inverted immediately to avoid localized precipitation. The suspension was transferred into a cartridge containing an equilibrated column. After removing the cartridge, the column was washed with $50 \mathrm{ml}$ washing buffer W8. The DNA was eluted with $15 \mathrm{ml}$ elution buffer E4. To precipitate the DNA, $10.5 \mathrm{ml}$ isopropanol were added and the Falcon tube was centrifuged for $45 \mathrm{~min}$ at $3500 \mathrm{rpm}$ at $4{ }^{\circ} \mathrm{C}$. The pellet was washed and transferred with $1 \mathrm{ml} 70 \%$ ethanol into a $1.5 \mathrm{ml}$ Tube and centrifuged for $4 \mathrm{~min}$ at $11,000 \mathrm{rpm}$ at RT. The supernatant was removed carefully. The dried pellet was dissolved in 50-100 $\mu$ EB buffer.

\section{BAC Maxi preparation (MACHERY-Nagel)}

For the BAC Maxi preparations, the column based Kit from MACHERY-NAGEL was used. This kit enables the isolation and purification $100 \mu \mathrm{g}$ BAC DNA over an anion-exchange resin column. The preparation was done according to the manufacturer's protocol with minor modifications. An overnight culture of $250 \mathrm{ml}$ was distributed to $5 \times 50 \mathrm{ml}$ Falcon tubes and centrifuged for $30 \mathrm{~min}$ with $3,500 \mathrm{rpm}$ at $4{ }^{\circ} \mathrm{C}$. The pellets were resuspended in a total volume of $24 \mathrm{ml} \mathrm{S1}$ buffer and distributed to $2 \times 50 \mathrm{ml}$ Falcon tubes. The cells were lysed with $12 \mathrm{ml} \mathrm{S} 2$ buffer and mixed carefully by inversion. After incubation for $5 \mathrm{~min}$ at RT, the precipitation buffer S3 was added. The Falcon tubes were inverted immediately and incubated for $10 \mathrm{~min}$ on ice. The suspension had to be cleared from the precipitated protein and cell debris before loading onto the column. This was done with a filter, wetted with $\mathrm{ddH}_{2} \mathrm{O}$, placed in an appropriate funnel. The flow-through was collected in a Falcon tube. The column was equilibrated with $6 \mathrm{ml} \mathrm{N2}$ buffer, before adding the cleared lysates from both Falcon tubes onto one column. The column was washed twice with $18 \mathrm{ml} \mathrm{N} 3$ buffer and the BAC DNA was eluted 3 times with $5 \mathrm{ml}$ preheated $\left(55^{\circ} \mathrm{C}\right) \mathrm{N} 5$ buffer. For precipitation $11 \mathrm{ml}$ of isopropanol were added. The Falcon tube was inverted carefully a few times to ensure proper mixing. The solution was distributed to 3 round bottom Greiner tubes for centrifugation at $12,000 \mathrm{rpm}$ for $25 \mathrm{~min}$ at $4{ }^{\circ} \mathrm{C}$. The supernatant was discarded and the pellets were dried. The BAC DNA was dissolved in $20 \mu$ EB buffer by incubation at RT for $30 \mathrm{~min}$ and the solution transferred very carefully into a $1.5 \mathrm{ml}$ tube. If the solution was too viscous for pipetting, another $20 \mu \mathrm{l}$ of EB buffer were added. The BAC DNA was allowed to dissolve overnight at $4{ }^{\circ} \mathrm{C}$ before measuring the concentration and further processing. 


\subsection{Gel electrophoresis}

Gel electrophoresis is a method to separate DNA, RNA, or protein depending on their size. DNA and RNA are negatively charged and migrate in a matrix gel to the anode when placed in an electric field. The matrix gel is a polymerized network with small pores. Depending on their size, the molecules migrate with inverse velocities. For DNA and RNA agarose gels are used as matrix. Polyacrylamide is used for small DNA fragments and for the separation of proteins (2.7.5).

\subsubsection{Agarose gels}

Agarose is a non-toxic polysaccharide that is widely used for the separation of DNA. In general, agarose gels are used at percentages from 0.7-3 \%. The agarose powder is dissolved in a buffer solution (TBE or TAE), containing ions to enable current flow and for stabilizing $\mathrm{pH}$.

\section{TBE and TAE buffer}

Tris/borate (TBE) and Tris/acetat (TAE) buffer are the most commonly used buffers for agarose gel electrophoresis. The advantage of TBE is its higher buffer capacity (Voytas, 2001), making it useful for high voltage electrophoresis over long time periods, like PFGE (2.2.3). A negative aspect of TBE is its low solubility in concentrated stock solutions. The maximal concentration of the stock solution is $10 x$ and even at this concentration precipitation occurs. In contrast to this, the TAE buffer can be stored as a 50x buffer. For preparative gels, TAE is the preferred buffer because TBE can inhibit the binding of DNA to silica membranes (Moore et al., 2002).

\section{Ethidium bromide}

Ethidium bromide (EtBr) is still the most commonly used substance to detect DNA in agarose gels. It is an aromatic compound and shows an increased fluorescence when intercalated into DNA. Detection of DNA with EtBr is a sensitive assay, which has a detection limit of about $1-5 \mathrm{ng} /$ band. Therefore, $0.3-0.8 \mu \mathrm{g} / \mathrm{ml}$ was added to the melted agarose before pouring the gel. 


\section{Loading buffer}

DNA solutions have mainly the same density as the electrophoresis buffer and second and they are usually clear solutions. Therefore, they cannot easily be loaded onto a gel without adding a loading buffer. The loading buffer contains glycerol or sucrose to increase the density so that the DNA sample sinks into the gel pocked. Additionally, the buffer contains a loading dye like bromophenol blue to make the solution visible and to simplify the observation of the gel run. Many loading buffers also contain EDTA to inhibit enzymes, like restriction enzymes or DNases.

\subsubsection{Gel extraction}

After separating restriction products with agarose gel electrophoresis, the bands of interest have to be isolated and purified. This can easily be done with the Gel Extraction kit (QIAprep Spin Miniprep Kit). The extraction was done accordingly to the manufacturer's protocol. The DNA fragment was excised from the agarose gel with a scalpel and weighed. 3 volumes of QG buffer were added and the gel slice was shaken at $50{ }^{\circ} \mathrm{C}$ for $10 \mathrm{~min}$. For precipitation, 1 volume of isopropanol was added to the completely dissolved gel slice solution and the mixture was loaded onto a column with a silica membrane.

\subsubsection{Pulsed field gel electrophoresis (PFGE)}

DNA fragments longer than $25 \mathrm{~kb}$ are difficult to separate by traditional agarose gel electrophoresis (Finney, 2001). Long fragments are twisted and need a lot time for reorientation to migrate through the agarose network. The time of re-orientation has a higher influence on the migration velocity than the size itself and this makes a separation by size almost impossible. One way to circumvent this problem is to change the current direction frequently. This method is called pulsed field gel electrophoresis (PFGE) and gives good results up to DNA sizes of $2000 \mathrm{~kb}$. In contour-clamped homogeneous electric field (CHEF) electrophoresis, the angle of the electric field is periodically changed (Figure 7).

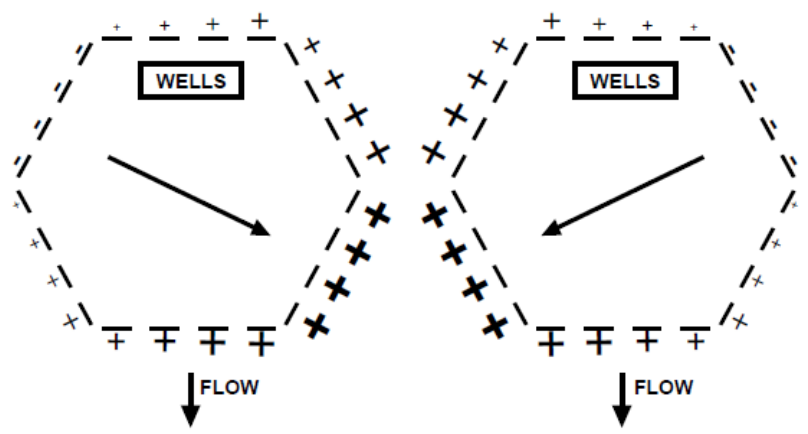

Figure 7: Voltage clamping of the CHEF DRII System (taken from the instruction manual), showing the hexagon with the $+60^{\circ}$ and $-60^{\circ}$ angle of the electric field. 
The CHEF DRII System from BioRad that was used has a hexagon structure with a maximal angle of $120^{\circ}$. PFGE is usually run for long time periods and at high voltages. To reduce the heat production $0.5 \mathrm{x}$ TBE was used to lower the current. A recirculation system with a cooling unit was used to cool the buffer to $14{ }^{\circ} \mathrm{C}$. The samples were run on a $1 \%$ agarose gel at a voltage of $6 \mathrm{~V} / \mathrm{cm}$. The run time was $24 \mathrm{~h}$ with pulse parameters of 1-25 s. The gel was then stained for $45 \mathrm{~min}$ with $\mathrm{EtBr}$. EtBr was not added before to the melted agarose because EtBr has been shown to slow down the re-orientation of the DNA.

\subsection{Polymerase chain reaction (PCR)}

The standard PCR is a method to produce millions of copies of a specific DNA sequence in a few hours. For PCR, only a small amount of DNA, an oligonucleotide primer pair, deoxyribonucleoside triphosphates (dNTPs), a thermostable DNA polymerase, and a thermocycler are required. The typical PCR program includes three steps: denaturation, annealing and elongation. During the denaturation, the DNA double strands are separated at high temperatures of about $95^{\circ} \mathrm{C}$. In the annealing step, the primers bind to the DNA. The hybridization temperature depends on the oligonucleotide sequence and length. The third step is the elongation phase, where the polymerase extends the primers at $72{ }^{\circ} \mathrm{C}$, the optimal extension temperature for the polymerase. The steps are repeated 20-40 times (cycles). Over the last years the application area for PCR has increased tremendously. In the cloning procedure of Viaat-HA-CEPOR \pm IRES-Venus, PCR was used to create the $3^{\prime}$ and $5^{\prime}$ miniarms for the homologous recombination.

\subsubsection{Creation of the 3 ' miniarm}

The PCR can be used to insert new restriction sites into DNA sequences. For this purpose, oligonucleotide primers have to be designed with 5' overhangs carrying the new restriction sites. This technique was used in the creation of the 3 ' miniarm (Figure 8).

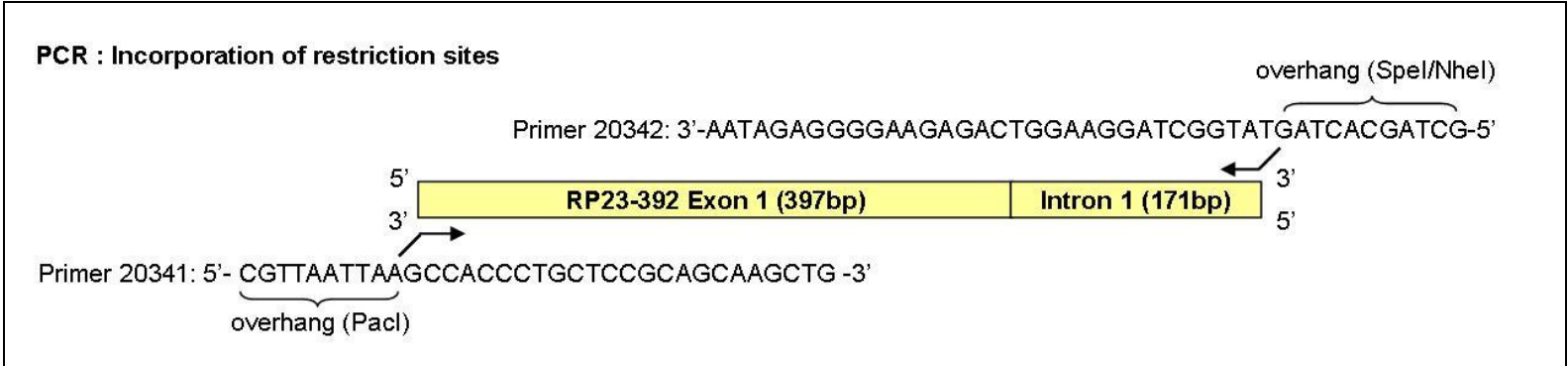

Figure 8: Illustration of the creation of the 3 ' miniarm with PCR. 
Both primers, 20341 and 20342, were designed with overhangs and integrated 3 new restrictions sites (Pacl, Spel, Nhel). For this, approximately $10 \mathrm{ng}$ of the BAC RP23-392P11 were amplified with $2.5 \mathrm{U}$ Pfu polymerase in 1x cloned Pfu buffer, with $200 \mu \mathrm{M}$ dNTPs and $12.5 \mathrm{pmol}$ of primer 20341 and 20342 in a total volume $50 \mu \mathrm{l}$. The PCR program started with an initial denaturation at $95^{\circ} \mathrm{C}$ for $1 \mathrm{~min}$. The amplification was carried out for 25 cycles including $45 \mathrm{~s}$ denaturation at $95^{\circ} \mathrm{C}, 45 \mathrm{~s}$ annealing at $66^{\circ} \mathrm{C}$ and $80 \mathrm{~s}$ elongation at $72{ }^{\circ} \mathrm{C}$. After the final elongation for $10 \mathrm{~min}$ at $72{ }^{\circ} \mathrm{C}, 1 \mathrm{U}$ REDTaq DNA Polymerase was added to the PCR mixture and incubated for $10 \mathrm{~min}$ at $72{ }^{\circ} \mathrm{C}$. The REDTaq polymerase has a terminal transferase activity and adds single $3^{\prime}$ overhanging adenosine nucleotides. This is needed for cloning the fragment into the TOPO vector (2.3.3).

\subsubsection{Creation of $5^{\prime}$ miniarm}

The creation of the $5^{\prime}$ miniarm included an introduction of a new restriction sites with primer 20289 (Sacl/EcoRI) and additionally used the method of an overlap extension PCR. The first step of an overlap extension PCR is the amplification of two separate fragments (Figure 9, PCR 1). Importantly, the 3' primer 20299 of fragment 1 (from template RP23-392P11) has an overhang, which is complementary to the $5^{\prime}$ end of fragment 2 (from template HA-CEPOR). Approximately $10 \mathrm{ng}$ of RP23-392P11 and alpha-CaMKII-HA-CEPOR were amplified with $2.5 \mathrm{U}$ Pfu polymerase in $1 x$ cloned Pfu buffer, with $200 \mu \mathrm{M}$ dNTPs and 12.5 pmol primers in a volume of $50 \mu \mathrm{l}$. The PCR programs started with an initial denaturation at $95^{\circ} \mathrm{C}$ for $1 \mathrm{~min}$. The amplification was carried out for 25 cycles including $45 \mathrm{~s}$ denaturation at $95^{\circ} \mathrm{C}, 45 \mathrm{~s}$ annealing at $66^{\circ} \mathrm{C}$ for fragment $1,45 \mathrm{~s}$ annealing at $57^{\circ} \mathrm{C}$ for fragment $2,80 \mathrm{~s}$ elongation for fragment 1 and 60 s elongation for fragment 2 at $72{ }^{\circ} \mathrm{C}$. The PCR program ended with a final elongation for $10 \mathrm{~min}$ at $72{ }^{\circ} \mathrm{C}$ and a cool down to $12{ }^{\circ} \mathrm{C}$. In the second PCR (Figure 9, PCR 2), the two fragments were put together. After denaturation, both fragments were fused through the overlapping sequence. Therefore, no primers were added and the Pfu polymerase was only filling in the 5' overhangs. For this, $2 \mu \mathrm{l}$ of both PCRs reactions were mixed with $200 \mu \mathrm{M}$ dNTPs, $2.5 \mathrm{U}$ Pfu-polymerase in 1x cloned Pfu buffer in a volume of $45 \mu \mathrm{l}$. The PCR program started again with an initial denaturation at $95^{\circ} \mathrm{C}$ for $1 \mathrm{~min}$, followed by only 5 cycles including $45 \mathrm{~s}$ denaturation at $95^{\circ} \mathrm{C}, 45 \mathrm{~s}$ annealing at $57^{\circ} \mathrm{C}$, and $2.5 \mathrm{~min}$ elongation at $72{ }^{\circ} \mathrm{C}$. The PCR program ended again with a final elongation for 10 min at $72{ }^{\circ} \mathrm{C}$ and a cool down to $12{ }^{\circ} \mathrm{C}$. In a third step, the fusion product was amplified (Figure 9, PCR 3). For this purpose, only 12.5 pmol of the primers 20301 and 20302 were added to the PCR 2- 
mixture and run with the same PCR program as PCR 2, but with 20 cycles. As for the 3' miniarm, single adenosine nucleotides were added with the REDTaq DNA polymerase to enable the TOPO cloning.

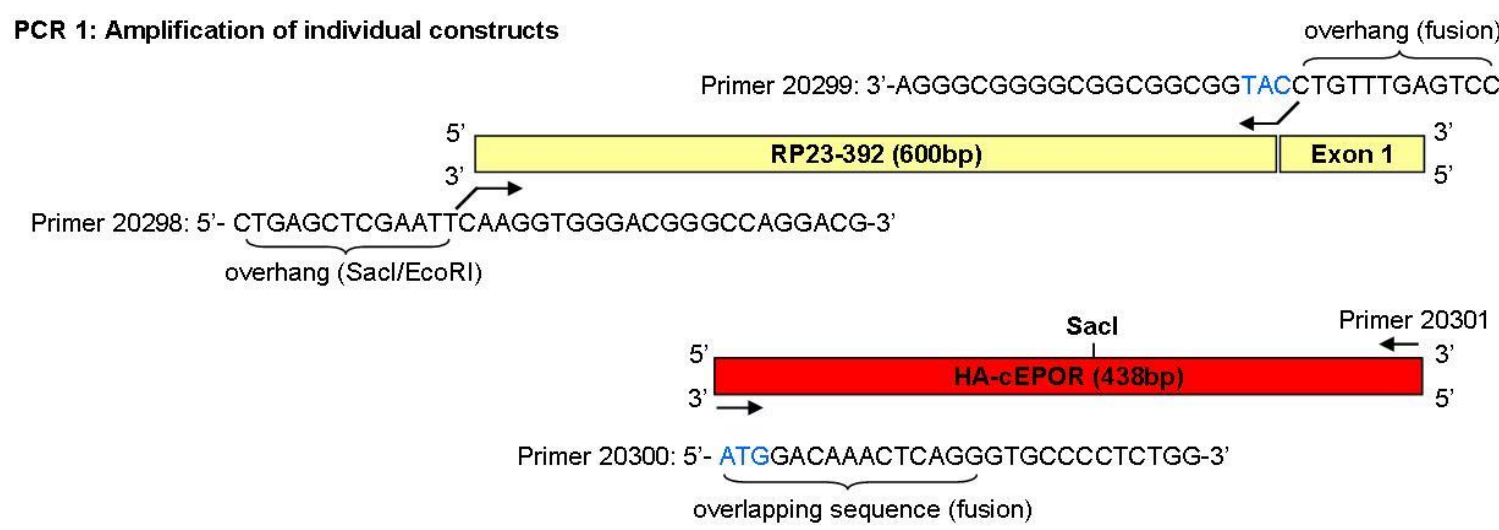

PCR 2: Formation of fusion-construct

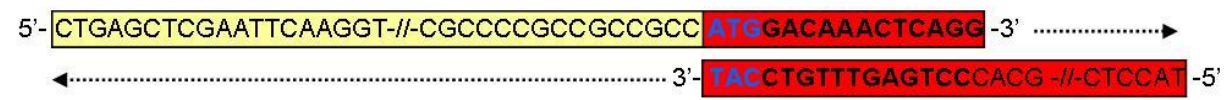

PCR 3: Amplification of fusion-construct

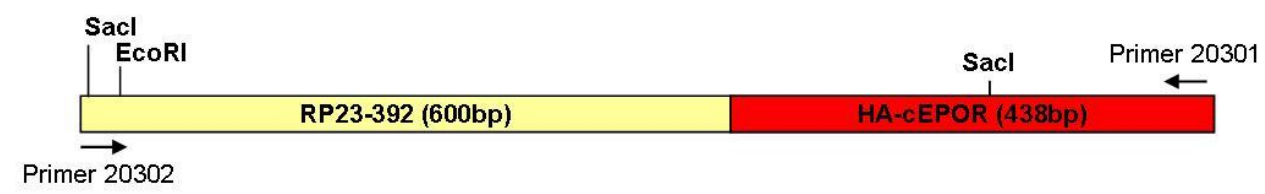

Figure 9: Illustration of the creation of the 5 'miniarm with PCR.

\subsubsection{Cloning of PCR products - TOPO TA Cloning Kit}

The classical way of cloning PCR products is to use primers with restrictions sites. After cutting the purified PCR product at the newly inserted restriction sites, it can be cloned into any vector with complementary restriction sites. This method has the disadvantage that some restriction enzymes cut with low affinity near the end of a fragment and that primers with the respective cutting sites need to be designed. An easier way of cloning PCR products is to use the TOPO TA cloning kit. This kit provides a vector cut with the vaccinia topoisomerase (cutting site CCCTT). The vector has two $5^{\prime}$ overhangs with T (Figure 10). This prevents re-closure by base pairing incompatibility and is suited for accepting PCR products 
produced by Taq polymerase. In contrast to the Pfu polymerase, which has a proofreading enzyme and creates blunt ends, the Taq polymerase has a terminal transferase activity and is adding single 3' overhanging adenosine nucleotides (as described above).

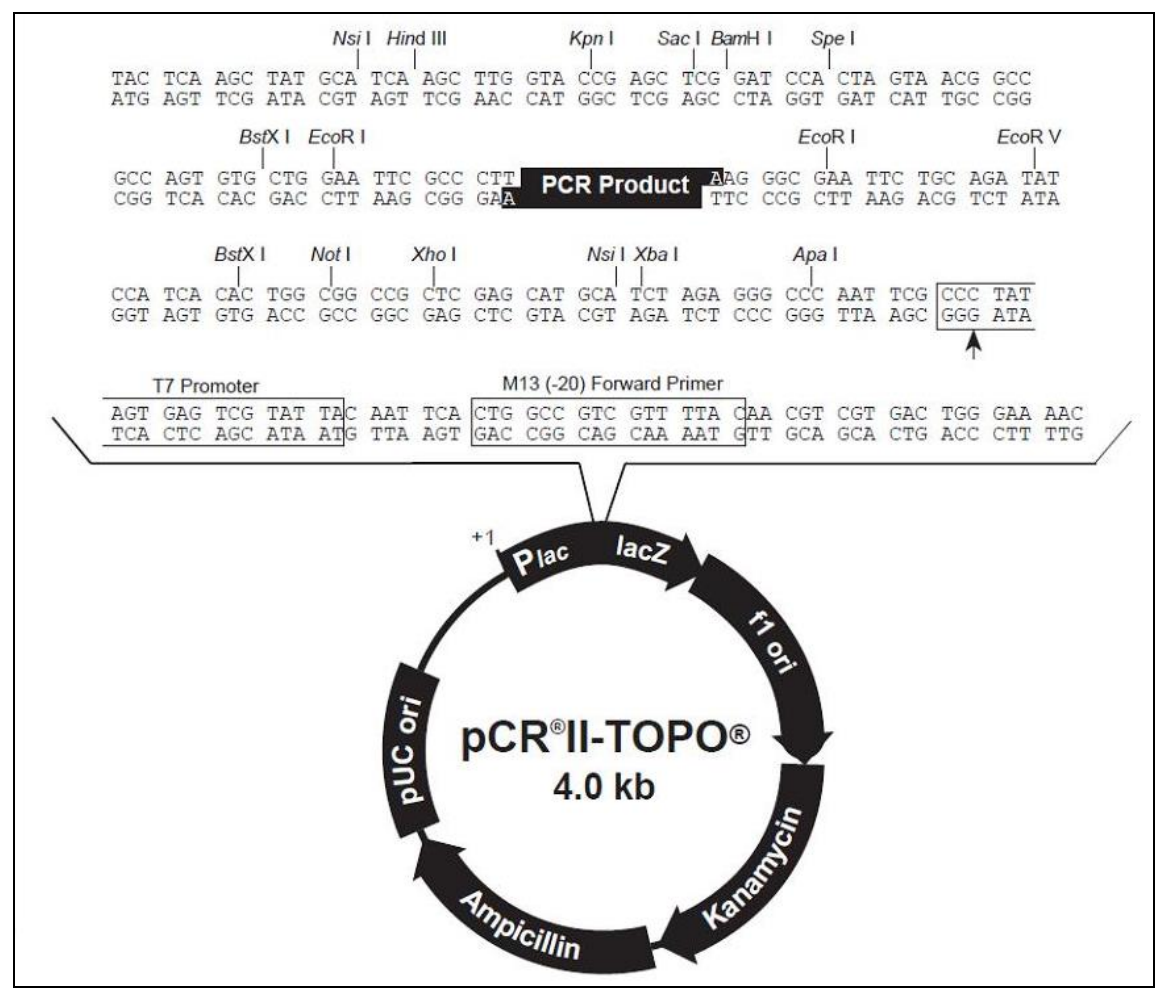

Figure 10: Illustration of the pCRII TOPO cloning (from the instruction manual).

According to the manufacturer's protocol, $1 \mu \mathrm{l}$ of the $3^{\prime}$ miniarm fragment or $4 \mu \mathrm{l}$ of the fused 5' miniarm fragment were incubated with $1 \mu \mathrm{l}$ of the TOPO-vector in a diluted salt solution for 5 min on ice. XL-1 Blue cells were transformed with the miniarm-TOPO-plasmidligation mixture and analyzed for the correct plasmids.

\subsubsection{Purification of PCR products from PCR reactions}

The purification was done with the MSB Spin PCR Kit (Life Technologies). Following the manufacturer's protocol, $500 \mu \mathrm{l}$ were added to $100 \mu \mathrm{l}$ of the PCR sample and mixed by vortexing. The solution was transferred to the spin filter column and centrifuged for $1 \mathrm{~min}$ at $11,000 \mathrm{rpm}$. The filtrate was removed and the column centrifuged for $2 \mathrm{~min}$ at 11,000 rpm. The spin filter was placed into a $1.5 \mathrm{ml}$ tube and $15 \mu \mathrm{l}$ EB buffer was added to the center of the spin filter. After incubation for $1 \mathrm{~min}$, the PCR product was eluted with centrifugation at $11,000 \mathrm{rpm}$ for $1 \mathrm{~min}$. 


\subsection{Genetic engineering (in vitro)}

The traditional genetic engineering uses restriction enzymes and DNA ligases to cut and rejoin DNA fragments (Copeland et al., 2001).

A typical genetic engineering process is made up as follows:

1.) The plasmid and insert are cut with restriction enzymes (2.4.1).

2.) The DNA is separated and purified by gel electrophoresis and gel extraction (2.2.2).

3.) The DNA can be blunt-ended if different restriction enzymes had to be used (2.4.2).

4.) The vector is dephosphorylated (2.4.3).

5.) The vector is ligated with the insert (2.4.4).

6.) The ligated construct is transformed and amplified in E. coli (2.4.5).

7.) The plasmid is isolated (2.1.1) and analyzed with a diagnostic restriction digest (2.4.6).

8.) E. coli clones carrying the correct plasmids are frozen in glycerol stocks (2.4.8).

\subsubsection{Restriction enzymes}

Restriction enzymes are sequence specific endonucleases. They originate from bacteria and serve as a protective mechanism against viral infections by cutting foreign DNA (Berg JM, 2002). There are several types of restriction enzymes which differ in the number of subunits, cofactor requirements, and the distance between recognition and cutting site (Bickle and Kruger, 1993). Type II restriction enzymes are the simplest ones and are mainly used for genetic engineering. They recognize and cleave DNA at the same sequence and need only $\mathrm{Mg}^{2+}$ as a cofactor. The recognition site is usually $4-8$ nucleotides in length and is palindromic.

In general, 3-7 $\mu$ g of vector and insert were cut with approximately $10 \mathrm{U}$ enzyme per $1 \mu \mathrm{g}$ DNA. The reactions were carried out in the recommended buffer with the addition of $100 \mu \mathrm{g} / \mathrm{ml} \mathrm{BSA}$ in a total volume of $100 \mu \mathrm{l}$ and incubated at $37^{\circ} \mathrm{C}$ for $2-4 \mathrm{~h}$. The digestion was stopped by adding the loading buffer/stop mix.

\subsubsection{Fill-in with Pfu (creation of blunt ends)}

The creation of blunt ends is helpful for ligating DNA fragments after restriction digestion with different enzymes. The Pfu polymerase is a 5'-3' polymerase with a high heat-stability (half-life of $12 \mathrm{~h}$ at $95^{\circ} \mathrm{C}$ ) and a $3^{\prime}-5^{\prime}$ exonuclease activity (proofreading). Additionally, the polymerase is able to remove 3 ' overhangs (polishing) and to fill-in 5'overhangs, which creates blunt ends. The reaction mixture included $5 \mathrm{U}$ Pfu polymerase, $1 x$ cloned buffer, 
$200 \mu \mathrm{M}$ dNTPs and $70 \mu \mathrm{l}$ of the purified restriction fragments. The reaction mix of $100 \mu \mathrm{l}$ was incubated for $30 \mathrm{~min}$ at $72^{\circ} \mathrm{C}$.

\subsubsection{Dephosphorylation of the vector}

The ability of self-ligation (re-ligation) of linearized vectors prevents the integration of inserts during in the ligation reaction. This can be reduced by dephosphorylation of 5 ' ends of the vector, catalyzed by alkaline phosphatases. According to the manufacturer's protocol the vector DNA was dephosphorylated with $1 \mathrm{U}$ of rAPid alkaline phosphatase, 1x rAPid alkaline phosphatase buffer in a volume of $20 \mu \mathrm{l}$ for $10 \mathrm{~min}$ at $37^{\circ} \mathrm{C}$. The alkaline phosphatase was inactivated by heating for 2 min at $75^{\circ} \mathrm{C}$.

\subsubsection{Ligation of vector and insert}

DNA ligases catalyzes the formation of a phosphodiester bond between a free 3 ' hydroxyl group of one DNA strand and a free 5' phosphate group of another DNA strand (Berg JM, 2002). This reaction is frequently used in traditional engineering. The reaction was performed according to the manufacturer's protocol with minor modification. Vector and insert were ligated with $2 \mathrm{U}$ of T4 ligase in a volume of $20 \mu \mathrm{l}$ overnight at $0-24^{\circ} \mathrm{C}$. The concentration of vector and insert was approximately 10-200 ng with a 3-fold molar excess of insert. The ligation product was immediately transformed into $\mathrm{E}$. coli or stored at $-20^{\circ} \mathrm{C}$.

\subsubsection{Transformation}

Electroporation is one of the most efficient ways to transform plasmid DNA into E. coli cells. It is recommended to work close to a Bunsen flame to avoid contamination. Electroporation cuvettes and E. coli cells were cooled on ice before transformation. For the transformation $1 \mu \mathrm{l}$ of the ligation mix was added to $50 \mu \mathrm{l}$ E. coli cells. The cell suspension was transferred into an electroporation cuvette ( $1 \mathrm{~mm}$ gap width) and electroporated at $1.8 \mathrm{kV}$. Afterwards $1 \mathrm{ml}$ LB medium was added to the cell suspension and the mixture was transferred into a $1.5 \mathrm{ml}$ reaction tube. The cells were incubated for $1 \mathrm{~h}$ at $37^{\circ} \mathrm{C}$. After the recovery phase, the cells were centrifuged for $30 \mathrm{~s}$ at 13,000 rpm. The supernatant was discarded and the cells were plated in approximately $50 \mu \mathrm{l}$ on pre-warmed selective agar plates and incubated overnight (approximately $16-24 \mathrm{~h}$ ) at $37^{\circ} \mathrm{C}$. 


\subsubsection{Diagnostic restriction digest}

Usually, 12 clones were picked from the agar plates and grown in $5 \mathrm{ml}$ selective LB medium overnight at $37^{\circ} \mathrm{C}$. For a the diagnostic restriction digest, $1.5 \mathrm{ml}$ of the overnight culture was used for the plasmid isolation (2.1.1) and $5 \mu \mathrm{l}$ of the isolated plasmid DNA were digested with $0.5 \mu \mathrm{l}$ of the restriction enzyme, $0.5 \mu \mathrm{l}$ RNase $\mathrm{A}(10 \mu \mathrm{g} / \mu \mathrm{l})$ and $5 \mu \mathrm{l}$ BSA $(10 \mu \mathrm{g} / \mu \mathrm{l})$ in the recommended buffer, in a total volume of $50 \mu \mathrm{l}$, at $37^{\circ} \mathrm{C}$ for $2 \mathrm{~h}$. The restriction digest was analyzed after gel electrophoresis (2.2.1).

\subsubsection{Bacterial culture medium}

Bacterial cultures are relatively easy to grow. The most commonly used medium is Luria Broth (LB) medium. It contains $10 \mathrm{~g}$ tryptone, $5 \mathrm{~g}$ yeast extract and $10 \mathrm{~g} \mathrm{NaCl}$ per liter. For liquid LB medium $25 \mathrm{~g}$ of LB powder was dissolved in $1 \mathrm{I} d \mathrm{ddH}_{2} \mathrm{O}$. To obtain solid LB medium, $15 \mathrm{~g}$ Bacto-Agar was added per liter. The medium was autoclaved at $121^{\circ} \mathrm{C}$ for $20 \mathrm{~min}$, cooled down to approximately $60^{\circ} \mathrm{C}$, and antibiotics as selective growth compounds were added. The antibiotic concentrations used were $50 \mu \mathrm{g} / \mathrm{ml}$ ampicillin (Amp), $25 \mu \mathrm{g} / \mathrm{ml}$ kanamycin (Kan) and $12.5 \mu \mathrm{g} / \mathrm{ml}$ chloramphenicol (Chl). Warm solid LB medium was poured into petri dishes (approximately $20 \mathrm{ml}$ per dish) to obtain selective agar plates.

\subsubsection{Glycerol stocks}

Glycerol is used as cryoprotectant for long-term storage of bacterial cells. For this purpose, $85 \%$ glycerol solution was diluted in LB medium to $30 \%(3.5 \mathrm{ml}$ of glycerol $6.5 \mathrm{ml}$ LB medium) and mixed 1:1 with the bacterial overnight culture $(750 \mu \mathrm{l} 30 \%$ glycerol solution and $750 \%$ bacterial culture). The bacterial-glycerol solution is mixed by pipetting and frozen at $-80^{\circ} \mathrm{C}$ in $2 \mathrm{ml}$ cryo tubes. Glycerol stocks stored at $-80^{\circ} \mathrm{C}$ are stable over many years.

\subsection{Recombineering}

Generation of BAC transgenic animals needs modern tools of genetic engineering. Recombineering is an in vivo method of genetic engineering based on homologous recombination (recombinogenic engineering) (Copeland et al., 2001; Sawitzke et al., 2007; Sharan et al., 2009). The method was originally used for chromosome engineering of Saccharomyces cerevisiae (yeast) (Baudin et al., 1993) and in contrast to the traditional in vitro genetic engineering, this method does not rely on restriction enzymes and ligases. This 
is a big advantage for the creation of transgenic mouse models using large vectors like bacterial artificial chromosomes (BACs). Modifying a BAC with the traditional genetic engineering is almost impossible because of the difficulties in finding unique restriction sites. This makes the recombineering technique indispensable and promoted the development of the method over the last years. One issue was that linear dsDNA is unstable in E. coli due to an exonuclease (RecBCD). This could be circumvented, for example with mutated forms of RecBCD or degradation-preventing sequences (Chi sites) at the ends of the linear DNA. Over the years two phage-encoded recombination systems with high efficacies were developed. One uses the RecE/RecT proteins from Rac prophage, the other the Red $\alpha \beta \gamma$ proteins from bacteriophage $\lambda$.

\subsubsection{Bacteriophage $\lambda$ recombination system}

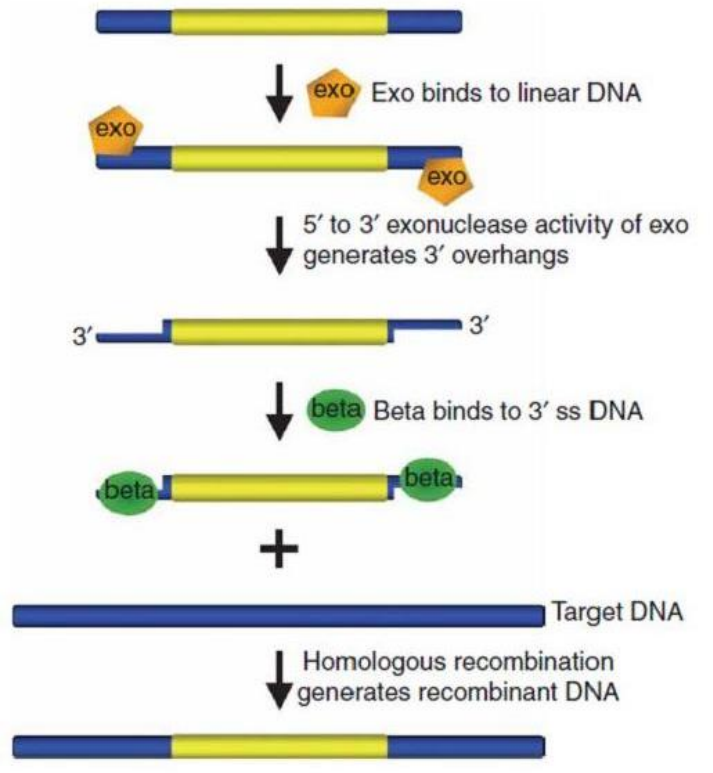

The bacteriophage $\lambda$ system uses the phage recombination proteins exo, bet and gam. The Gam protein inhibits the nuclease activity of RecBCD and stabilizes the linear dsDNA. The Exo protein is a 5'-3' exonuclease, binds to the 5 ' end of linear dsDNA and produces 3'overhangs (Figure 11). Protein Beta binds to 3' ssDNA, promotes the annealing to the complementary strand and generates recombinant DNA.

Figure 11: Schematic illustration of the bacteriophage $\lambda$ recombination system (from Sharan et al., 2009).

\subsubsection{Defective $\lambda$-prophage-based system}

Two bacteriophage $\lambda$ derived constructs used for recombination are shown in Figure 12 . The red genes exo, bet and gam are located in the PL operon. Additionally, $N$, kil, xis and int are located in this transcriptional unit. The $\mathrm{N}$ protein is an anti-terminator for the termination sites $\mathrm{tL} 1 \mathrm{tL2}$ and $\mathrm{tL3}$, needed for the complete transcription of the PL operon genes. Xis and Int are proteins originally necessary for the excision and integration of the phage DNA, whereas the attachment sites (att) are complementary to the bacterial genome and navigate the integration of the phage DNA in between the galactose and biotin operon of the E. coli genome. Kil is killing the bacterial cell when expressed over $1 \mathrm{~h}$ and is important for the lysis 
and release of the virus particle. This is why the timing and expression level of the genes are critical in using the system for recombineering. A temperature-sensitive mutation c/857 assists to circumvent this issue (Defective $\lambda$-prophage-based system). The repressor $\mathrm{Cl} 857$ is stable at $32-37^{\circ} \mathrm{C}$ but degrades with a temperature shift to $42^{\circ} \mathrm{C}$. Thus, the expression of the genes can be easily regulated by the cultivation temperature.

The second operon is the replication operon $\mathrm{PR}$ and harbors the genes $c r o, O P, Q, S R A-J . O P$ are replication genes, the Cro protein can partially repress the transcription of PL and PR when $\mathrm{Cl} 857$ is inactive. $\mathrm{Q}$ is the regulator of the lysis and structural genes SRA-J. The replication operon PR is not needed for recombination and was deleted in some recombinogenic bacterial strains (Figure 12b). In addition, the attachment site was deleted. This has the advantage that the prophage has neither the ability for excision nor replication.

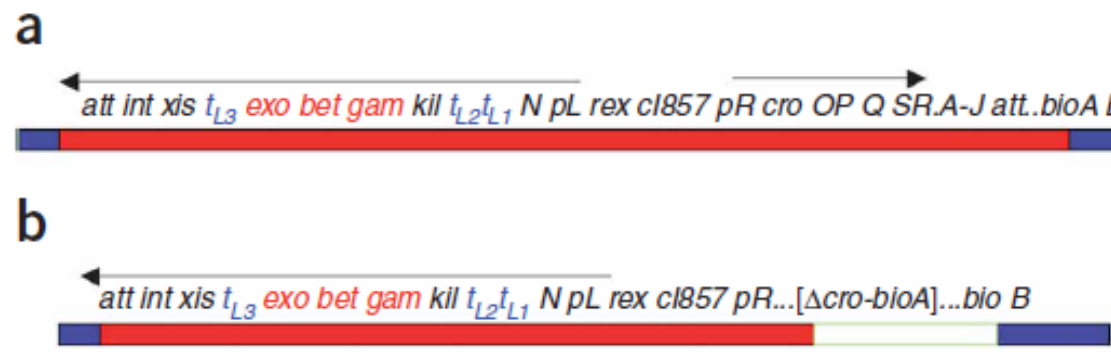

Figure 12: Schematic representation of the bacteriophage $\lambda$ construct used for recombination (from Sharan et al., 2009). (a) The phage DNA (red) is flanked by attachment sites (att). The integration of the phage takes place in between the galactose and biotin operon (bioAB) of the bacterium genome (blue). The $P_{L}$ operon $(p L)$ contains genes for the anti-terminator $(N)$, the killing gene ( $k i l)$, the recombinogenic genes (exo, bet, gam) and the excision and integration genes (int, xis). The replication operon (pR) contains a repressor gene (cro), the replication genes (OP), a regulator gene (Q) and structural genes (SRA-J). The mutated repressor gene (cl857) leads to temperature regulated transcription of the ${ }_{P L}$ and $P_{R}$ operon. (b) The replication operon (PR) and the attachment sites (att) are deleted from the bacteriophage $\lambda$ construct, preventing the excision and replication of the prophage.

\subsubsection{Recombinogenic strain - SW105}

SW105 is one of the newest E. coli recombinogenic strains and was used in the current study. It is derived from EL250, which itself is a derivate of DY380, the first recombinogenic strain derived from the parent strain DH10B. In SW105, the PR operon and the attachment sites are deleted (Figure 12b), preventing excision and replication of the prophage. The strain carries an additional araC inducible flpe gene ( $\left.\operatorname{araC}-P_{B A D} F / p e\right)$. This allows the excision of sequences framed by frt-sites by L-arabinose treatment. 


\subsubsection{Generation of electrocompetent SW105}

SW105 cells were grown overnight in $5 \mathrm{ml} \mathrm{LB}$ medium at $32{ }^{\circ} \mathrm{C}$ (no expression of recombineering genes). $3 \mathrm{ml}$ of the overnight culture were used to inoculate $60 \mathrm{ml}$ LB medium. The cells were grown to an $\mathrm{OD}_{600}$ of $0.5-0.6$. The flasks were cooled down in ice water. The cell suspension was transferred into 8 prechilled $15 \mathrm{ml}$ Falcon tubes. The cells were washed 3 times with ice-cold water. For this, the cell suspension was centrifuged for $10 \mathrm{~min}$ at $3,500 \mathrm{rpm}$ at $0{ }^{\circ} \mathrm{C}$ and the pellet was resuspended in ice-cold water on a rotating wheel in a $4{ }^{\circ} \mathrm{C}$ cold room. After three rounds of washing, the pellet was resuspended in $100 \mu \mathrm{l}$ water, distributed in $2 \times 1.5 \mathrm{ml}$ reaction tubes and placed on ice.

\subsubsection{Transformation of the BAC into the recombinogenic strain SW105}

In the next step, the Viaat-BAC RP23-392P11 (which carries a chloramphenicol resistance) was transformed into the recombinogenic strain, SW105. Therefore, the BAC DNA was isolated (2.1.3) and $1 \mu \mathrm{l}$ of the isolated BAC DNA was used for the transformation of the freshly generated electrocompetent SW105 cells. The transformed bacteria were plated on $\mathrm{LB} / \mathrm{Chl}$ agar plates for $16-24 \mathrm{~h}$ at $32^{\circ} \mathrm{C}$. Four colonies were picked, transferred into $6 \mathrm{ml}$ $\mathrm{LB} / \mathrm{Chl}$ medium, and were grown overnight at $32{ }^{\circ} \mathrm{C}$. Glycerol stocks were generated with $750 \mu$ of the overnight culture (2.4.8). The BAC DNA was isolated for diagnostic restriction digestion (2.4.6) with Pacl and Pmel. For this purpose, $10 \mu \mathrm{l} \mathrm{BAC} \mathrm{DNA} \mathrm{was} \mathrm{cut} \mathrm{with} 15 \mathrm{U}$ Pacl or Pmel in the recommended buffer in a reaction volume of $50 \mu \mathrm{l}$ for $16 \mathrm{~h}$ at $37^{\circ} \mathrm{C}$. The correct fragment size was confirmed by PFGE (2.2.3).

\subsubsection{Recombineering}

BAC RP23-392P11 containing SW105 cells were grown at $32{ }^{\circ} \mathrm{C}$ in $60 \mathrm{ml} \mathrm{LB} / \mathrm{Chl}$ medium. When the cells reached an $\mathrm{OD}_{600}$ of $0.5-0.6$, the expression of the recombineering genes was induced by incubating the cells for $15 \mathrm{~min}$ at $42{ }^{\circ} \mathrm{C}$, followed by cooling Afterwards the cell suspension was cooled down on ice. The cells were made electrocompetent (2.5.4) and $1 \mu \mathrm{l}$ (120-165 ng) of the linearized purified constructs (which carry an ampicillin resistance) were used for electroporation. The cells were allowed to recover at $32{ }^{\circ} \mathrm{C}$ for $1 \mathrm{~h}$ and plated on LB/Chl/Amp agar plates. Cells which have integrated the linearized construct by homologous recombination (Figure 13) were able to grow. 


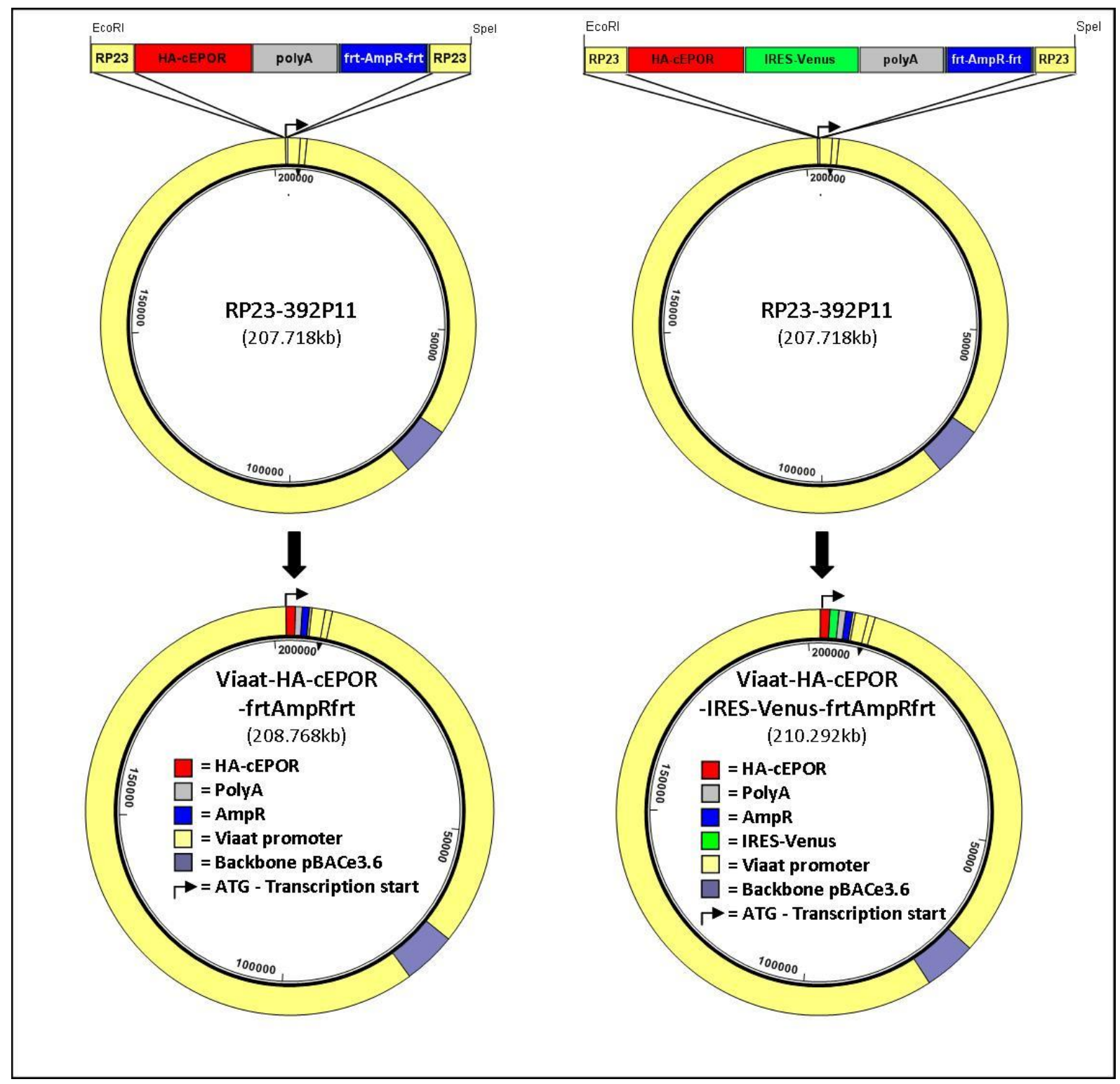

Figure 13: Illustration of the homologous recombination in cloning step 10.

\subsubsection{Flpe/FRT recombination system and excision of AmpR}

The Flpe/FRT recombination system mechanism was used in the cloning procedure for the excision of the $A m p R$ gene and is therefore explained in more detail. The arabinose operon allows E. coli to grow on L-arabinose. The operon is controlled by the repressor protein AraC, which inhibits the transcription of the arabinose genes if no L-arabinose is present. In the recombinogenic stain SW105, the Flpe gene (derived from Saccharomyces cerevisiae) is inserted behind the $\mathrm{p}_{B A D}$ promoter of the arabinose operon (Figure 14). Without L-arabinose, the dimeric AraC protein binds in two separate DNA regions creating a DNA loop (Schleif, 2003). In this configuration, the RNA polymerase cannot bind the $\mathrm{p}_{\mathrm{BAD}}$ promoter (Figure 14A). With addition of L-arabinose AraC, the dimeric AraC protein prefers to bind adjacent 
DNA sites, allowing the transcription of the Flpe gene. The Flpe gene codes for a flippase, which recombines at defined target sites, termed FRT (Branda and Dymecki, 2004; Lacroix et al., 2011). Flpe excises DNA located between two FRT sites having the same orientation (Figure 14B). This mechanism was used to excise the $A m p R$ gene in cloning step 11.

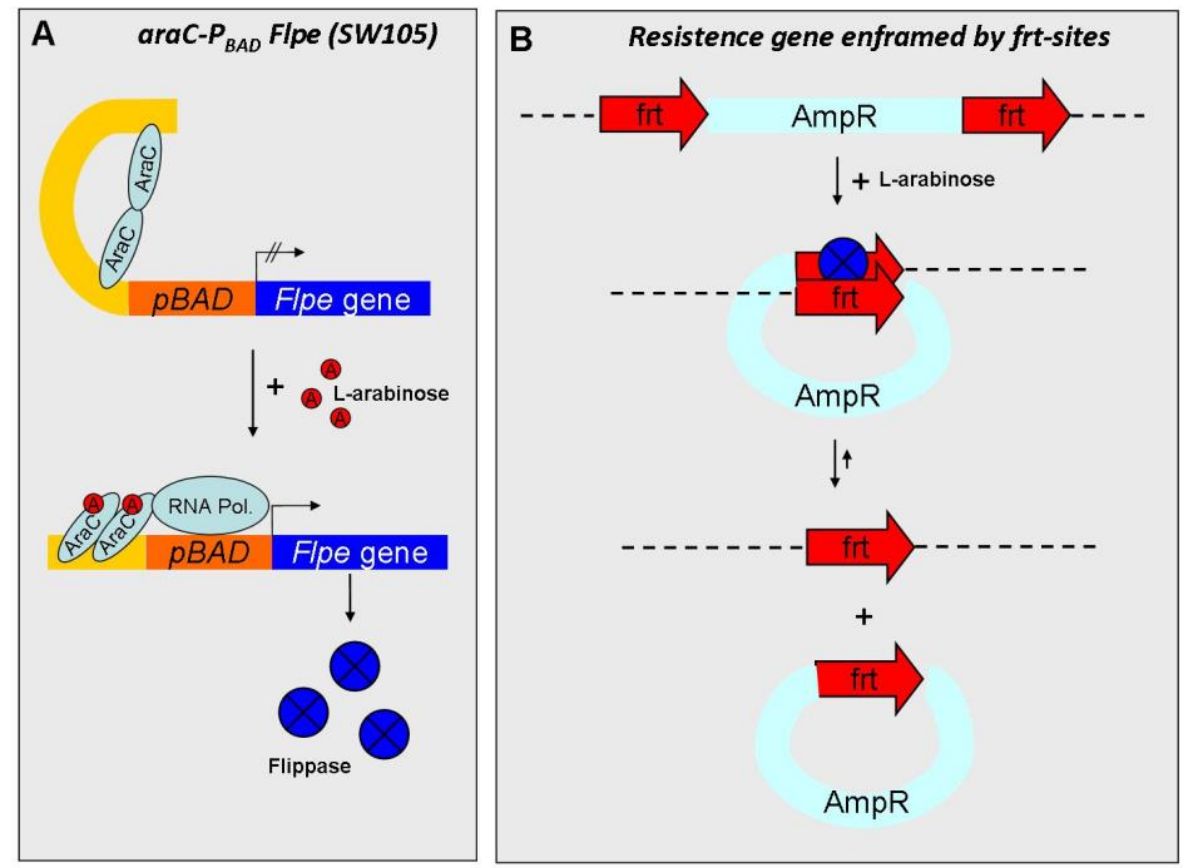

Figure 14: Illustration demonstrating the L-arabinose induced excision of DNA with the site specific FLpe/FRT recombination system. (A) L-arabinose induced expression of Flpe (adapted from Schleif, 2003) (B) Flpe induced excision of the $A m p R$.

Therefore, $5 \mathrm{ml}$ overnight cultures of Viaat-HA-CEPOR-frtAmpRfrt and HA-cEPOR-IRES-VenusfrtAmpRfrt were used to inoculate $250 \mathrm{ml}$ selective $\mathrm{LB} / \mathrm{Chl}$ medium. The cells were grown to an $\mathrm{OD}_{600}=0.4$ before $2.5 \mathrm{ml} 10 \%$ arabinose solution were added. The cells were shaken for $1 \mathrm{~h}$ at $32{ }^{\circ} \mathrm{C} .10 \mu \mathrm{l}$ of an 1:1000 dilution were plated on LB/Chl agar plates. Two clones were analyzed to check if the excision was successful. 


\subsection{Linearization of the BAC and pronuclear injection}

\subsubsection{Linearization of the BAC}

The BAC Viaat-HA-EPOR and Viaat-HA-EPOR-IRES-Venus were amplified in $250 \mathrm{ml} \mathrm{LB} / \mathrm{Chl}$ medium and the BAC DNA was isolated with BAC maxi preparation (2.1.3). Nrul was used to cut out the backbone pBAC3.6 and to linearize the BAC constructs. For this, $24 \mu \mathrm{g}$ of BAC DNA were digested with $70 \mathrm{U}$ Nrul with BSA in a total volume of $100 \mu$ l overnight at $37^{\circ} \mathrm{C}$. The next day, the digest was purified by a self-made sepharose-column. A $5 \mathrm{ml}$ plastic pipette served as the column. The cotton plug from the top of the pipette was pushed to the narrow end and the top part was cut off at the -1 mark. The pipette was mounted in a ringstand and CL-4B sepharose was diluted 1:4 with injection buffer and was filled into the pipette up to the $5.5 \mathrm{ml}$ mark. A $10 \mathrm{ml}$ syringe (with plunger removed) was mounted on top of the pipette and sealed with Parafilm. The column was equilibrated 2 times with $10 \mathrm{ml}$ injection buffer. The volume of the digest was adjusted to $200 \mu \mathrm{l}$ and mixed with $5 \mu \mathrm{l} 0.25 \%$ bromophenol blue. The sample was loaded to the column. After the sample entered the bedding, $5 \mathrm{ml}$ of injection buffer was added and fractions of approximately $200 \mu \mathrm{l}$ ( 3 drops) were collected. For quality control, $25 \mu \mathrm{l}$ of the fractions with the highest amount of DNA were separated by PFGE. The selected fraction was diluted to $1 \mathrm{ng} / \mu \mathrm{l}$ with injection buffer for microinjection.

\subsubsection{Pronuclear injection}

The microinjection was done in the animal facility of the Max Planck Institute of Experimental Medicine under the direction of Dr. Ursula Fünfschilling. The microinjection was performed on 6 days per construct, Viaat-HA-EPOR and Viaat-HA-EPOR-IRES-Venus (Table 2). On each day approximately 150 fertilized eggs (of 15 superovulated bred C57BL/6N females, day 0.5) were isolated and injected. Injected eggs appearing vital were

\begin{tabular}{|l|l|c|c|}
\hline construct & date & $\begin{array}{l}\text { Reimplanted } \\
\text { injected pronuclei }\end{array}$ & $\begin{array}{c}\text { Number of } \\
\text { foster mother }\end{array}$ \\
\hline Viaat-HA-CEPOR & 08.09 .2011 & 93 & 3 \\
\hline Viaat-HA-CEPOR & 12.09 .2011 & 81 & 3 \\
\hline Viaat-HA-CEPOR & 15.09 .2011 & 99 & 3 \\
\hline Viaat-HA-CEPOR & 23.11 .2011 & 62 & 2 \\
\hline Viaat-HA-CEPOR & 24.11 .2011 & 57 & 2 \\
\hline Viaat-HA-CEPOR & 25.11 .2011 & 56 & 2 \\
\hline Viaat-HA-CEPOR-IRES-Venus & 09.09 .2011 & 88 & 3 \\
\hline Viaat-HA-CEPOR-IRES-Venus & 13.09 .2011 & 67 & 2 \\
\hline Viaat-HA-CEPOR-IRES-Venus & 16.09 .2011 & 109 & 3 \\
\hline Viaat-HA-CEPOR-IRES-Venus & 15.12 .2011 & 28 & 1 \\
\hline Viaat-HA-CEPOR-IRES-Venus & 16.12 .2011 & 50 & 2 \\
\hline Viaat-HA-CEPOR-IRES-Venus & 19.12 .2011 & 65 & 2 \\
\hline
\end{tabular}

re-implanted into the oviducts of pseudopregnant females (foster mothers). The offspring was genotyped to identify transgenic animals.

Table 2: Table presenting the construct injections dates, the number of the vital appearing injected pronuclei and number of the foster mothers. 


\section{Methods Part II}

\subsection{Analysis of the transgenic mouse}

\subsubsection{PCR-based genotyping}

\section{Isolation of DNA from tail biopsies}

The DNA for the genotyping was isolated from tail biopsies of 2-3 week old mice with the NucleoSpin Tissue Kit. For lysis, the mouse tails were incubated in $180 \mu \mathrm{l} \mathrm{T1}$ buffer with $25 \mu \mathrm{l}$ Proteinase $\mathrm{K}$ for at least $3 \mathrm{~h}$ at $56^{\circ} \mathrm{C}$. The lysate was vortexed after addition of $200 \mu \mathrm{l} \mathrm{buffer}$ B3 and $210 \mu$ lethanol and transferred to a silica column. After centrifugation at 11,000 rpm for $1 \mathrm{~min}$ at RT, the column was washed with $500 \mu \mathrm{l}$ buffer BW and $600 \mu \mathrm{l}$ buffer B5. The membrane was dried by centrifugation at 11,000 rpm for $1 \mathrm{~min}$ and the DNA was eluted with $100 \mu$ l pre-warmed $\left(70^{\circ} \mathrm{C}\right) \mathrm{BE}$ buffer.

\section{Genotyping-PCR (Viaat HA-cEPOR IRES-Venus)}

The genotyping for the identification of the founders was done by PCR with one primer pair binding in the polyA sequence of the construct (25763/25764) and another primer pair binding in the gene of Interleukin 2 (5063/5064), which was used as endogenous control. The founder animals were further genotyped with three other primer pairs located in different regions of the construct (26857/26958, 2521/24016, 26859/26860). In all PCRs, $1 \mu$ l of the isolated DNA from tail biopsies was amplified using $1 \cup$ REDTaq polymerase in 1xREDTaq buffer, with $125 \mu \mathrm{M}$ dNTPs and $250 \mathrm{nM}$ primers in a volume of $20 \mu \mathrm{l}$. The PCR program started with an initial denaturation at $95^{\circ} \mathrm{C}$ for $1 \mathrm{~min}$. The amplification was carried out for 32 cycles including $45 \mathrm{~s}$ denaturation at $95^{\circ} \mathrm{C}, 45 \mathrm{~s}$ annealing at $58^{\circ} \mathrm{C}$ and $45 \mathrm{~s}$ elongation at $72{ }^{\circ} \mathrm{C}$. After the final elongation for $7 \mathrm{~min}$ at $72{ }^{\circ} \mathrm{C}$, the PCR mixture was cooled down to $4{ }^{\circ} \mathrm{C}$. The PCR samples were run on a $2 \%$ agarose gel at $120 \mathrm{~V}$ for $45 \mathrm{~min}$.

\subsubsection{Immunohistochemistry}

The analysis of the construct expression was done with fluorescent immunohistochemistry. Young animals of 4-6 weeks were perfused and stained with antibodies against the HA-tag and IRES-Venus (GFP). 


\section{Perfusion, cutting and storage of brain tissue}

To achieve a sufficient fixation and good preservation of the brain tissue (Zeller, 2001), the animals were transcardially perfused with $4 \%$ formaldehyde (FA). Therefore the mouse was anesthetized by intraperitoneal injection with $0.276 \mathrm{mg} / \mathrm{g}$ Avertin. Before opening the thorax, the mouse was tested to be negative for reflexes in the hind paw. Then, the rib cage was carefully cut and the diaphragm removed to get access to the heart. A butterfly needle connected to the running peristaltic pump was inserted into the left ventricle and right atrium was cut open. Blood was flushed out with cold Ringer solution for approximately $1 \mathrm{~min}$, before the solution was switched to the cold $4 \%$ FA solution for fixation. After 4 min perfusion with $4 \% \mathrm{FA}$, the brain was dissected and postfixated for $24 \mathrm{~h}$ in $4 \% \mathrm{FA}$ at $4{ }^{\circ} \mathrm{C}$. The brains were placed for 2 days in a $30 \%$ sucrose solution for dehydration and frozen in liquid nitrogen. Afterwards, they were stored at $-80^{\circ} \mathrm{C}$ until cutting. The brains were embedded in Tissue-Tek, cut into $30 \mu \mathrm{m}$ thick coronal sections on a cryostat, and stored in an ethylene glycol based cryoprotectant solution at $-20^{\circ} \mathrm{C}$ (Watson et al., 1986).

\section{Immunofluorescence staining}

There are several immunofluorescent staining methods, which differ in their sensitivity. In the simplest staining, the primary antibody is directly conjugated with the fluorescent dye (Figure 15A). The advantages of direct labeling are the shorter staining times and a reduced risk of cross reactivity. This can be very helpful in multiple staining, where antibodies are raised in the same species. But direct fluorescent labeling has the lowest sensitivity and, in general, is only successful if the antigen is present in very large amounts. The most commonly used method is the indirect labeling, where the secondary antibody is labeled with a fluorophore (Figure 15B). The method shows a higher sensitivity compared to the direct fluorescent labeling, but the combination of antibodies has to be planned thoroughly, especially in multiple staining to avoid cross reactivity. An enhanced staining method with an even higher sensitivity uses the streptavidin-biotin system. In this method, fluorescently labeled streptavidin molecules bind with high affinity to the biotin labeled secondary antibody (Figure 15C). Another method, which has a tremendously high sensitivity, combines the avidin-biotin complex $(A B C)$ technique with the tyramide signal amplification (TSA) (Figure 15D). The staining starts with a biotin labeled secondary antibody. In the next step, the avidin-biotin peroxidase complex from the $A B C$ kit is added. The peroxidase converts the 
biotin labeled tyramine into a reactive free radical, which binds covalently to surrounding protein molecules. In the last step, a fluorescently labeled streptavidin binds to biotin. This method includes many steps and is time consuming and expensive, but in some cases it is the only option to receive a good staining result. The dimensions of amplification are illustrated in Figure 15D.
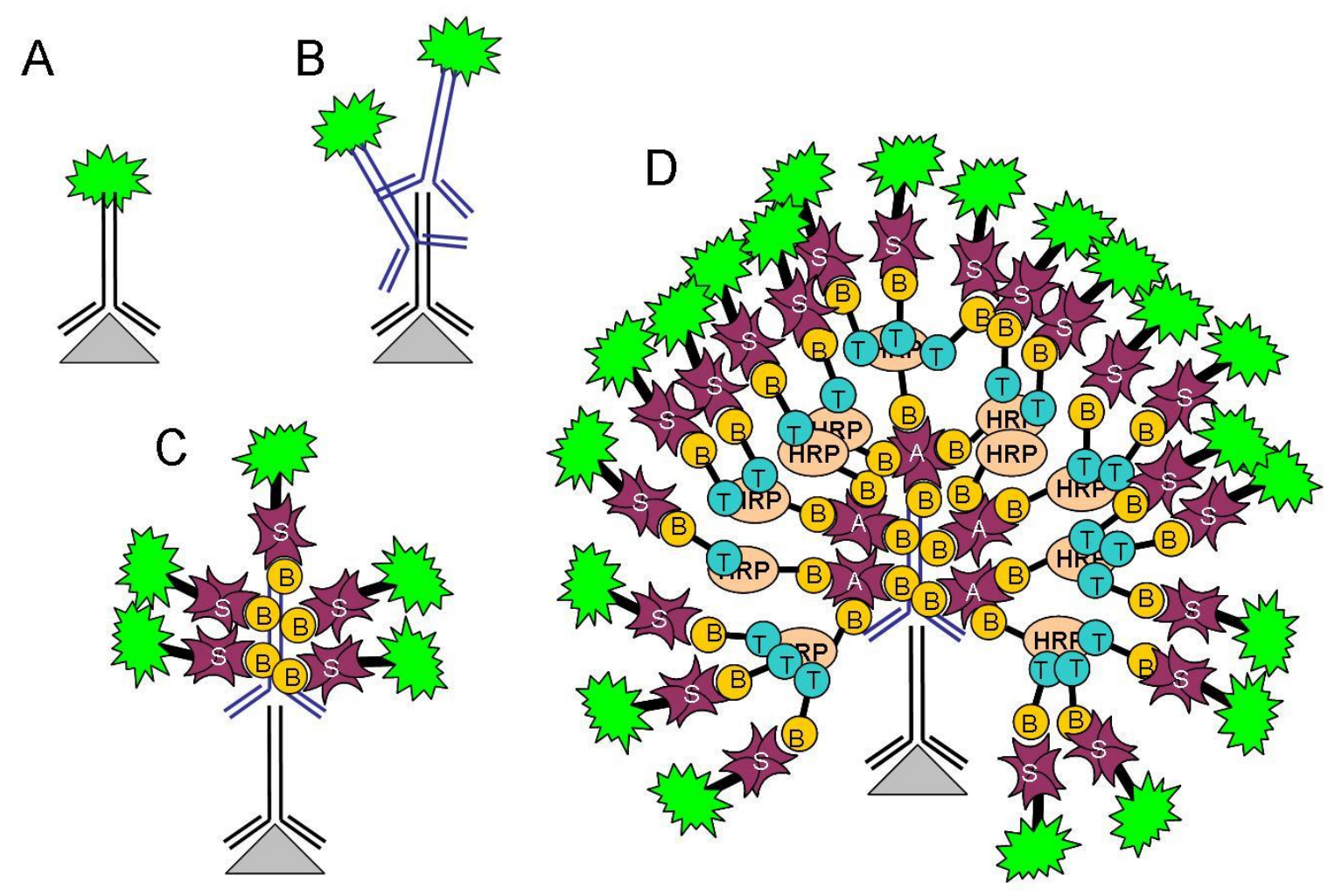

Figure 15: Illustration of different immunofluorescent staining methods. (A) Direct fluorescent staining method. (B) Indirect fluorescent staining method. (C) Biotin-streptavidin enhanced indirect fluorescent staining method. (D) $A B C$ and TSA enhanced indirect fluorescent staining method. Primary antibody (black), secondary antibody (dark blue), B=Biotin, $\mathrm{S}=$ Streptavidin, $\mathrm{A}=$ Avidin, $\mathrm{HRP}=$ Horseradish peroxidase, $\mathrm{T}=$ Tyramine.

\section{Testing single staining of the HA-tag and IRES-Venus}

The coronal brain sections, which were stored in ethylene glycol based cryoprotectant solution at $-20^{\circ} \mathrm{C}$, were washed 3 times for $15 \mathrm{~min}$ in $1 \times$ PBS at RT. The brain sections were mounted on superfrost ultra plus slides and dried overnight. The next day the sections were rehydrated for $5 \mathrm{~min}$ in $\mathrm{dd}_{2} \mathrm{O}$. The sections were cooked 3 times for $2 \mathrm{~min}$ in citrate buffer. They were cooled down for $5 \mathrm{~min}$ in $\mathrm{ddH}_{2} \mathrm{O}$ and washed 3 times in $1 x$ PBS. Afterwards they were incubated in $0.5 \% \mathrm{H}_{2} \mathrm{O}_{2}$ for 30 min to inactivate endogenous peroxidases and washed again 3 times for $15 \mathrm{~min}$ with 1x PBS. Then, the sections were blocked with $5 \%$ normal horse serum (NHS), $0.5 \%$ TritonX-100 in 1x PBS for $1 \mathrm{~h}$ at RT. The sections were incubated for $72 \mathrm{~h}$ 
with 1:500 monoclonal rabbit anti-HA-tag (Cell Signaling) or 1:500 polyclonal anti-GFP (SYSY) antibodies in $3 \%$ NHS, $0.5 \%$ TritonX-100 in $1 \times$ PBS at $4{ }^{\circ} \mathrm{C}$. After 3 days, the slides were washed 10 times for 6 min with 1x PBS. The sections were split into 3 groups to test 3 different staining methods. Group 1 was incubated for $2 \mathrm{~h}$ at RT with the AlexaFluor488conjugated donkey anti-rabbit secondary antibody at a concentration of 1:500 in $3 \% \mathrm{NHS}$, $0.5 \%$ TritonX-100 in 1x PBS. Group 2 was first incubated with the biotinylated goat antirabbit antibody with a concentration of $1: 500$ for $1 \mathrm{~h}$ at RT. The sections were washed 8 times for 6 min with 1x PBS, and AlexaFluor488-conjugated streptavidin antibody was added and incubated for $2 \mathrm{~h}$ at RT. Group 3 was also incubated with the biotinylated goat antirabbit antibody at a concentration of $1: 500$ for $1 \mathrm{~h}$ at RT, and was washed 8 times for 6 min with 1x PBS. In contrast to group 2, the ABC solution was added afterwards. Therefore, $11.25 \mu \mathrm{l}$ of solution A was mixed with $11.25 \mu \mathrm{l}$ solution B in $10 \mathrm{ml} 1 x$ PBS and pre-incubated for $30 \mathrm{~min}$ at $\mathrm{RT}$ for $\mathrm{ABC}$ complex formation. The sections were incubated with $100 \mu \mathrm{l} /$ section for $45 \mathrm{~min}$ at RT. The sections were then washed again 3 times for $5 \mathrm{~min}$ and $50 \mu \mathrm{l} /$ section of the TSA solution (biotinylated tyramide stock solution dissolved 1:50 in the amplification diluent) were added. After incubated for $20 \mathrm{~min}$, the sections were rinsed again 8 times for 6 min and AlexaFluor488-conjugated streptavidin was added and incubated for $2 \mathrm{~h}$ at RT at a concentration of 1:500 in $3 \% \mathrm{NHS}, 0.5 \%$ TritonX-100 in 1x PBS. The sections of all groups were washed twice for 15 min with $1 x$ PBS and the sections were stained with $100 \mu \mathrm{l} /$ section $125 \mathrm{ng} / \mathrm{ml}$ DAPI solution for $5 \mathrm{~min}$. After 3 more washing steps for 15 min with $1 x$ PBS, the sections were dried overnight and mounted with AquaPoly/Mount the next day. The fluorescently stained sections were stored in the dark at $4{ }^{\circ} \mathrm{C}$ before imaging.

\section{Double staining of HA-tag and parvalbumin}

The sections were washed, cooked, pre-treated with $\mathrm{H}_{2} \mathrm{O}_{2}$, and blocked as described for the single staining test. Then, the sections were incubated for $72 \mathrm{~h}$ with 1:500 monoclonal rabbit anti-HA-tag and 1:2000 monoclonal mouse anti-parvalbumin antibody in $3 \% \mathrm{NHS}, 0.5 \%$ Triton $\mathrm{X}-100$ in $1 \mathrm{x}$ PBS at $4{ }^{\circ} \mathrm{C}$. After 3 days the slides were washed 10 times for 6 min with $1 \mathrm{x}$ PBS. The biotinylated goat anti-rabbit antibody was applied at a dilution of 1:500 for $1 \mathrm{~h}$ at RT followed by 8 times washing for 6 min with 1x PBS. For the ABC complex, $11.25 \mu \mathrm{l}$ of solution A was mixed with $11.25 \mu \mathrm{l}$ of solution $B$ in $10 \mathrm{ml} 1 \times$ PBS and was incubated for 30 min at RT before usage. $100 \mu$ of the complex solution was added and the mixture kept 
for $45 \mathrm{~min}$ at RT. The sections were washed again 3 times for $5 \mathrm{~min}$ and $50 \mu$ of the TSA solution (biotinylated tyramide stock solution dissolved 1:50 in the amplification diluent) were added per section and incubated for $20 \mathrm{~min}$. The sections were rinsed again 8 times with 1xPBS for $6 \mathrm{~min}$ and AlexaFluor633-conjugated streptavidin and AlexaFluor488conjugated goat anti-mouse antibody were added in a concentration of 1:500 in $3 \% \mathrm{NHS}$, $0.5 \%$ Triton X-100 in 1x PBS and incubated for $2 \mathrm{~h}$ at RT. The sections were washed twice for $15 \mathrm{~min}$ with $1 \times$ PBS and the sections were stained $100 \mu \mathrm{l} /$ section $125 \mathrm{ng} / \mathrm{ml}$ DAPI solution for $5 \mathrm{~min}$. After washing 3 times for $15 \mathrm{~min}$ with $1 \mathrm{x}$ PBS, the sections were dried overnight and mounted with Aqua-Poly/Mount the next day. The fluorescently stained sections were stored in the dark at $4{ }^{\circ} \mathrm{C}$ before imaging.

\subsubsection{Microscopy}

Images were obtained using an inverted light microscope (Leica DMI 6000B) with a 20x (single staining) or $40 x$ (double staining) air objective. Pictures were processed using Fiji software.

\subsubsection{Quantitative real-time PCR (qPCR)}

In many studies, the amount or change in gene expression is of major interest. The expression can be measured at the level of transcription (mRNA) or translation (protein). Both, transcription as well as translation can be influenced by specific treatments or the integration of the transgene. Today, the most commonly used method to measure the level of transcription is quantitative real-time PCR (qPCR).

\section{RNA isolation}

The method used in the current work to isolate RNA was published as early as in 1987 by Chomczynski and Sacchi (Chomczynski and Sacchi, 1987; Chomczynski and Sacchi, 2006). They showed that RNA can be isolated in a single-step using an acid guanidinium thiocyanate-phenol-chloroform mixture. Only the RNA accumulates in the acidic aqueous upper phase after centrifugation at 12,000 xg. Genomic DNA accumulates in the interphase and proteins are located in the interphase and the organic phase. Conveniently, RNA isolation kits are used, which include TRIzol (Invitrogen) or QIAzol (Qiazol) reagent, which essentially are the acid guanidinium thiocyanate-phenol-chloroform mixture. 
In this study, 6 week old mice were anesthetized by intraperitoneal injection with $0.276 \mathrm{mg} / \mathrm{g}$ Avertin and sacrificed. Hippocampus (HP), cortex (CX) and cerebellum (CB) were dissected, immediately frozen on dry ice, and stored at $-80^{\circ} \mathrm{C}$ until further processing. RNA isolation was done with the miRNeasy Mini Kit from Qiagen accordingly to the manufacturer's protocol. HP, CX and CB were homogenized on ice with a polytron PT 1200E tissue homogenizer in $700 \mu \mathrm{l}$ QIAzol. The cell lysate was further homogenized by passing through a syringe with a $27 \mathrm{G}$ needle twice. The samples were then incubated for $5 \mathrm{~min}$ at RT and $140 \mu \mathrm{l}$ of chloroform were added. The samples were vortexed for approximately $15 \mathrm{~s}$ and then centrifuged at $12,000 \mathrm{rpm}$ at $4{ }^{\circ} \mathrm{C}$ for $15 \mathrm{~min}$. The aqueous phase was transferred into a new reaction tube and mixed with 1.5 volumes of $100 \%$ ethanol. The mixture was loaded onto a miRNeasy Mini column and centrifuged for $15 \mathrm{~s}$ at $8,000 \mathrm{rpm}$ at RT. The column was washed once with $700 \mu$ RWT buffer and twice with $500 \mu$ RPE buffer. The column was dried by centrifugation at $14,500 \mathrm{rpm}$ for $1 \mathrm{~min}$. The RNA was eluted with $50 \mu \mathrm{l}$ RNase free water at $8,000 \mathrm{rpm}$ for $1 \mathrm{~min}$ at RT. The RNA concentration was measured spectrophotometrically with a dilution of 1:25 in EB buffer at $260 \mathrm{~nm}$ in a quartz cuvette with a path of $1 \mathrm{~cm}$. The ratio of the optical density (OD) of 260/280 nm was additionally analyzed to confirm the purity of the RNA (the optimal range is 1.8-2.0).

\section{Reverse transcription (cDNA)}

Next, the RNA was transcribed into cDNA. $1 \mu \mathrm{g}$ of the isolated total RNA was incubated with $120 \mathrm{pmol} N 9$ random primers and $0.6 \mathrm{pmol}$ anchored oligo(dT) primers $\left(\mathrm{N}_{23} \mathrm{VN}\right)$ in a volume of $12 \mu \mathrm{l}$ for $2 \mathrm{~min}$ at $70^{\circ} \mathrm{C}$. Then, $8 \mu \mathrm{l}$ of the master mix, consisting of $1 \mu \mathrm{l} 200 \mathrm{U} / \mu \mathrm{l}$ SuperScript III, $4 \mu \mathrm{l} 5 \mathrm{x}$ first strand buffer, $2 \mu \mathrm{l} 0.1 \mathrm{M}$ DTT and $1 \mu \mathrm{l} 10 \mathrm{mM}$ dNTPs, were added. The reaction was incubated for $10 \mathrm{~min}$ at $25^{\circ} \mathrm{C}, 45 \mathrm{~min}$ at $50{ }^{\circ} \mathrm{C}$, and $45 \mathrm{~min}$ at $55^{\circ} \mathrm{C}$. The samples were cooled down, diluted $1: 10$ with $\mathrm{ddH}_{2} \mathrm{O}$ and stored at $-20^{\circ} \mathrm{C}$ until usage.

\section{Quantitative real-time PCR (qPCR)}

qPCR is the method of choice to quantify gene expression on transcriptional level. The method was invented in 1991 and Higuchi and colleagues published a paper about the simultaneous amplification and detection of DNA during PCR in 1992 (Higuchi et al., 1992). By using fluorescent dyes, the PCR can be monitored in real time. Initially, EtBr was used as fluorescent dye. $\mathrm{EtBr}$ increases its fluorescence when intercalated into double-stranded DNA. Nowadays, EtBr has been replaced by other dyes with better signal to noise ratios, 
such as SYBR Green. To analyze the expression level of EPOR in wt and transgenic animals, $4 \mu \mathrm{l}$ of the diluted cDNA was mixed with $5 \mu \mathrm{l} 2 \times$ SYBR Green and 1 pmol primers (EPOR 11329,11330 or GAPDH 6038, 6039) in a total volume of $10 \mu \mathrm{l}$. The cDNA and the master mix were pipetted into 384 well plates aided by the epmotion robot 7075 . Cycling and detections was done using a LightCycler 480 system. The initiation was done for $2 \mathrm{~min}$ at $50{ }^{\circ} \mathrm{C}$, followed by denaturation at $95{ }^{\circ} \mathrm{C}$ for $10 \mathrm{~min}$. The amplification consisted of $45 \mathrm{cycles}$ of $95{ }^{\circ} \mathrm{C}$ for $15 \mathrm{~s}$ and $60{ }^{\circ} \mathrm{C}$ for $60 \mathrm{~s}$. The relative concentrations of EPOR mRNA were determined from three replicates using the cycle threshold (CT) method. The CT values of EPOR were normalized to the CT values of GAPDH. The specificity of the primer pairs was controlled by melting curve analysis.

\subsubsection{Western blot (WB)}

Similar as for the RNA isolation, 6 week old mice were anesthetized by intraperitoneally injection with $0.276 \mathrm{mg} / \mathrm{g}$ Avertin and sacrificed. Hippocampus (HP), cortex (CX) and cerebellum (CB) were dissected, immediately frozen on dry ice, and stored at $-80^{\circ} \mathrm{C}$ until further processing.

\section{Protein extraction}

For the analysis of the transgene CEPOR expression in the brain, the brain samples were homogenized on ice using a polytron PT 1200E tissue homogenizer in $300 \mu$ phosphosafe buffer, containing $1 \mathrm{mM}$ phenylmethylsulfonyl fluoride, $10 \mu \mathrm{g} / \mathrm{ml}$ aprotinin and $1 \mathrm{mg} / \mathrm{ml}$ leupeptin. The tissue lysates were further homogenized by pulling through a syringe with a $21 \mathrm{G}$ needle 10 times and centrifugation at $12,000 \mathrm{rpm}$ for $45 \mathrm{~min}$. The supernatant was transferred into a reaction tube. Approximately $15 \mu \mathrm{l}$ of the supernatant were stored in a separate reaction tube for measuring protein concentration. The remaining supernatant was mixed with $4 x$ Laemmli buffer (1/3 of the supernatant volume). The protein samples were denatured for $5 \min$ at $95^{\circ} \mathrm{C}$ and stored at $-80^{\circ} \mathrm{C}$.

\section{Protein measurement (Lowry)}

The concentration of protein was measured with the method of Lowry (Lowry et al., 1951). The HP protein samples were diluted 1:100 and the CX and CB protein samples were diluted 1:200 in a total volume of $200 \mu \mathrm{l}$. In parallel, the dilutions for the standard curve were prepared $(0,2.5,5,7.5,10,12.5,15,20 \mu \mathrm{g} / 200 \mu \mathrm{l})$ from a $2 \mathrm{mg} / \mathrm{ml}$ BSA stock solution. 
Afterwards $1 \mathrm{ml}$ of a fresh copper solution was added to all samples, protein and standard curve samples. The mixtures were vortexed and incubated for $15 \mathrm{~min}$. Then, $100 \mu \mathrm{l}$ of FolinCiocalteu reagent were added and the samples were vortexed immediately. After incubation of $45 \mathrm{~min}$, the absorbance at $595 \mathrm{~nm}$ was measured in triplicates of $200 \mu \mathrm{l} /$ well in a 96-well plate. The concentrations were calculated from the standard curve.

\section{Sodium dodecyl sulfate - polyacrylamide gel electrophoresis (SDS-PAGE)}

Gel electrophoresis is a method to separate DNA, RNA, or protein depending on their size. The separation of DNA and RNA is described in 2.2.1. The separation of protein is based on the same principles. Negatively charged proteins migrate in a matrix gel to the anode when placed in an electric field. In this case, polyacrylamide is used for the polymer network. The size of the pores can be regulated through the percentage of polyacrylamide. It is generally recommended to use $4-5 \%$ gels for protein $>250 \mathrm{kDa}, 7.5 \%$ gels for proteins of 250 $120 \mathrm{kDa}, 10 \%$ gels for proteins of $120-40 \mathrm{kDa}, 13 \%$ gels for proteins of $40-15 \mathrm{kDa}$ and $15 \%$ gels for proteins $<20 \mathrm{kDa}$. In contrast to DNA and RNA, proteins are not uniformly charged, because of their varying amino acid composition. Therefore, they are not separated depending to their size in a native PAGE. By the addition of the detergent SDS that covers the protein with a total negative charge, the proteins can be separated according to their size (Kurien and Scofield, 2006; Laemmli, 1970). After separation (Figure 16A), the proteins are blotted onto an absorbent membrane (Figure 16B), where the protein of interest can be detected and visualized with antibodies (Figure 16C-E).

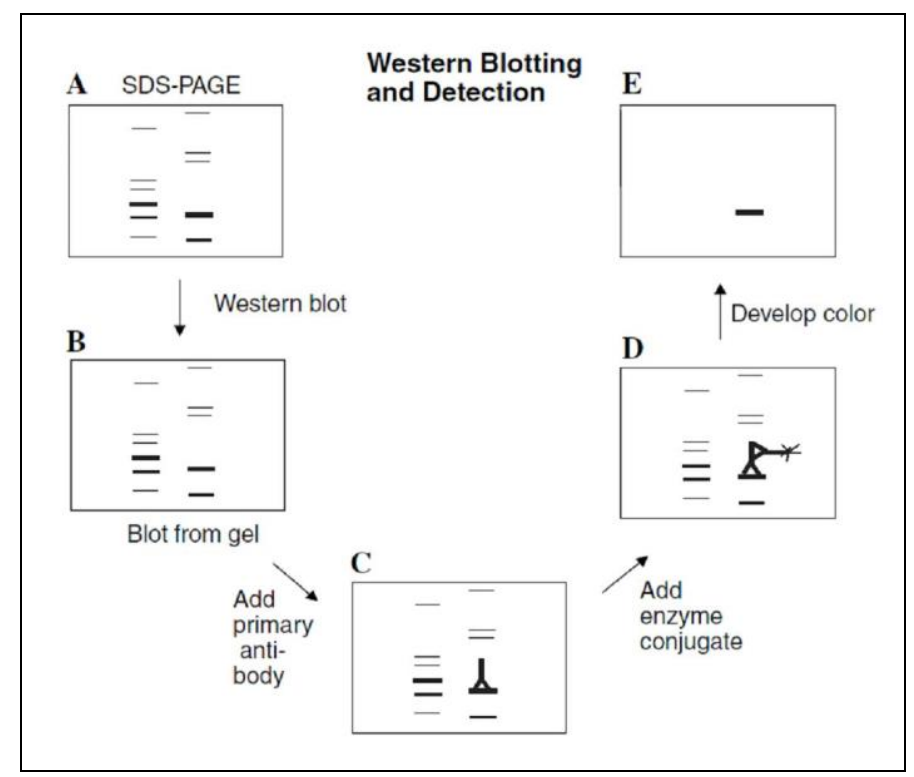

Figure 16: Illustration of the western blot procedure (from Kurien and Scofield, 2006) 
The used acrylamide percentage for separating the proteins of EPOR ( $70 \mathrm{kDa})$ and GAPDH (36 kDa) was $12 \%$. For the stacking gel, $15 \mathrm{ml}$ of $30 \%$ acrylamide, $9.77 \mathrm{ml}$ of the lower

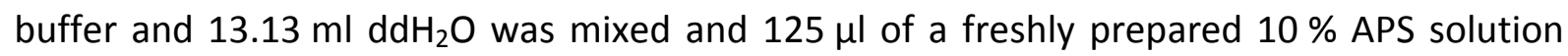
and $30 \mu \mathrm{l}$ of TEMED were added. The solution was briefly mixed and immediately filled into 4 glass plate sandwiches (width: $1.0 \mathrm{~mm}$ ). After $30 \mathrm{~min}$, the stacking gel was prepared: $1.3 \mathrm{ml}$

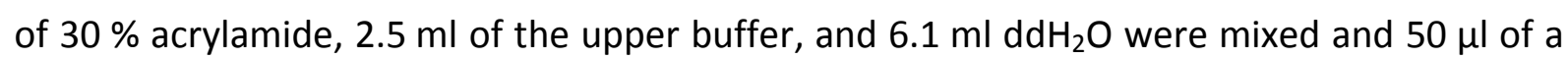
freshly prepared $10 \%$ APS solution and $10 \mu \mathrm{l}$ of TEMED were added. The solution was briefly mixed and poured on top of the running gel and a comb for 10 pockets was inserted. After approximately $1 \mathrm{~h}$, the gels were placed into the electrode assembly and the chamber was filled with $1 x$ running buffer. The combs were removed and $50 \mu \mathrm{g}$ of the protein samples were loaded for each lane. In one lane, $5 \mu$ l of a protein ladder was run as a size control. The gel was run for $15 \mathrm{~min}$ at $80 \mathrm{~V}$ and approximately $1.5 \mathrm{~h}$ at $120 \mathrm{~V}$ until the ladder reached the bottom of the gel. The proteins were then transferred onto a nitrocellulose membrane for $2 \mathrm{~h}$ at $235 \mathrm{~mA}$. The membranes were blocked for $1 \mathrm{~h}$ in $5 \%$ milk in Tris buffered saline with $0.05 \%$ Tween (TBST). The membranes were incubated with rat anti-HA (1:250) overnight at $4{ }^{\circ} \mathrm{C}$. The next day, the membranes were washed 3 times for $15 \mathrm{~min}$ with TBST and incubated with the secondary HRP-coupled anti-rat antibody (1:2500) for $1 \mathrm{~h}$ at RT. After washing 3 times for $15 \mathrm{~min}$ with TBST, the membranes were incubated with $2 \mathrm{ml}$ of chemiluminescent substrate for $5 \mathrm{~min}$ at RT. The bands were visualized on a photographic film. Afterwards, the membranes were incubated with stripping buffer for $1 \mathrm{~h}$ at RT to remove the bound antibodies and washed 3 times for $15 \mathrm{~min}$ with TBST. The membranes were then blocked again for $1 \mathrm{~h}$ with $5 \%$ milk in TBST at RT followed by incubation with mouse anti-GAPDH (1:5000) overnight at $4{ }^{\circ} \mathrm{C}$. The next day, the membranes were washed 3 times for $15 \mathrm{~min}$ with TBST and incubated with the secondary HRP-coupled anti-mouse antibody (1:5000) for $1 \mathrm{~h}$ at RT. After washing 3 times for $15 \mathrm{~min}$ with TBST, the membranes were finally incubated with $2 \mathrm{ml}$ of chemiluminescent substrate for $5 \mathrm{~min}$ at RT. The bands were visualized on a photographic film. The protein bands of HA and GAPDH were densitometrically analyzed using the Fiji software and the HA values were normalized to the values of GAPDH.

\subsubsection{Hematocrit}

For measuring the hematocrit, the mice were anesthetized by intraperitoneal injection with $0.276 \mathrm{mg} / \mathrm{g}$ Avertin solution. The blood was removed with a syringe directly from the left ventricle, filled into EDTA Microvettes and inverted several times. The blood was then 
transferred into micro hematocrit capillaries and centrifuged for $10 \mathrm{~min}$ at $8,000 \mathrm{rpm}$. The percentage of erythrocytes was analyzed with a micro hematocrit reader.

\subsubsection{Behavior analysis}

The behavioral experiments have been performed in the Clinical Neuroscience Behavior Unit by Daniela Winkler. For all experiments, male and female Viaat-HA-cEPOR mice, strain D140023, and wildtype (wt) C57BL/6N mice (littermates) of the second generation were used.

All experiments were approved by the local Animal Care and Use Committee in accordance with the German Animal Protection Law. Unless stated otherwise, the mice were housed in groups of 3-5 in standard plastic cages for behavioral testing, with food and water ad libitum. The temperature in the colony room was maintained at $20-22^{\circ} \mathrm{C}$, with a $12 \mathrm{~h}$ lightdark cycle (lights on at 8:00 AM). All behavioral experiments were conducted by a blinded investigator unaware of the genotype during the light phase of the day (between 8:30 AM and 6:00 PM). Basic behavioral functions were assessed in two large consecutive cohorts of male and female mice in the following order: elevated plus maze, open field, rotarod, prepulse inhibition of the startle response (PPI), hearing, olfaction, hot plate. Only males were subjected to the working and reference memory version of the hole board task. The age of mice at the beginning of testing was 11 weeks. Inter-test intervals varied depending on the degree of the test invasiveness of the respective test but were at least 1 day. During the time of behavioral testing, the weights of the mice were measured approximately every other week.

\section{Elevated Plus Maze Test}

This test measures anxiety-related behavior in a novel environment. The cross-shaped apparatus made of grey Perspex consisted of two open (I: $30 \times \mathrm{h}: 15 \times \mathrm{w}: 5 \mathrm{~cm}$ ) and two walled arms $(30 \times 15 \times 5 \mathrm{~cm})$, which were elevated from the floor to a height of $40 \mathrm{~cm}$. Illumination intensity was set to 135 lux. It is assumed that a very anxious mouse would spend significantly more time in the walled arms as compared to a less anxious mouse and would also show an increased avoidance of the fear-inducing open arms as compared to a less anxious mouse. The mice were placed on the maze facing an open arm and were observed for $5 \mathrm{~min}$. During this time, the duration spent (s) in the open and the closed arms were measured using the automated tracking software Viewer 2. After each trial, the apparatus was cleaned with water followed by $70 \%$ ethanol. 


\section{Open Field Test}

In order to examine exploratory activity and anxiety-related behavior in a novel environment, the animals were exposed to a large circular open field (diameter $120 \mathrm{~cm}$, height $25 \mathrm{~cm}$ ) that was divided into 3 concentric zones. While the activity in the peripheral zone is considered to be indicative of exploratory behavior, the activity in the intermediate and center zones of the apparatus are thought to reflect anxiety-like behavior. Given that rodents tend to avoid open unsheltered spaces they generally spend significantly more time in the periphery as compared to the intermediate and center zones. The open field was made of grey Perspex. Individual animals were placed in the center of the open field and were allowed to explore it for $7 \mathrm{~min}$. The following parameters were measured using the same automated tracking system as described for the elevated plus-maze test: a) distance traveled and b) the time spent in the central, intermediate, and peripheral zones of the open field. After each trial, the apparatus was cleaned with water followed by $70 \%$ ethanol.

\section{Rotarod}

The rotarod comprised a rotating drum which was accelerated from 4 to $40 \mathrm{rpm}$ over the course of $5 \mathrm{~min}$. Individual mice were placed on the drum and once they were balanced, the drum was accelerated. The time in seconds at which the respective animal fell from the drum was recorded using a trip switch. Each animal went through two consecutive trials at one trial per day.

\section{Pre-pulse Inhibition}

Individual mice were placed in small metal cages $(8.2 \times 4.0 \times 4.0 \mathrm{~cm})$ to restrict movements and ambulation. The cages were attached to a sensor that recorded vertical movements of the floor. The cages were placed in four sound-attenuated cabinets. Startle reflexes were evoked by acoustic stimuli delivered by a loudspeaker that was suspended above the cage and connected to an acoustic generator. The startle reaction initiated a movement of the platform, which generated a transient force. A recording device registered the force exerted onto the platform for $260 \mathrm{~ms}$. Recording was started simultaneously with the onset of the acoustic stimulus. All acoustic stimuli used had a frequency of $10 \mathrm{kHz}$ but differed in terms of loudness $(\mathrm{dB})$. An experimental session consisted of a $2 \mathrm{~min}$ habituation period to the continuous white noise with an intensity of $65 \mathrm{~dB}$. This background noise was present throughout the session. The background noise habituation phase was followed by a baseline 
recording for $1 \mathrm{~min}$. After baseline recording, six pulse-alone trials using startle stimuli of $120 \mathrm{~dB}$ intensity and $40 \mathrm{~ms}$ duration were applied to decrease the influence of withinsession habituation. This data was not included in the $120 \mathrm{~dB} / 40 \mathrm{~ms}$ analysis of the pre-pulse inhibition. For tests of pre-pulse inhibition, the startle pulse was applied either alone or after the application of a pre-pulse stimulus of $70 \mathrm{~dB}, 75 \mathrm{~dB}$, or $80 \mathrm{~dB}$ intensity and with a duration of $20 \mathrm{~ms}$. An inter-puls-interval of $100 \mathrm{~ms}$ with background white noise was used between each pre-pulse and pulse stimulus. The trials were presented in a pseudorandom order with an interval ranging from 8 to $22 \mathrm{~s}$. The amplitude of the startle response (expressed in arbitrary units) was defined as a difference between the maximum force detected during the recording window and the force measured immediately before the stimulus onset. Amplitudes were averaged for each individual animal, separately for both types of trials (i.e. stimulus alone or stimulus preceded by a pre-pulse). Pre-pulse inhibition was calculated as percentage of the startle response using the following formula: \% prepulse inhibition $=100-$ [(startle amplitude after pre-pulse) / (startle amplitude after pulse only) x 100].

\section{Hearing}

Hearing was measured in the same apparatus as pre-pulse inhibition by the determination of the threshold intensity that was able to evoke a maximal acoustic startle response. The mouse was placed in the metal cage and the tones were randomly presented. The intensity of the tones ranged from 68 to $120 \mathrm{~dB}$. In healthy mice, the startle response increases with increased stimulus intensity. The startle amplitudes were measured and plotted.

\section{Buried food finding test}

Starting 6 days before testing, the mice were habituated to clear cages $(29.5 \times 18.5 \times 13 \mathrm{~cm})$ for $30 \mathrm{~min}$, with 3 trials per day. Starting four days before testing, the mice received a piece of chocolate cookie $(1.6 \mathrm{~g})$ during each habituation trial. Additionally, the mice received 3-5 cookies in their home cage overnight. Once the mice regularly consumed the cookies during the habituation trials, testing was performed on the next day. Starting $24-48 \mathrm{~h}$ before testing, the mice were deprived of food but with water available ad libitum. For testing, individual mice were placed into clear cages filled with bedding up to a height of $1.5 \mathrm{~cm}$, in which a piece of chocolate cookie was hidden at a distance of approximately $3 \mathrm{~cm}$ from the wall. The mouse was placed in the right corner at the opposite end of the cage, and the time 
needed to find the food, i.e. the time from the moment the mouse was placed into the cage to the time it located the cookie and initiated digging, was recorded. As soon as the cookie was detected, the mouse was removed from the cage. Fresh bedding was used for each trial.

\section{Hot plate}

The hot plate test evaluates pain/heat perception in mice. In this test heat was used as the noxious stimulus and the latency of the animal's response to the stimulus was recorded as the dependent variable. The hot plate apparatus had a temperature of $55 \pm 0.1^{\circ} \mathrm{C}$. The mouse was placed into the apparatus and the time until the mouse started licking its paws was measured (time cut-off: $40 \mathrm{~s}$ ). Immediately after showing the licking response, the animal was removed from the plate and placed back into its home cage.

\section{Reference and working memory version of the hole board test}

The hole board task evaluates both working and reference memory in mice. It consists of an open field with 16 holes drilled into the floor. Mice readily show nose pokes into the holes while exploring the hole board. Nose pokes are registered by infrared light beams. The number of nose pokes to each of the 16 holes is recorded and used to calculate working and reference memory errors.

The test is comprised of different phases including habituation, acquisition, long-term retention, and reversal learning. The basic procedure was followed with minor modifications (Kuc et al., 2006). During habituation, the mice were trained to investigate each of the 16 holes. Every hole was baited with $6 \mu l 6 \%$ sucrose solution. A trial was terminated after the animal had visited all 16 holes or at the latest after $15 \mathrm{~min}$. During the habituation phase each mouse was tested once per day for 6 days.

During the acquisition stage, only 4 out of the 16 holes were baited with $6 \mu$ l $6 \%$ sucrose solution. The combination of baited holes remained the same throughout the acquisition phase. Over the course of 6 days, each mouse received 2 trials with an inter-trial interval of $2.5 \mathrm{~h}$. A trial was terminated after the animal had visited all the 4 baited holes or after $5 \mathrm{~min}$ (cut off). From the number of visits to each of the 16 holes, a number of parameters were determined separately for the first and second trial of a given day to evaluate spatial learning performance. Two parameters were calculated from the raw data: first reference memory errors, i.e. each visit to a non-baited hole, and working memory errors, i.e. each revisits to a baited hole. After a retention interval of 4 weeks, the animals were tested for 
long-term memory with 2 trials per day over 4 days. The procedure was identical to the one described for the acquisition phase.

The day after the last long-term retention trial, the animals were subjected to a novel combination of baited holes in order to measure reversal learning, which is thought to measure prefrontal cortex function. The animals were tested with 2 trials per day over 2 days and the procedure was identical to the one described for the acquisition phase.

\subsubsection{Electrophysiology-gamma oscillation}

Gamma oscillation was measured in collaboration with Dr. Sonja Wojcik by Christoph Bredack.

\section{Preparation of acute slices}

Male mice 41-46 days of age were anesthetized by isoflurane and decapitated. The brain was quickly dissected and put into ice-cold sucrose based slicing solution, which was bubbled with carbogen gas. Brains were trimmed and serial horizontal sections of $400 \mu \mathrm{m}$ were cut using a vibratome. During the sectioning the tissue was immersed in ice-cold sucrose based solution and oxygenated with carbogen. The sections were transferred to a custom-made interface holding chamber until recording. The solution was pre-warmed to $30^{\circ} \mathrm{C}$, continuously bubbled with carbogen gas and kept under constant stirring.

\section{Gamma oscillations in interface conditions}

After slicing, the sections were kept in a custom-made interface holding chamber. The ACSF was kept under constant stirring, saturated with carbogen gas. Network activity was recorded in $400 \mu \mathrm{m}$ thick hippocampal slices cut in horizontal orientation in an interface recording chamber at $33{ }^{\circ} \mathrm{C}$. Slices were kept on a nylon mesh at the interface of a stream of extracellular recording solution and a stream of warm, moist carbogen gas. Extracellular recording electrodes with a resistance of around $2 \mathrm{M} \Omega$ were filled with extracellular solution and placed in the pyramidal cell layer of the CA3b region in the hippocampus. Extracellular field potentials were recorded with a MultiClamp 700B amplifier and a Digidata $1440 \mathrm{~A}$, filtered at $3 \mathrm{kHz}$ and a gain of 100 with a Bessel filter. Gamma oscillations were induced by bath application of $100 \mathrm{nM}$ kainate. Stable and long lasting oscillatory activity could be recorded 5-7 min after the start of kainate application. Baseline field-potentials were recorded for $20 \mathrm{~min}$ and gamma-oscillation field potentials for 2 times $20 \mathrm{~min}$. Data were analyzed with Axograph X software. Traces were filtered at $100 \mathrm{kHz}$ and power spectra were 
calculated for twelve-minute epochs (last $12 \mathrm{~min}$ of each recording) of recorded field activity. Baseline power spectra were subtracted from kainate traces and the frequency and the power of the maximum peak was determined.

\subsubsection{Electrophysiology - Long Term Potentiation (LTP)}

LTP was measured in male mice (39-51 days of age) in collaboration with Prof. Michael Müller by Oliwia Jank. Field excitatory postsynaptic potentials (fEPSPs) were elicited by 0.1 ms unipolar stimuli (Grass S88 stimulator with PSIU6 stimulus isolation units) delivered via steel micro wire electrodes ( $50 \mu \mathrm{m}$ diameter) that were placed on the surface of the stratum radiatum of the hippocampus CA1 area. Orthodromic responses were elicited by stimulation of Schaffer collaterals and recorded in the apical dendrites of stratum radiatum of the CA1 region with a locally constructed extracellular DC-potential amplifier via a glass electrode filled with ACSF solution. An input-output curve was generated to determine the stimulus strength needed to elicit a half-maximal field excitatory post-synaptic potential (fEPSP). Baseline fEPSP was determined using the half-maximal stimulus intensity (current), and a low stimulation frequency $(0.71 \mathrm{~Hz})$ (measured every $15 \mathrm{~s}$ and 4 times averaged for $1 \mathrm{~min}$ ). Long term potentiation (LTP) was induced by giving 3 tetanic stimuli of $100 \mathrm{~Hz}$ for $1 \mathrm{~s}$ every $5 \mathrm{~min}$. LTP was calculated by averaging the normalized fEPSP amplitude collected for $60 \mathrm{~min}$ after the last tetanic stimulus. All electrophysiological data were sampled using an Axon Instruments Digitizer 1322A and pClamp 9.2 software.

\subsubsection{Statistics}

The EPOR mRNA and the cEPOR protein level, hematocrit, and the body weight data were statistically analyzed by unpaired two-tailed student t-test. Open field (distance), buried food test, and hot plate were analyzed by 1-way ANOVA. Elevated plus maze, open field (time in zones), prepulse inhibition, and startle response were analyzed by 2-way ANOVA.

Rotarod, hole board, gamma oscillation, and STP and LTP data were analyzed by 1-way ANOVA for repeated measures. All data were expressed as mean \pm SEM. Results were considered significant if $\mathrm{p}$-values smaller than 0.05 were obtained. All data were plotted and analyzed using GraphPad Prism 5 or SPSS software. 


\subsection{Materials}

\subsubsection{Chemicals}

\begin{tabular}{|c|c|c|}
\hline \multicolumn{3}{|c|}{ Product number } \\
\hline Acrylamide $30 \%$ & Merck KGaA, Darmstadt (Germany) & 100639 \\
\hline Agarose (UltraPure) & Life Technologies GmbH, Darmstadt (Germany) & 16500500 \\
\hline Albumin standard ( $2 \mathrm{mg} / \mathrm{ml})$ & Thermo Scientific, Rockford (USA) & 23210 \\
\hline Ammonium persulfate (APS) & Sigma-Aldrich, Taufkirchen (Germany) & A-3678 \\
\hline Amylalcohol & Merck KGaA, Darmstadt (Germany) & 100999 \\
\hline Aprotinin & Roche Diagnostics GmbH, Mannheim (Germany) & 10236624001 \\
\hline Arabinose & Sigma-Aldrich, Taufkirchen (Germany) & A3256 \\
\hline Aqua-Poly/Mount & Polyscience, Philadelphia (USA) & 18606 \\
\hline Bacto-Agar & BD, Heidelberg (Germany) & 211705 \\
\hline Boric acid & Merck KGaA, Darmstadt (Germany) & 100165 \\
\hline Bromophenol blue & Sigma-Aldrich, Taufkirchen (Germany) & B5525 \\
\hline BSA $10 \mathrm{mg} / \mathrm{ml}(100 \mathrm{x})$ & New England Biolabs (NEB), Hitchin (UK) & B9001S \\
\hline Chloroform & Merck KGaA, Darmstadt (Germany) & 102445 \\
\hline Citric acid monohydrate & Merck KGaA, Darmstadt (Germany) & 100244 \\
\hline CL-4B Sepharose & Sigma-Aldrich, Taufkirchen (Germany) & CL4B200 \\
\hline $\mathrm{CuSO}_{4}$ & Merck KGaA, Darmstadt (Germany) & 102790 \\
\hline EDTA & Sigma-Aldrich, Taufkirchen (Germany) & E5134 \\
\hline Ethidium bromide $1 \%$ (EtBr) & Merck KGaA, Darmstadt (Germany) & 1116080030 \\
\hline Ethylene glycol & Sigma-Aldrich, Taufkirchen (Germany) & 293237 \\
\hline Folin-Ciocalteu reagent & Merck KGaA, Darmstadt (Germany) & 109001 \\
\hline Glycin & Sigma-Aldrich, Taufkirchen (Germany) & 33226 \\
\hline Formaldehyde & Merck KGaA, Darmstadt (Germany) & 104003 \\
\hline Glacial acetic acid & Merck KGaA, Darmstadt (Germany) & 100063 \\
\hline Glycerol $85 \%$ & Merck KGaA, Darmstadt (Germany) & 104094 \\
\hline $\mathrm{HCl} 37 \%$ & Merck KGaA, Darmstadt (Germany) & 100317 \\
\hline $\mathrm{H}_{2} \mathrm{O}_{2}$ & Merck KGaA, Darmstadt (Germany) & 107210 \\
\hline Isopropanol & Merck KGaA, Darmstadt (Germany) & 109634 \\
\hline Isoflurane & Actavis Deutschland GmbH \& Co. K, München (Germa & \\
\hline K-Na-tartrate & Merck KGaA, Darmstadt (Germany) & 108087 \\
\hline LB medium & Sigma-Aldrich, Taufkirchen (Germany) & L3522 \\
\hline Leupeptin & Roche Diagnostics GmbH, Mannheim (Germany) & 11017101001 \\
\hline ß-Mercaptoethanol & Sigma-Aldrich, Taufkirchen (Germany) & $\mathrm{M}-3148$ \\
\hline $\mathrm{Na}_{2} \mathrm{CO}_{3}$ & Merck KGaA, Darmstadt (Germany) & 106392 \\
\hline $\mathrm{NaOH}$ & Merck KGaA, Darmstadt (Germany) & 106498 \\
\hline Normal horse serum & Jackson ImmunoResearch Laboratories, Inc. (USA) & $008-000-121$ \\
\hline Nonfat dried milkpowder & AppliChem, Darmstadt (Germany) & A0830 \\
\hline Phosphosafe buffer & Merck KGaA, Darmstadt (Germany) & $71296-3$ \\
\hline Ponceau-S solution & SERVA Electrophoresis GmbH, Heidelberg (Germany) & 33427 \\
\hline Power SYBR Green & Life Technologies GmbH, Darmstadt (Germany) & 4367659 \\
\hline Pyronin $Y$ & Sigma-Aldrich, Taufkirchen (Germany) & P-7017 \\
\hline Ringer solution & B.Braun Melsungen AG, Melsungen (Germany) & 64341242 \\
\hline SDS (sodium dodecyl sulfate) & Sigma-Aldrich, Taufkirchen (Germany) & L-4509 \\
\hline Sodium citrate dihydrate & Merck KGaA, Darmstadt (Germany) 112005 (new r & 10. 106448) \\
\hline Sucrose & Merck KGaA, Darmstadt (Germany) & 107651 \\
\hline TEMED & SERVA Electrophoresis GmbH, Heidelberg (Germany) & 35925 \\
\hline Tribromoethanol & Sigma-Aldrich, Taufkirchen (Germany) & T48402 \\
\hline
\end{tabular}


Trizma base

Tissue-Tek

TritonX-100

Trizma base

Tween20
Sigma-Aldrich, Taufkirchen (Germany)

T1503

VWR International GmbH, Darmstadt (Germany)

Sigma-Aldrich, Taufkirchen (Germany)

25608-930

T8787

Sigma-Aldrich, Taufkirchen (Germany)

T1503

Sigma-Aldrich, Taufkirchen (Germany)

P7949

\subsubsection{Consumables}

\section{Product}

Chromatography paper

Cryotubes

Electroporation cuvettes

Hematocrit sealing compound

Microvette 500 EDTA

Micro-hematocrit capillaries

Microwell plate 96

Multiwell plate 384

Nitrocellulose membrane

PAP pen

SuperFrost ultra plus slides

\section{Supplier}

GE Healthcare Life Sciences, Buckinghamshire (UK) VWR International GmbH, Darmstadt (Germany)

Carl Roth $\mathrm{GmbH}+\mathrm{CO}$ KG, Karlsruhe (Germany)

BRAND GmbH and CO KG, Werheim (Germany)

SARSTEDT AG \& Co., Nümbrecht (Germany)

BRAND GmbH and CO KG, Werheim (Germany)

Thermo Fisher Scientific, Roskilde (Denmark)

Roche Diagnostics, Mannheim (Germany)

GE Healthcare Life Sciences, Buckinghamshire (UK)

Zytomed Systems, Berlin (Germany)

MenzelGmbH, Braunschweig (Germany)
Product number

303091

479-3221

PP38.1

749510

20.1341

749311

269620

04729749001

10401396

LP 0002

J1800AMN

\subsubsection{Equipment}

\section{Product}

Axon Digidata 1440 A

Axon MultiClamp 700B amplifier

Cryostat CM 1900

Vibratome VT1200S

EpMotion robot 5075

Grass 588 stimulator

(with PSIU6 stimulus isolation units)

Interface recording chamber

(BSC-BU Base Unit with BSC-HT Haas Top)

Light Cycler 480

Leica DMI 6000B

Microplate reader Revelation

Mini-peristaltic pump

Polytron PT1200E

PPI cages

Rotarod

Steel micro wire electrodes $50 \mu \mathrm{m}$ diameter

T3 Thermocycler

Thermomixer Compact

UNO Thermocylcer

Vibratome VT1200S

Water purification system arium 611

\section{Supplier}

Molecular Devices, Sunnyvale (USA)

Molecular Devices, Sunnyvale (USA)

Leica, Wetzlar (Germany)

Leica, Wetzlar (Germany)

Eppendorf AG, Hamburg (Germany)

Grass Instruments, Warwick (USA)

Harvard apparatus, Freiburg (Germany)

Roche Diagnostics GmbH, Mannheim (Germany)

Leica Microsystems CMS GmbH, Wetzlar (Germany)

Dynex Technologies, Frankfurt (Germany)

Harvard Apparatus, Freiburg (Germany)

KINEMATICA AG, Luzern (Switzerland)

TSE Systems GmbH, Bad Homburg (Germany)

Med associates Inc., St. Albans (UK)

A-M Systems, Sequim (USA)

Biometra GmbH, Göttingen (Germany)

Eppendorf AG, Hamburg (Germany)

Biometra, Göttingen (Germany)

Leica, Wetzlar (Germany)

Sartorius, Göttingen (Germany)

Thermo Fisher Scientific, Bonn (Germany)

Thermo Fisher Scientific, Bonn (Germany)

Thermo Fisher Scientific, Bonn (Germany)

Eppendorf AG, Hamburg (Germany)

Eppendorf AG, Hamburg (Germany) 
Mini Spin Plus

Centrifuge 5415

Biofuge Haemo

\subsubsection{Software}

\section{Product}

Software LAS AF 3

Fiji

SPSS

GraphPad Prism 5

Viewer 2

AxographX

Axon Instruments Digitizer 1322A

(and pClamp 9.2)
Eppendorf AG, Hamburg (Germany)

Eppendorf AG, Hamburg (Germany)

Thermo Fisher Scientific, Bonn (Germany)

\section{Supplier}

Leica Microsystems CMS GmbH, Wetzlar (Germany)

Free open source software (http://fiji.sc/Fiji)

IBM Deutschland GmbH, Ehningen (Germany)

GraphPad Software Inc., La Jolla (USA)

BIOBSERVE GmbH, St. Augustin (Germany)

Axon Instruments Inc., Foster City (USA)

Molecular Devices, Sunnyvale (USA)

\subsubsection{Enzymes}

\section{Product}

Pfu polymerase

T4 DNA ligase $1 \mathrm{U} / \mu \mathrm{l}$

rAPid alkaline phosphatase

RED Taq DNA polymerase

BstBI $(20 \mathrm{U} / \mu \mathrm{l})$

EcoRV

Notl $(10 \mathrm{U} / \mu \mathrm{l})$

Sall

Xhol

Sacl

$\operatorname{Pacl}(10 \mathrm{U} / \mu \mathrm{l})$

Pmel $(10 \mathrm{U} / \mu \mathrm{l})$

EcoRI $(20 \mathrm{U} / \mu \mathrm{l})$

Nhel $(20 \mathrm{U} / \mu \mathrm{l})$

RNase A

SuperScript III

\section{Supplier}

Agilent Technologies GmbH, Böblingen (Germany)

Life Technologies GmbH, Darmstadt (Germany)

Roche Diagnostics $\mathrm{GmbH}$, Mannheim (Germany)

Sigma-Aldrich, Taufkirchen (Germany)

New England Biolabs (NEB), Hitchin (UK)

New England Biolabs (NEB), Hitchin (UK)

New England Biolabs (NEB), Hitchin (UK)

New England Biolabs (NEB), Hitchin (UK)

New England Biolabs (NEB), Hitchin (UK)

New England Biolabs (NEB), Hitchin (UK)

New England Biolabs (NEB), Hitchin (UK)

New England Biolabs (NEB), Hitchin (UK)

New England Biolabs (NEB), Hitchin (UK)

New England Biolabs (NEB), Hitchin (UK)

Roche Diagnostics $\mathrm{GmbH}$, Mannheim (Germany)

Life Technologies GmbH, Darmstadt (Germany)
Product number

600153

15224-025

04898141001

D4309

R0519

R0195

R0189

R0138

R0146

R0156

R0547

R0560

R0101

R0131

10109169001

18080-044

\subsubsection{Kits}

\section{Product}

ABC kit

miRNeasy Mini Kit

MSB Spin PCRapace

Nucleobond BAC 100

NucleoSpin Tissue Kit

PureLink Quick

Plasmid Miniprep Kit

Plasmid Midiprep Kit

Plasmid Maxiprep Kit

QIAprep Spin

TSA Biotin system kit

\section{Supplier}

Vector Laboratories, Burlingame (USA)

Qiagen, Hilden (Germany)

STRATEC Molecular GmbH, Berlin (Germany)

MACHERY-NAGEL GmbH \& Co. KG, Düren (Germany)

MACHERY-NAGEL GmbH \& Co. KG, Düren (Germany)

Life Technologies GmbH, Darmstadt (Germany)

Life Technologies GmbH, Darmstadt (Germany)

Life Technologies GmbH, Darmstadt (Germany)

Qiagen, Hilden (Germany)

Qiagen, Hilden (Germany)

PerkinElmer, Massachusetts (USA)

\section{Product number}

PK-4000

217004

1020220200

740579

740952

K2100-10

K2100-05

K2100-06

12362

27106

NEL700A 


\subsubsection{Ladders}

\section{Product}

$1 \mathrm{~kb}$ DNA ladder

100 bp Plus DNA ladder

Midrange I PFG marker

Prestained protein ladder
Supplier

Life Technologies GmbH, Darmstadt (Germany)

Thermo Fisher Scientific, Bonn (Germany)

New England Biolabs (NEB), Hitchin (UK)

Thermo Fisher Scientific, Roskilde (Denmark)
Product number

15615-016

SM0321

N3551S

26119

\subsubsection{Buffers and solutions}

\section{X TBE (10 I)}

$1.08 \mathrm{~kg}$ Tris base

$550 \mathrm{~g}$ Boric acid

$400 \mathrm{ml} 0.5 \mathrm{M}$ EDTA

\section{0x TAE (1 I)}

$242 \mathrm{~g}$ Tris base

$57.1 \mathrm{ml}$ glacial acetic acid

$100 \mathrm{ml} 0.5 \mathrm{M}$ EDTA $\mathrm{pH}=8.0$

Filled up to $900 \mathrm{ml}$ with $d d \mathrm{H}_{2} \mathrm{O}, \mathrm{pH}$ adjusted to 8.0 with $\mathrm{HCl}$, then filled up to 1 I with $\mathrm{ddH}_{2} \mathrm{O}$.

5x Loading buffer for agarose gels/STOP-MIX $(10 \mathrm{ml})$ :

$5 \mathrm{ml}$ Glycerol (50\%)

$20 \mu \mathrm{l}$ 0,5 M EDTA pH 8.0 (1 mM)

$15 \mathrm{mg}$ Bromophenol blue (0.15\%)

$5 \mathrm{ml} \mathrm{ddH_{2 } \mathrm { O }}$

\section{STET buffer (100 $\mathrm{ml})$ :}

$5 \mathrm{ml} 1 \mathrm{M}$ TrisHCl pH=8.0 (50 mM)

$10 \mathrm{ml}$ 0.5M EDTA (50 mM)

5 g TritonX-100 (5\%)

5 g Saccharose (8\%)

TritonX-100 added after sterile filtration, stored at $4{ }^{\circ} \mathrm{C}$.

Injection buffer $(500 \mathrm{ml})$ :

$5 \mathrm{ml} 1 \mathrm{M}$ Tris $\mathrm{pH}=7.5(10 \mathrm{mM})$

$100 \mu \mathrm{l} 0.5 \mathrm{M}$ EDTA $\mathrm{pH}=8.0(0.1 \mathrm{mM})$

$10 \mathrm{ml} 5 \mathrm{M} \mathrm{NaCl}(100 \mathrm{mM})$

$484.9 \mathrm{ml}$ endotoxinfree water

Filtered sterile through $0.2 \mu \mathrm{m}$ pore filter.

\section{Avertin (100 ml)}

$1 \mathrm{~g}$ Tribromoethanol

$71.49 \mathrm{ml}$ Pre-warmed $\mathrm{H}_{2} \mathrm{O}\left(40{ }^{\circ} \mathrm{C}\right)$

$0.81 \mathrm{ml}$ Amylalcohol

Mixed in a small glass bottle, stirred for $10 \mathrm{~min}$, sterile filtered, stored at $4{ }^{\circ} \mathrm{C}$ for a maximum of one week. 
20x PBS ( 2 l)

$8 \mathrm{~g} \mathrm{NaCl}$

$320 \mathrm{~g} \mathrm{KCl}$

$57,6 \mathrm{~g} \mathrm{Na}_{2} \mathrm{HPO}_{4}$

$9,6 \mathrm{~g} \mathrm{KH}_{2} \mathrm{PO}_{4}$

Filled up to $2 \mathrm{I}$ with $\mathrm{ddH}_{2} \mathrm{O}$, adjusted to $\mathrm{pH}=7.4$.

Ethylene glycol cryoprotectant solution (2 I)

$498 \mathrm{ml}$ Glycerol (85 \%)

$588 \mathrm{ml}$ Ethylene glycol

$912 \mathrm{ml}$ PBS (1x)

Citrate buffer (10mM)

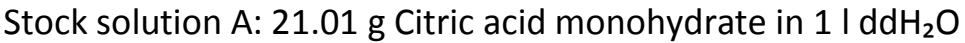

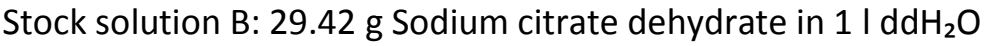

10x Ready-to-use-solution: $3 \mathrm{ml}$ of stock $A$ and $17 \mathrm{ml}$ of stock $B$, pH adjusted to 6 .

4x Laemmli buffer (10 $\mathrm{ml})$

$2.5 \mathrm{ml} 1 \mathrm{M}$ Tris $\mathrm{HCl}(\mathrm{pH}=8.3)$

$0.8 \mathrm{~g}$ SDS

$4 \mathrm{ml}$ Glycerin

$2 \mathrm{ml}$ ß-Mercaptoethanol

$4 \mathrm{mg}$ Pyronin $\mathrm{Y}$

$1.5 \mathrm{ml} \mathrm{ddH} \mathrm{H}_{2} \mathrm{O}$

\section{$0.1 \mathrm{M} \mathrm{NaOH}$}

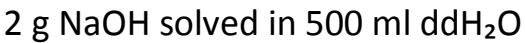

$2 \% \mathrm{Na}_{2} \mathrm{CO}_{3}$

$10 \mathrm{~g} \mathrm{Na}_{2} \mathrm{CO}_{3}$ solved in $500 \mathrm{ml} 0.1 \mathrm{M} \mathrm{NaOH}$

$2 \%$ K-Na-tartrat

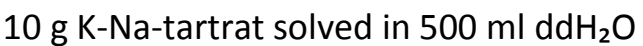

$1 \% \mathrm{CuSO}_{4}$

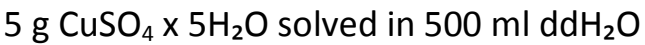

Fresh copper solution $(20.4 \mathrm{ml})$

$20 \mathrm{ml} 2 \% \mathrm{Na} 2 \mathrm{CO} 3$ (100 parts)

$200 \mu \mathrm{l} 2 \%$ K-Na-tartrat (1 part)

$200 \mu \mathrm{l} 1 \%$ CuSO4 (1 part)

$10 \%$ SDS stock solution

$50 \mathrm{~g}$ SDS

Filled up to $500 \mathrm{ml}$ with $\mathrm{ddH}_{2} \mathrm{O}$ and filtered sterile.

Gel lower buffer

$182 \mathrm{~g}$ Tris Base

$40 \mathrm{ml} 10 \%$ SDS (0.4\%)

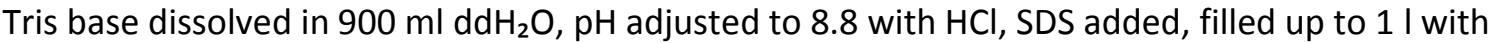
$\mathrm{ddH}_{2} \mathrm{O}$. 


\section{Gel upper buffer}

$60.5 \mathrm{~g}$ Tris Base

$40 \mathrm{ml} 10 \%$ SDS (0.4\%)

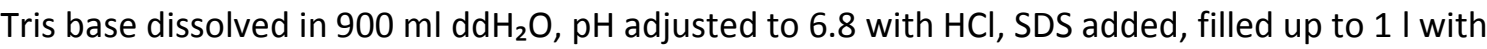
$\mathrm{dd}_{2} \mathrm{O}$.

\section{5x Running buffer}

$15 \mathrm{~g}$ Tris Base

93.89 g Glycine

$5 \mathrm{~g}$ SDS

Filled up to 1 I with $\mathrm{ddH}_{2} \mathrm{O}$.

\section{5x Transfer buffer}

$12.13 \mathrm{~g}$ Tris Base

57.68 g Glycine

Filled up to 1 I with dd $\mathrm{H}_{2} \mathrm{O}$.

\section{0x TBS (2 I)}

$242 \mathrm{~g}$ Tris base

$350 \mathrm{~g} \mathrm{NaCl}$

Filled up to 2 I with $d d \mathrm{H}_{2} \mathrm{O}$.

\section{1x TBST (5 I)}

$250 \mathrm{ml} 20 \mathrm{x}$ TBS

$2.5 \mathrm{ml}$ Tween 20

Filled up to $5 \mathrm{I}$ with $d \mathrm{dH}_{2} \mathrm{O}$ and mixed for $5 \mathrm{~min}$.

\section{Stripping buffer (1 I)}

$125 \mathrm{ml} 0.5 \mathrm{M}$ Tris $\mathrm{HCl}(\mathrm{pH}=6.8)$

$20 \mathrm{~g}$ SDS

$7 \mathrm{ml}$ ß-Mercaptoethanol

Filled up to $1 \mathrm{I}$ with $\mathrm{dd}_{2} \mathrm{O}$ and stored at $4{ }^{\circ} \mathrm{C}$.

\section{$5 x$ Stock slicing solution}

$1150 \mathrm{mM}$ Sucrose

$130 \mathrm{mM} \mathrm{NaHCO}_{3}$

$10 \mathrm{mM} \mathrm{KCl}$

$5 \mathrm{mM} \mathrm{KH}_{2} \mathrm{OP}_{4}$

$5 \mathrm{mM} \mathrm{MgCl} 2 \times 6 \mathrm{H}_{2} \mathrm{O}$

$50 \mathrm{mM}$ Glucose $\times \mathrm{H}_{2} \mathrm{O}$

Sterilized by filtration through a $0.22 \mu \mathrm{m}$ filter and stored at $4{ }^{\circ} \mathrm{C} . \mathrm{CaCl}_{2}$ was added to the $1 \mathrm{x}$ slice solution for $0.5 \mathrm{mM}$ final concentration from a $1 \mathrm{M}$ stock.

\section{Kainate solution}

$25 \mathrm{mM}$ in $\mathrm{H}_{2} \mathrm{O}$

Diluted in ACSF to $100 \mathrm{nM}$ 
10x Stock recording and slice storing solution (ACSF)

$1200 \mathrm{mM} \mathrm{NaCl}$

$260 \mathrm{mM} \mathrm{NaHCO}_{3}$

$10 \mathrm{mM} \mathrm{KH}_{2} \mathrm{PO}_{4}$

$20 \mathrm{mM} \mathrm{KCl}$

$20 \mathrm{mM} \mathrm{MgCl} 2 \times 6 \mathrm{H}_{2} \mathrm{O}$

$100 \mathrm{mM}$ Glucose $\times \mathrm{H}_{2} \mathrm{O}$

Sterilized by filtration through a $0.22 \mu \mathrm{m}$ filter and stored at $4{ }^{\circ} \mathrm{C} . \mathrm{CaCl}_{2}$ was added to the $1 \mathrm{x}$ solution for $2 \mathrm{mM}$ final concentration from a $1 \mathrm{M}$ stock.

\title{
2.8.9 Primers
}

\begin{tabular}{|c|c|}
\hline Nr. & Sequence \\
\hline \multicolumn{2}{|l|}{ Cloning } \\
\hline 20298 & 5'-CTGAGCTCGAATTCAAGGTGGGACGGGCCAGGACG-3' \\
\hline 20299 & 5'-CCTGAGTTTGTCCATGGCGGCGGCGGGGCGGGA-3' \\
\hline 20300 & 5'-ATGGACAAACTCAGGGTGCCCCTCTGG-3' \\
\hline 20301 & 5'-ATGGATGATGCGGTGATAGC-3' \\
\hline 20302 & 5'-CTGAGCTCGAATTCAAGGTGGGACG-3' \\
\hline 20341 & 5'-CGTTAATTAAGCCACCCTGCTCCGCAGCAAGCTG-3' \\
\hline 20342 & 5'-GCTAGCACTAGTATGGCTAGGAAGGTCAGAGAAGGGGAGATAA-3' \\
\hline \multicolumn{2}{|l|}{ Genotyping } \\
\hline $5063($ IL-2) & 5'-CTAGGCCACAGAATTGAAAGATCT-3' \\
\hline 5064 (IL-2) & 5'-GTAGGTGGAAATTCTAGCATCATCC-3' \\
\hline 2521 (Venus) & 5'-CATGGTCCTGCTGGAGTTCGTG-3' \\
\hline 24016 (Venus) & 5'-GTCAAGGCACTATACATCAAA-3' \\
\hline 25763 (polyA) & 5'-TGGATCGATCCCGCCATGGTAT-3' \\
\hline 25764 (polyA) & 5'-GGAGCAGGGTGGCTTAATTAAGAAGT-3' \\
\hline 26857 (5' UTR Viaat) & 5'-CTGGCCGTCGACATTTAGGTG-3' \\
\hline 26858 (5' UTR Viaat) & 5'-ATGCTGGGATGTGGGAGGTTCTT -3' \\
\hline 26859 (pBACe3.6) & 5'-TGTCGGGTGCGGAGAAAGAGGTAA-3' \\
\hline 26860 (pBACe3.6) & 5'-TGGCAGGGCGGGGCGTAAT-3' \\
\hline \multicolumn{2}{|l|}{ cDNA } \\
\hline 4542 (N9) & 5'-NNNNNNNNN-3' \\
\hline 9578 oligo(dT)-Mix & 5'-TTTTTTTTTTTTTTTTTTTTTTTTTTVN -3' \\
\hline \multicolumn{2}{|l|}{ qPCR } \\
\hline 11329 (EPOR) & 5'-CCTCATCTCGTTGTTGCTGA-3' \\
\hline 11330 (EPOR) & 5'-CAGGCCAGATCTTCTGCTG-3' \\
\hline 6038 (GAPDH) & 5'-GTGCAGCGAACTTTATTGATGGTATTCAAGAG -3' \\
\hline 6039 (GAPDH) & 5'-GGCATTGCTCTCAATGACAACTTTGTCAAG -3' \\
\hline
\end{tabular}

\subsubsection{Antibodies}

\section{Primary antibodies}

Mouse parvalbumin

Rabbit HA

Mouse HA

Rat HA

Rabbit HA

Rabbit GFP

Mouse GAPDH

\author{
Sigma-Aldrich, Taufkirchen (Germany) \\ Cell Signaling Technology Inc., Danvers (USA) \\ Covance Inc., Princeton (USA) \\ Roche Diagnostics GmbH, Mannheim (Germany) \\ Abcam plc, Cambridge (UK) \\ Synaptic Systems GmbH, Göttingen (Germany) \\ Enzo Life Sciences $\mathrm{GmbH}$, Lörrach (Germany)
}

P3088

\#3724

MMS-101P

11867423001

ab9110

132002

ADI-CSA-335E 


\section{Secondary antibodies}

Biotinylated anti-rabbit IgG Biotinylated anti-mouse IgG

Vector Laboratories, Burlingame (USA)

BA-1000

Goat anti-mouse-AF488

Donkey anti-rabbit-AF488

Streptavidin-AF488

Streptavidin-AF633

Goat anti-mouse-HRP

Goat anti-rat-HRP

Dyes

DAPI
Vector Laboratories, Burlingame (USA)

BA-2001

Life Technologies $\mathrm{GmbH}$, Darmstadt (Germany)

A11001

Life Technologies $\mathrm{GmbH}$, Darmstadt (Germany)

A-21206

Life Technologies $\mathrm{GmbH}$, Darmstadt (Germany)

S-32354

Life Technologies GmbH, Darmstadt (Germany)

S-21375

Sigma-Aldrich, Taufkirchen (Germany)

A-3682

Sigma-Aldrich, Taufkirchen (Germany)

A-9037

Sigma-Aldrich, Taufkirchen (Germany)
D954 


\section{Results}

The results section is divided into the following parts:

Part I - Cloning of the Viaat-HA-cEPOR construct

Part II - Analysis of the transgenic Viaat-HA-CEPOR mouse

\section{Results Part I}

\subsection{Cloning of Viaat-HA-cEPOR ( \pm IRES-Venus)}

The basis of the Viaat-HA-CEPOR construct was the alpha-CaMKII-HA-CEPOR vector, which was used for the generation of the alpha-CaMKII-HA-cEPOR mice, published in 2011 (Sargin et al., 2011). The HA-CEPOR construct was cut out and placed under control of the Viaat promoter, using the mouse bacterial artificial chromosome (BAC) RP23-392P11. RP23392P11 contains the SLC32A1 gene (solute carrier family 32 member 1 ) coding for the vesicular inhibitory amino acid transporter (Viaat), also known as vesicular GABA transporter (VGAT). Importantly, the BAC includes the upstream region of $\sim 125 \mathrm{~kb}$ and the downstream region of $\sim 68 \mathrm{~kb}$ and therefore most likely contains all regulatory sequences necessary for gene expression. The detection of HA-cEPOR expression was problematic in the alphaCaMKII-HA-cEPOR mice and the staining against the HA-tag was very weak. Therefore, this study aimed to include an additional construct with a fluorescent marker. The internal ribosomal entry site (IRES)-Venus was chosen as alternative for the detection of cEPOR. This construct was named Viaat-HA-CEPOR-IRES-Venus. The cloning of both constructs, Viaat-HACEPOR and Viaat-HA-CEPOR-IRES-Venus, is explained in detail on the following pages.

\subsubsection{Step 1 - Validation of restriction cutting sites of alpha-CaMKII-HA-cEPOR}

The alpha-CaMKII-HA-cEPOR vector was used as basis for cloning the Viaat-HA-CEPOR and Viaat-HA-CEPOR-IRES-Venus construct. In the first step, several restriction cutting sites, which were used in the following cloning procedures, were tested. The results of the restriction digests with Kpnl, Notl, Sall, EcoRI, Spel, Nrul and Sacl are presented in Figure 17A. The locations of the respective restriction sites are illustrated in Figure 17B, and the predicted band sizes for each restriction digest are given in Figure 17C. The alpha-CaMKIIHA-CEPOR vector has a total size of $13.953 \mathrm{~kb}$. Restriction enzymes with one cutting site, 
such as Sall and Nrul, produce a $13.953 \mathrm{~kb}$ linearized plasmid, which appears as a single band on the gel. Circular plasmids would show more than one band because of supercoiled structures. Thus, the cutting sites for Sall and Nrul were validated. Restriction enzymes with more than one cutting site produce fragments with specific sizes. Comparing the predicted sizes with the digestion results, the cutting sites for EcoRI, Spel and Sacl could be confirmed. But there was a discrepancy between the actual and the predicted sizes for Kpnl and Notl (Figure 17C, highlighted in red). Based on the fragment sizes obtained, the conclusion was that some cutting sites, which were expected from the available plasmid sequence, do not exist. These were 2 cutting sites for Kpnl and 1 cutting site for Notl, which should have been located in the pBS II SK (+) region (Figure 17B encircled in red). For the following cloning steps, neither the restriction sites nor the sequence of the source plasmid pBS II SK(+) were important. Therefore, the cloning was continued and the experimentally determined product sizes were used for further calculations.

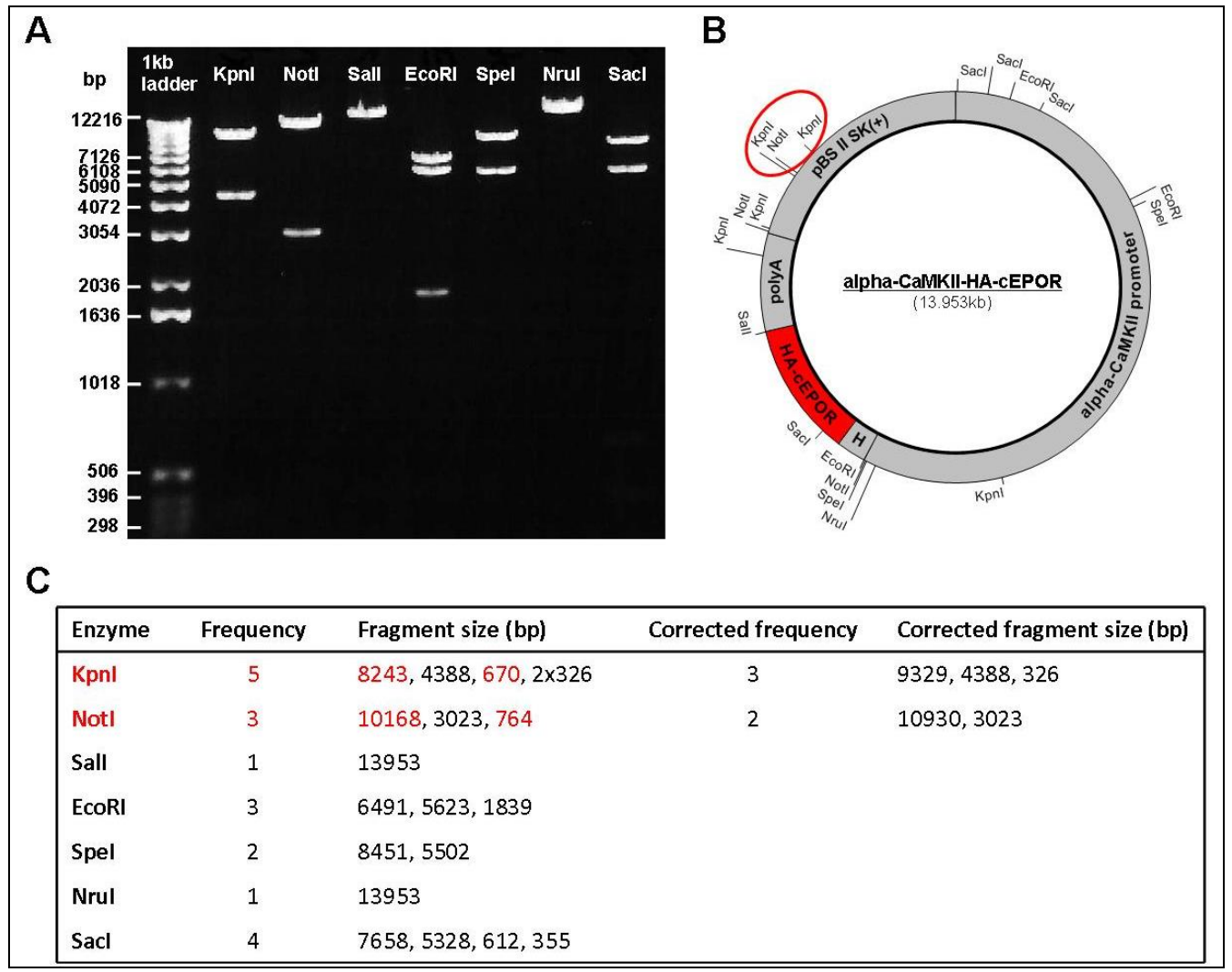

Figure 17: Cloning Step 1 - Validation of the restriction sites of alpha-CaMKII-HA-cEPOR. (A) Agarose gel visualizing the different fragment sizes of alpha-CaMKII-HA-CEPOR after restriction digest with Kpnl, Notl, Sall, EcoRI, Spel, Nrul and Sacl. The $1 \mathrm{~kb}$ ladder was used as size marker. (B) Circular illustration of the plasmid alpha-CaMKII-HA-cEPOR with the respective cutting sites for the restriction enzymes Kpnl, Notl, Sall EcoRI, Spel, Nrul and Sacl. The promoter region for alpha-CaMKII, the Hybrid Intron $(H)$, the polyA coding sequence, and the ampicillin resistance sequence of pBS II SK(+) are drawn in grey. The HA-cEPOR sequence is highlighted in red. Encircled in red are 2 cutting sites for Kpnl and 1 cutting site for Notl that were expected based on the sequence file but could not be verified experimentally. (C) Table of the restriction enzymes with their cutting frequency and fragment sizes for alpha-CaMKII-HA-CEPOR. Labeled in red are fragment sizes which are in discrepancy with the sizes shown in A. 


\subsubsection{Step 2 - Insertion of IRES-Venus into alpha-CaMKII-HA-cEPOR}

To obtain an alternative for the detection of cEPOR expression, IRES-Venus was inserted into the alpha-CaMKII-HA-cEPOR plasmid as illustrated in Figure 18A. For this purpose, $3 \mu \mathrm{g}$ of alpha-CaMKII-HA-CEPOR were linearized with Sall and the insert IRES-Venus was cut out of $4 \mu \mathrm{g}$ pcDNA3-EMCV-IRES-PV-IRES-VENUS with EcoRV and Notl. The vector (13.95 kb) and the insert $(1.52 \mathrm{~kb})$ were separated on a preparative agarose gel and extracted (Figure 18B, red dots). The purified fragments were blunt-ended and the vector was dephosphorylated. Before ligation, both fragments were analyzed again on the agarose gel (Figure 18C) and 2 different ratios of vector to insert (10:4 and 8:6) were ligated. Elektro10 cells were transformed with the new construct alpha-CaMKII-HA-CEPOR-IRES-Venus and 12 clones were picked for a diagnostic restriction digest with Kpnl (Figure 18D and E). Clone \#1, \#2 and $\# 10$ of ligation mixture 10:4 (Figure 18D) and clone \#8, \#9, \#10, and \#11 of ligation mixture 8:6 (Figure 18E) showed the correct fragment sizes of 9239, 3614, 2298, and 326 bp (326 bp is not visible in the picture). Clone \#8 was purified, confirmed by sequencing and used for cloning step 3.

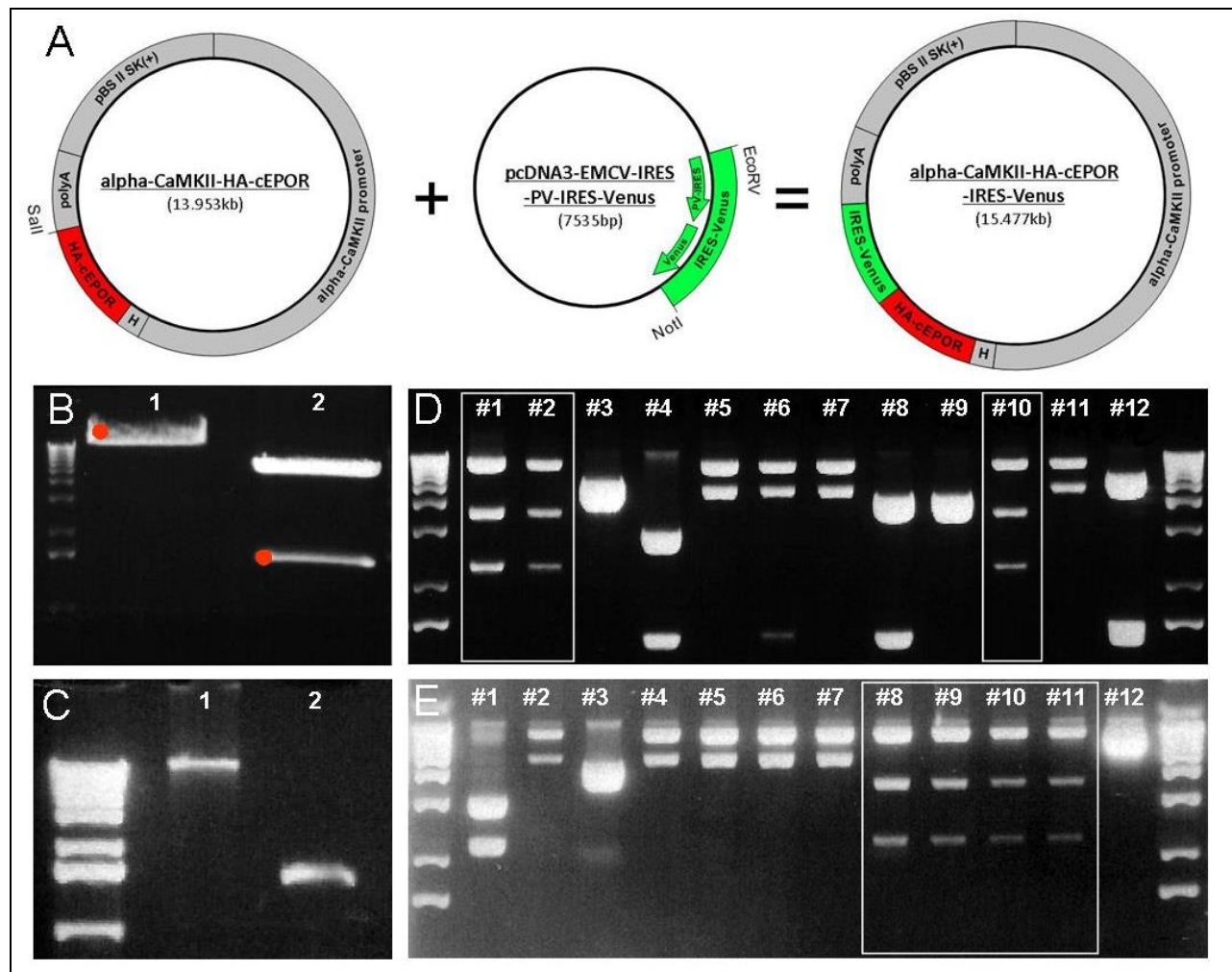

Figure 18: Cloning step 2 - Insertion of IRES-Venus into alpha-CaMKII-HA-cEPOR. (A) Illustration of the cloning step. (B) Preparative agarose gel showing the isolated restriction fragments of alpha-CaMKII-HA-cEPOR (lane 1, red dot) and IRES-Venus (lane 2, red dot). (C) Agarose gel presenting the DNA of vector (lane 1) and insert (lane 2) before ligation. (D) Agarose gel visualizing the restriction fragments after Kpnl digestion of 12 clones (\#1-12). Ligation ratio of vector to insert is 10:4. (E) Agarose gel visualizing the restriction fragments after Kpnl digestion of 12 clones (\#1-12). Ligation ratio of vector to insert is 8:6. Framed are clones with correct fragment sizes. In all agarose gels the $1 \mathrm{~kb}$ ladder was used as size marker. 


\subsubsection{Step 3 - Insertion of ampicillin resistance (AmpR) with FRT sites}

In the following cloning step HA-CEPOR and HA-CEPOR-IRES-Venus were cloned into the phCre2myc_nucNP plasmid to obtain an FRT-framed ampicillin resistance gene. The resistance gene is needed in cloning step 10 for selecting clones after successful homologous recombination. The FRT sites enable removal of the bacterial resistance gene from the BAC before linearization and integration into the mouse genome. In this step, $5 \mu \mathrm{g}$ phCre2myc_nucNP were cut with Xhol and $7 \mu \mathrm{g}$ of alpha-CaMKII-HA-CEPOR \pm IRES-Venus were cut with Notl. The digestion fragments were purified and blunt-ended. Vector and inserts were then cut with Sacl. The cEPOR gene contains an internal restriction site for Sacl; the missing 5 ' fragment was introduced as part of the $5^{\prime}$ miniarm in the next step. The fragments of the restriction digests were separated on a preparative agarose gel (Figure 19A). The vector phCre2myc_nucNP (3.13 kb, lane 1, red dot) and the inserts HA-cEPOR (2.446 kb, lane 3, red dot) and HA-CEPOR-IRES-Venus (3.970 kb, lane 2, red dot) were isolated, and purified and fragment sizes were again confirmed on an agarose gel (Figure 19B).

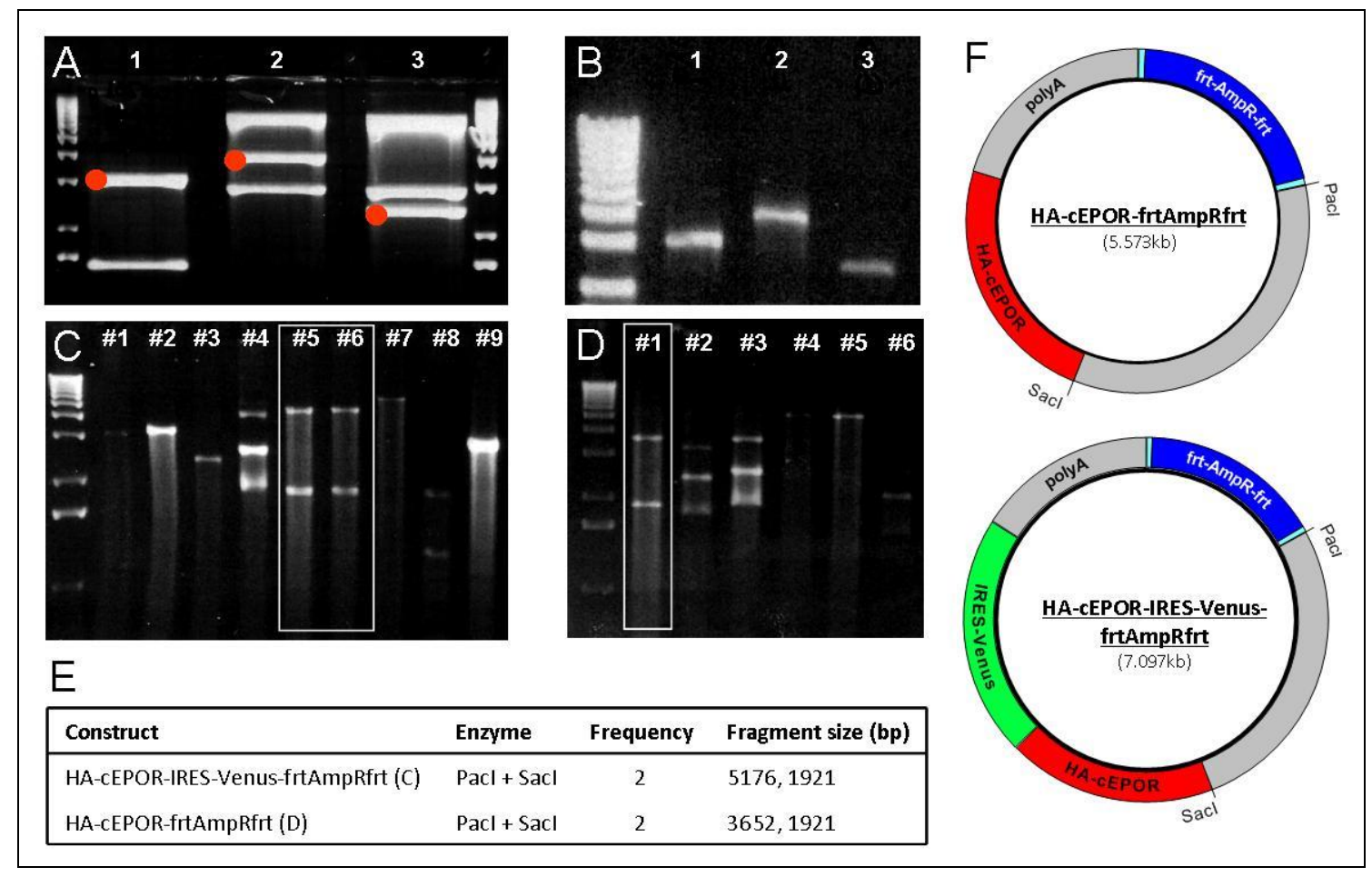

Figure 19 Cloning step 3 -Insertion of ampicillin resistance (AmpR) with FRT-site. (A) Preparative agarose gel of restrictions fragments after digestion. PhCre2myc nucNP was digested with Xhol and Sacl (lane 1), alphaCaMKII-HA-CEPOR digested with Notl and Sacl (lane 2) and alpha-CaMKII-HA-CEPOR-IRES-Venus digested with Notl and Sacl (lane 3). Extracted bands are labeled with a red dot. (B) Agarose gel of vector (lane 1) and inserts (lane 2, 3) before ligation. (C) Agarose gel of restriction fragments after Pacl + Sacl digestion of 9 clones (\#1-9) of HA-cEPOR-IRES-Venus-frtAmpRfrt. (D) Agarose gel visualizing the restriction fragments after Pacl, Sacl digestion of 6 clones (\#1-6) of HA-cEPOR-frtAmpRfrt. Framed are clones with correct fragment sizes. (E) Table of constructs and product sizes after cutting with the respective restriction enzymes. (F) Illustration of the new constructs HA-CEPOR-IRES-Venus-frtAmpRfrt and HA-cEPOR-frtAmpRfrt. On all agarose gels, the $1 \mathrm{~kb}$ ladder was used as size marker. 
XL1-Blue cells were transformed with the ligated construct. The clones were analyzed with a Pacl+Sacl digestion (Figure 19C, D). Clones with the correct plasmid of HA-CEPOR-IRESVenus-frtAmpRfrt (Figure 19C, E, F) should have fragment sizes of $5176 \mathrm{bp}$ and $1921 \mathrm{bp}$. Clones with the correct plasmid of HA-cEPOR-frtAmpRfrt (Figure 19D, E, F) should have fragment sizes of 3652 bp and 1921 bp. Clones \#5 and \#6 showed correct fragment sizes for HA-cEPOR-IRES-Venus-frtAmpRfrt (Figure 19C, framed), clone \#1 for HA-cEPOR-frtAmpRfrt (Figure 19E, framed). All three clones were confirmed by sequencing and clone \#6 and \#1 were used for further cloning.

\subsubsection{Step 4 - Creation of 5' and 3' miniarms for recombineering}

The aim was to integrate the Viaat-HA-CEPOR \pm IRES-Venus construct into the BAC RP23$392 \mathrm{P} 11$ by homologous recombination (cloning step 10). For this purpose, the cEPOR construct had to be framed by sequences homologous to the desired integration site. In this step, the homologous sequences (called $5^{\prime}$ and 3 ' miniarms) were created by PCR. It has been shown that long homology arms of 200-500 bp increase the efficacy of homologous recombination to an accuracy of more than $95 \%$ correctly constructed clones (Liu et al., 2003). Therefore, relatively long miniarms of 400-600 bp were created (see 2.3.1, 2.3.2). Since some restriction enzymes do not cut efficiently near the end of fragments, the miniarms were cloned afterwards into the $p C R I I-T O P O$ vector (Figure 20A, B).

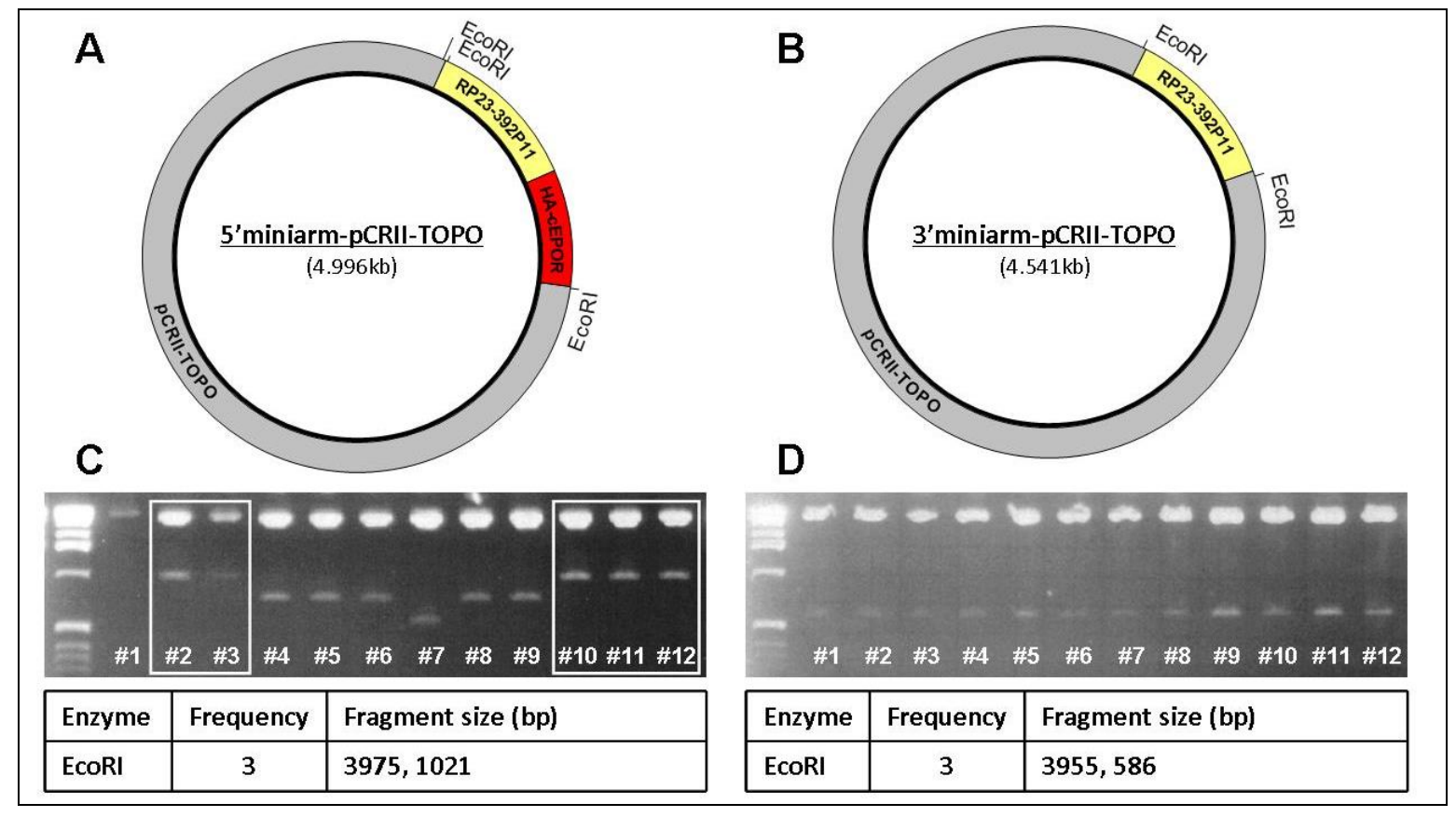

Figure 20: Cloning step 4 - Creation of 5' and 3' miniarms for recombineering. (A,B) Circular illustration of the 5 'miniarm-pCRII-TOPO and 3'miniarm-pCRII-TOPO vector. (C) Agarose gels visualizing the fragment sizes of 5 'miniarm-pCRII-TOPO after diagnostic restriction digest with EcoRI. (D) Agarose gels visualizing the fragment sizes of 3 'miniarm-pCRII-TOPO vector after diagnostic restriction digest with EcoRI. 
The miniarm-TOPO plasmids were transformed into XL-1 Blue cells. The next day, 12 clones of each miniarm-TOPO vector were picked for a diagnostic restriction digest with EcoRI. The restriction digests were analyzed on an agarose gel. Clone \#2, \#3, \#10, \#11 and \#12 of the 5'miniarm-pCRII-TOPO (Figure 20C) and all clones of the 3 'miniarm-pCRII-TOPO (Figure 20D) were of the correct fragment sizes.

\subsubsection{Step 5 - Insertion of the 5 ' miniarm}

Now the 5 ' miniarm, which additionally carries the missing 5 ' fragment of the HA-cEPOR gene, was integrated into the HA-CEPOR-frtAmpRfrt \pm IRES-Venus construct. For this purpose, the 5'miniarm-pCRII-TOPO, HA-cEPOR-frtAmpRfrt and HA-cEPOR-IRES-Venus-frtAmpRfrt were cut with Sacl. The fragments were separated on a preparative agarose gel (Figure 21A) and the fragments of HA-cEPOR-frtAmpRfrt (5.573 kb), HA-cEPOR-IRES-Venus-frtAmpRfrt (7.097 kb) and 5'miniarm-pCRII-TOPO (0.813 kb) were purified (Figure 21B). The vectors HACEPOR-frtAmpRfrt and HA-CEPOR-IRES-Venus-frtAmpRfrt were dephosphorylated and ligated with the 5' miniarm. The new plasmids HA-CEPOR-frtAmpRfrt-5'miniarm and HA-CEPOR-IRESVenus-frtAmpRfrt-5'miniarm, illustrated in (Figure 21C), were transformed into XL-1 Blue cells. For a diagnostic restriction digest 12 clones were picked and cut with EcoRI and Pacl. Clone \#6, \#8, \#11 of HA-cEPOR-frtAmpRfrt-5'miniarm and clone \#6, \#8, \#10, \#11 of HACEPOR-IRES-Venus-frtAmpRfrt-5'miniarm showed the predicted fragment sizes (Figure 21D, E, F). Clone \#6 of HA-cEPOR-frtAmpRfrt-5'miniarm and clone \#10 of HA-cEPOR-IRES-VenusfrtAmpRfrt-5'miniarm were confirmed by sequencing and used for further cloning.

\subsubsection{Step 6 - Insertion of the 3' miniarm and a kanamycin resistance (KanR)}

Cloning step 6 was a 3-way ligation, in which the 3' miniarm and an additional Kanamycin resistance gene (KanR) were integrated. For this purpose, the HA-cEPOR-frtAmpRfrt5'miniarm and the HA-CEPOR-IRES-Venus-frtAmpRfrt-5'miniarm were cut with EcoRI and Pacl, the 3 'miniarm-pCRII-TOPO was cut with Nhel and Pacl and the plasmid $p E G F P-N$, which contains the KanR, was cut with EcoRI and Nhel. All digests were separated on a preparative agarose gel (Figure 22A, B). All four fragments were isolated and controlled on an agarose gel before ligation (Figure 22C). XL1-Blue cells were transformed with the new plasmids $H A$ cEPOR-frtAmpRfrt-5'3'miniarm-KanR (Figure 22F) and HA-cEPOR-IRES-Venus-frtAmpRfrt5'3'miniarm-KanR (Figure 22G). Only a few clones grew on Amp/Kan agar plates and all had correct plasmids as shown with the EcoRI and Spel restriction digest (Figure 22D, E). 


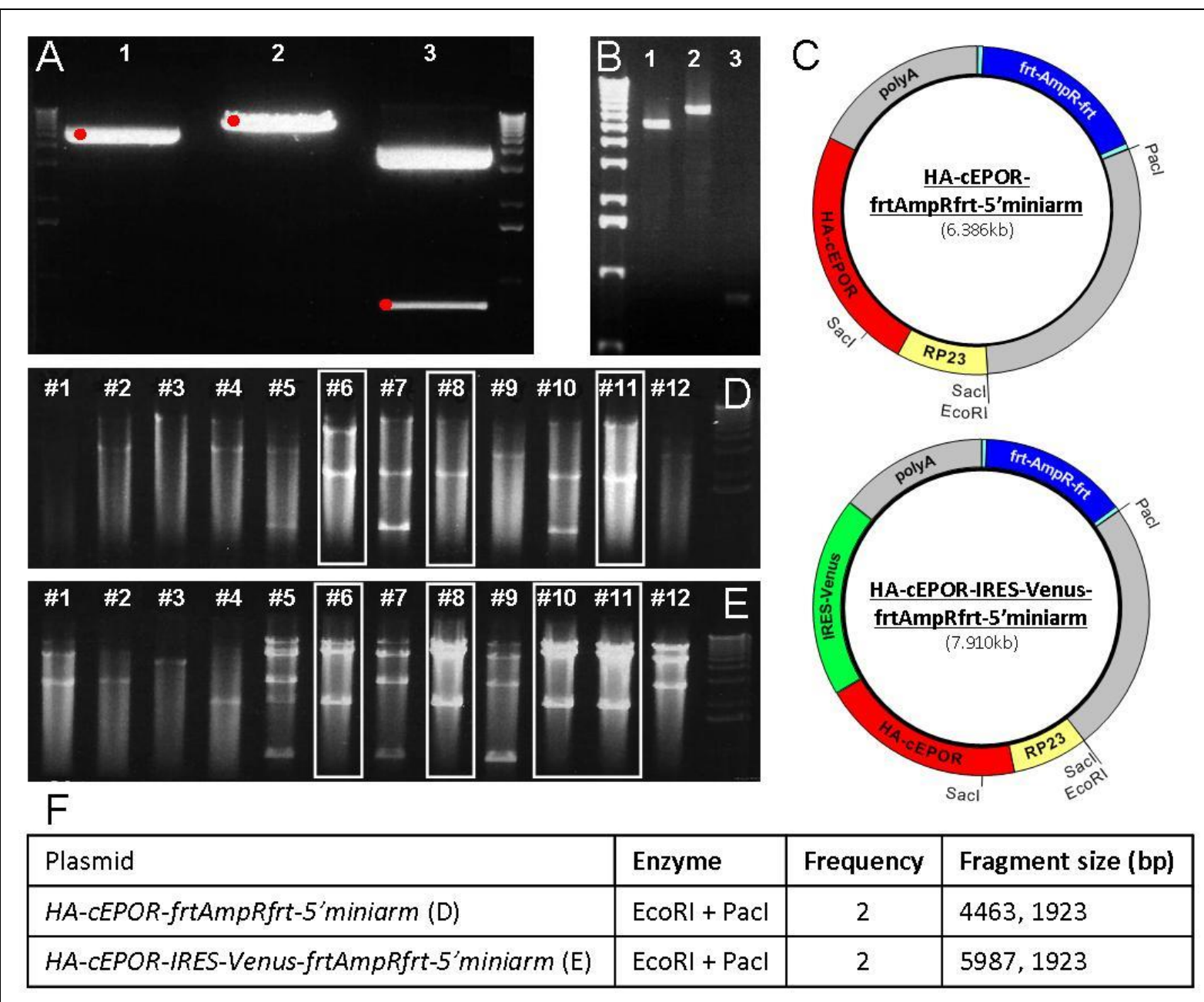

Figure 21: Cloning Step 5 - Insertion of the $\mathbf{5}$ ' miniarm. (A) Preparative agarose gel after Sacl digestion; HAcEPOR-frtAmpRfrt (lane 1) HA-CEPOR-IRES-Venus-frtAmpRfrt (lane 2) and 5'miniarm-pCRII-TOPO (lane 3). Extracted bands are labeled with a red dot. (B) Agarose gel of HA-CEPOR-frtAmpRfrt (lane 1), HA-CEPOR-IRESVenus-frtAmpRfrt (lane 2), and 5'miniarm-pCRII-TOPO (lane 3) before ligation. (C) Illustration of the new constructs. (D) Agarose gel after EcoRI, Pacl digestion of 12 clones (\#1-12) of HA-cEPOR-frtAmpRfrt-5'miniarm. (E) Agarose gel after EcoRI, Pacl digestion of 12 clones (\#1-12) of HA-cEPOR-IRES-Venus-frtAmpRfrt-5'miniarm. Framed are clones with correct fragment sizes. (F) Table of constructs and fragment sizes after cutting with the respective restriction enzymes. In all agarose gels, the $1 \mathrm{~kb}$ ladder was used as size marker.

\subsubsection{Step 7 - Sequencing of the construct}

HA-cEPOR-frtAmpRfrt-5'3'miniarm-KanR and HA-cEPOR-IRES-Venus-frtAmpRfrt-5'3'miniarmKanR were the final plasmid constructs and used for recombineering with the BAC RP23392P11, which contains the Viaat gene including the promoter region. Clone \#1 of $H A$ cEPOR-frtAmpRfrt-5'3'miniarm-KanR and clone \#7 of HA-cEPOR-IRES-Venus-frtAmpRfrt5'3'miniarm-KanR were amplified (Plasmid Maxi Preparation) and sequenced in order to verify that no unintended mutation had been introduced. Both clones had the predicted sequences. 


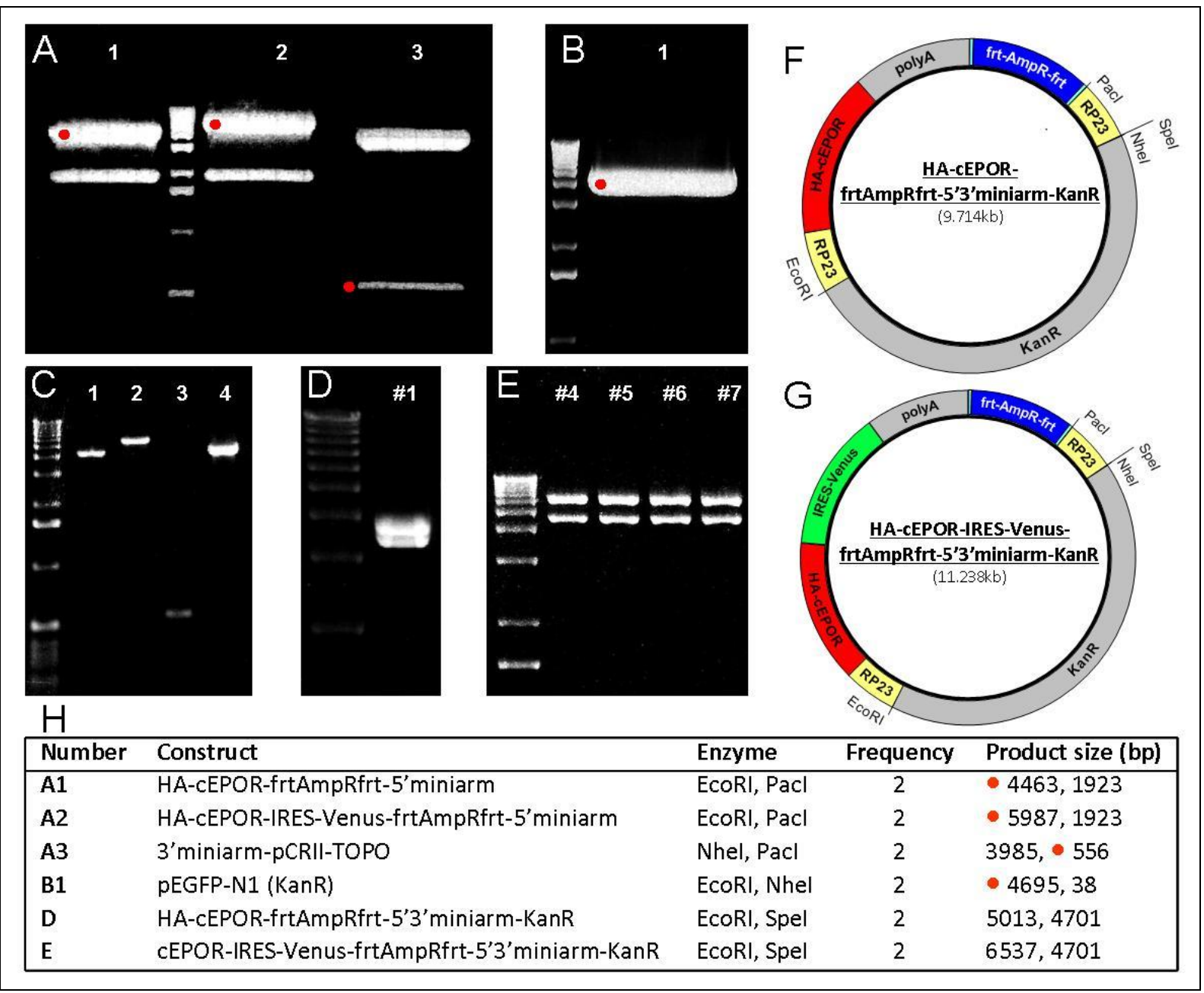

Figure 22: Cloning step 6 - Insertion of the 3' miniarm and a kanamycin resistance (KanR). (A) Preparative agarose gel of HA-CEPOR-frtAmpRfrt-5'miniarm after digestion with EcoRI and Pacl (lane 1), HA-CEPOR-IRESVenus-frtAmpRfrt-5'miniarm after digestion with EcoRI and Pacl (lane 2), and 3'miniarm-pCRII-TOPO after digestion with Nhel and Pacl (lane 3). Extracted bands are labeled with a red dot. (B) Preparative agarose gel visualizing the restrictions fragment of $p E G F P-N 1$ (KanR) after digestion with EcoRI and Nhel. (C) Agarose gel of vectors and inserts before ligation, HA-CEPOR-frtAmpRfrt-5'miniarm (lane 1), HA-cEPOR-IRES-Venus-frtAmpRfrt5'miniarm (lane 2), 3'miniarm-pCRII-TOPO (lane 3), and pEGFP-N1 (lane 4). (D) Agarose gel of HA-CEPORfrtAmpRfrt-5'3'miniarm-KanR after EcoRI, Spel digestion of clone \#1. (E) Agarose gel of EcoRI, Spel digestion of 4 clones (\#4-7) of HA-CEPOR-IRES-Venus-frtAmpRfrt-5'3'miniarm-KanR. (F, G) Illustration of the new constructs. (H) Table with constructs and fragment sizes after cutting with the respective restriction enzymes. In all agarose gels, the $1 \mathrm{~kb}$ ladder was used as size marker. 


\subsubsection{Step 8 - Linearization of the construct}

The last step of the in vitro genetic engineering was the linearization of the two constructs. $10 \mu \mathrm{g}$ of HA-cEPOR-frtAmpRfrt-5'3'miniarm-KanR and HA-cEPOR-IRES-Venus-frtAmpRfrt$5^{\prime} 3^{\prime}$ miniarm-KanR were cut with Spel, EcoRI and BstBI in a volume of $100 \mu \mathrm{l}$ for $4 \mathrm{~h}$ at $37^{\circ} \mathrm{C}$. $\mathrm{BstBI}$ was used to cut the vector backbone. Without BstBI, both fragments would have been almost similar in size and the linearized construct could not have been purified. The restriction digestion was separated on a preparative agarose gel (Figure 23A) and purified. Before using the linearized construct for recombineering, the fragment sizes and purities were confirmed on another agarose gel (Figure 23B). The concentration was spectrophotometrically determined. HA-CEPOR-frtAmpRfrt-5'3'miniarm had a concentration of $120 \mathrm{ng}$ and HA-CEPOR-IRES-Venus-frtAmpRfrt-5'3'miniarm a concentration of $165 \mathrm{ng}$. Approximately 100-200 ng should be used for recombination. Therefore, $1 \mu$ l each was used for the recombineering step.

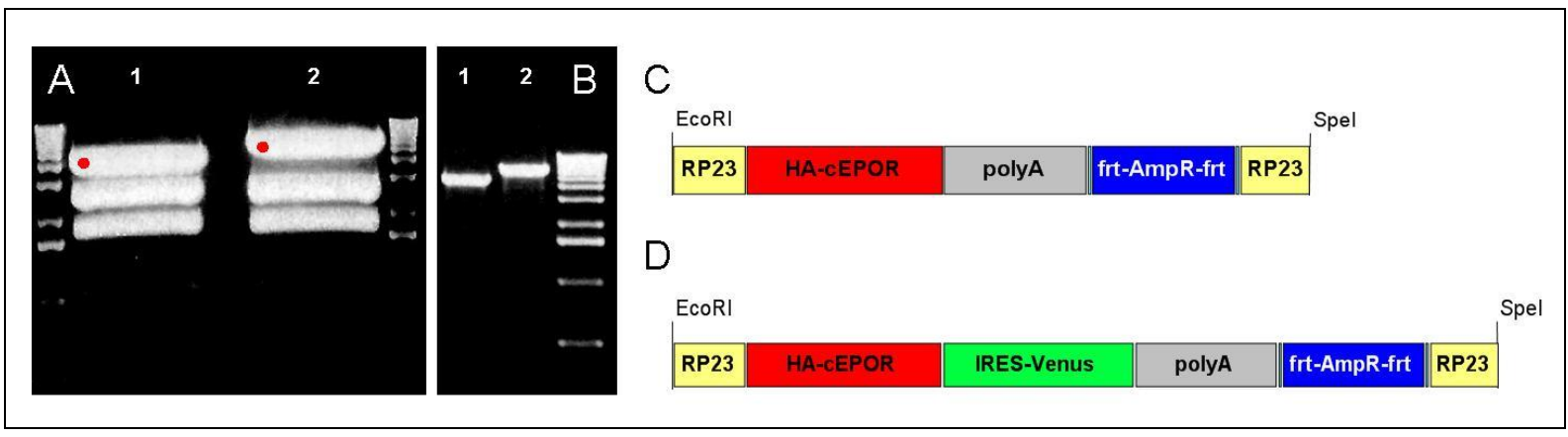

Figure 23: Cloning step 8 - Linearization of HA-cEPOR-(IRES-Venus)-frtAmpRfrt-5'3'miniarm-KanR (A) Preparative agarose gel of HA-CEPOR-frtAmpRfrt-5'3'miniarm-KanR after digestion with EcoRI, Spel and BstBI (lane 1), and HA-CEPOR-IRES-Venus-frtAmpRfrt-5'3'miniarm-KanR after digestion with EcoRI, Spel and BstBI (lane2). Extracted bands are labeled with a red dot. (B) Agarose gel presenting the purity and amount of the extracted linearized DNA which was later on used for recombineering. (C) Illustration of the linear DNA construct HA-cEPOR-frtAmpRfrt-5'3'miniarm used for recombineering. (D) Illustration of the linear DNA construct HA-CEPOR-IRES-Venus-frtAmpRfrt-5'3'miniarm used for recombineering. On both agarose gels, the $1 \mathrm{~kb}$ ladder was used as size marker.

\subsubsection{Step 9 - Transformation of RP23-392P11 into SW105}

After successful cloning, amplification and linearization of HA-cEPOR-frtAmpRfrt-5'3'miniarm and HA-CEPOR-IRES-Venus-frtAmpRfrt-5'3'miniarm, the recombineering had to be set up. The BAC RP23-392P11 (Figure 24A) was transformed into the recombinogenic strain SW105. For this, the BAC RP23-392P11 was isolated by the BAC mini preparation and visualized on a $0.7 \%$ TBE agarose gel (Figure 24B). Electrocompetent SW105 cells were transformed with the BAC DNA from clone \#4. RP23-392P11 was isolated from the resulting SW105 clones 
\#4(1) and \#4(2), followed by a diagnostic restriction digest with Pacl and Pmel. The fragments were separated with PFGE (Figure 24C) and both clones had the same fragment sizes as the control, the BAC \#4 before transformation.
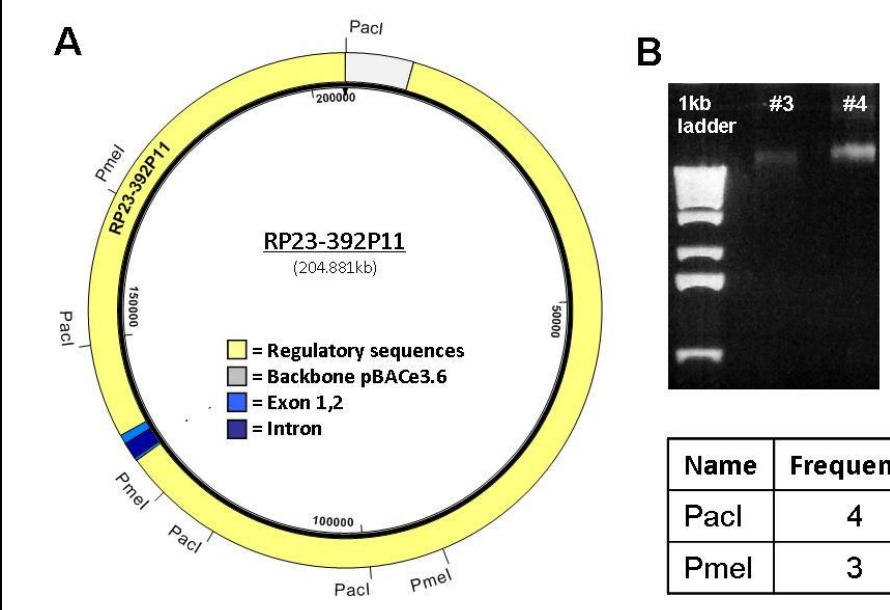

C

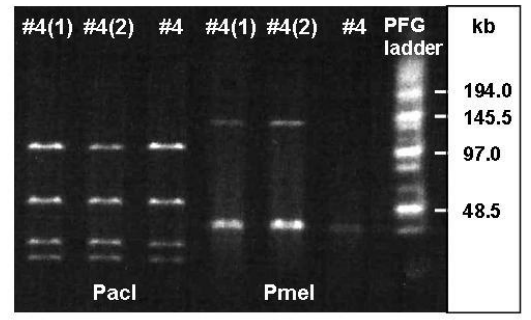

\begin{tabular}{|l|c|l|}
\hline Name & Frequency & Product size (bp) \\
\hline Pacl & 4 & $99001,55747,29233,20900$ \\
\hline Pmel & 3 & $125657,40823,38401$ \\
\hline
\end{tabular}

Figure 24: Cloning Step 9 - Transformation of RP23-392P11 into the recombinogenic strain SW105. (A) Circular illustration of the BAC RP23-392P11. (B) Agarose gel of the isolated BAC DNA from Clone \#3 and \#4. The $1 \mathrm{~kb}$ ladder was used as size marker (C) PFGE showing the fragment sizes of the BAC before and after transformation, digested with Pacl and Pmel. Midrange I PFG marker was used as size standard.

\subsubsection{Step 10 - Recombineering}

Recombinogenic and electrocompetent cells of SW105-RP23-392P11, clone \#4(1), were transformed with the linearized and purified constructs of HA-CEPOR-(IRES-Venus)frtAmpRfrt-5'3'miniarm. To identify clones with successful recombination and integration of the EPOR construct into the BAC RP23-392P11 (Figure 25A, B), the isolated BAC DNA was digested with Pacl and separated by PFGE (Figure 25C, D). Both constructs, Viaat-HA-CEPORfrtAmpRfrt and Viaat-HA-cEPOR-IRES-Venus-frtAmpRfrt have an additional restriction site for Pacl. Thus, by successful recombination, the $29.233 \mathrm{~kb}$ fragment of the wt-BAC is replaced by smaller fragments (Figure $25 \mathrm{C}$ and $\mathrm{E}$, highlighted in red). This was the case in clone \#1, \#4, \#5, and \#6 for Viaat-HA-cEPOR-frtAmpRfrt (1) and clone \#2, \#4 and \#6 for Viaat-HA-cEPORIRES-Venus-frtAmpRfrt (2). These clones were then digested with Pmel (Figure 17D and E). In case of successful recombination, the wt fragment size of $40.823 \mathrm{~kb}$ should increase to $44.710 \mathrm{~kb}(1)$ or $46.234 \mathrm{~kb}$ (2). This was the case for all clones and verified the successful recombination. Clone \#5 and \#6 for Viaat-HA-cEPOR-frtAmpRfrt and clone \#2 and \#4 for Viaat-HA-cEPOR-IRES-Venus-frtAmpRfrt were used for the next step, the excision of the AmpR gene. 

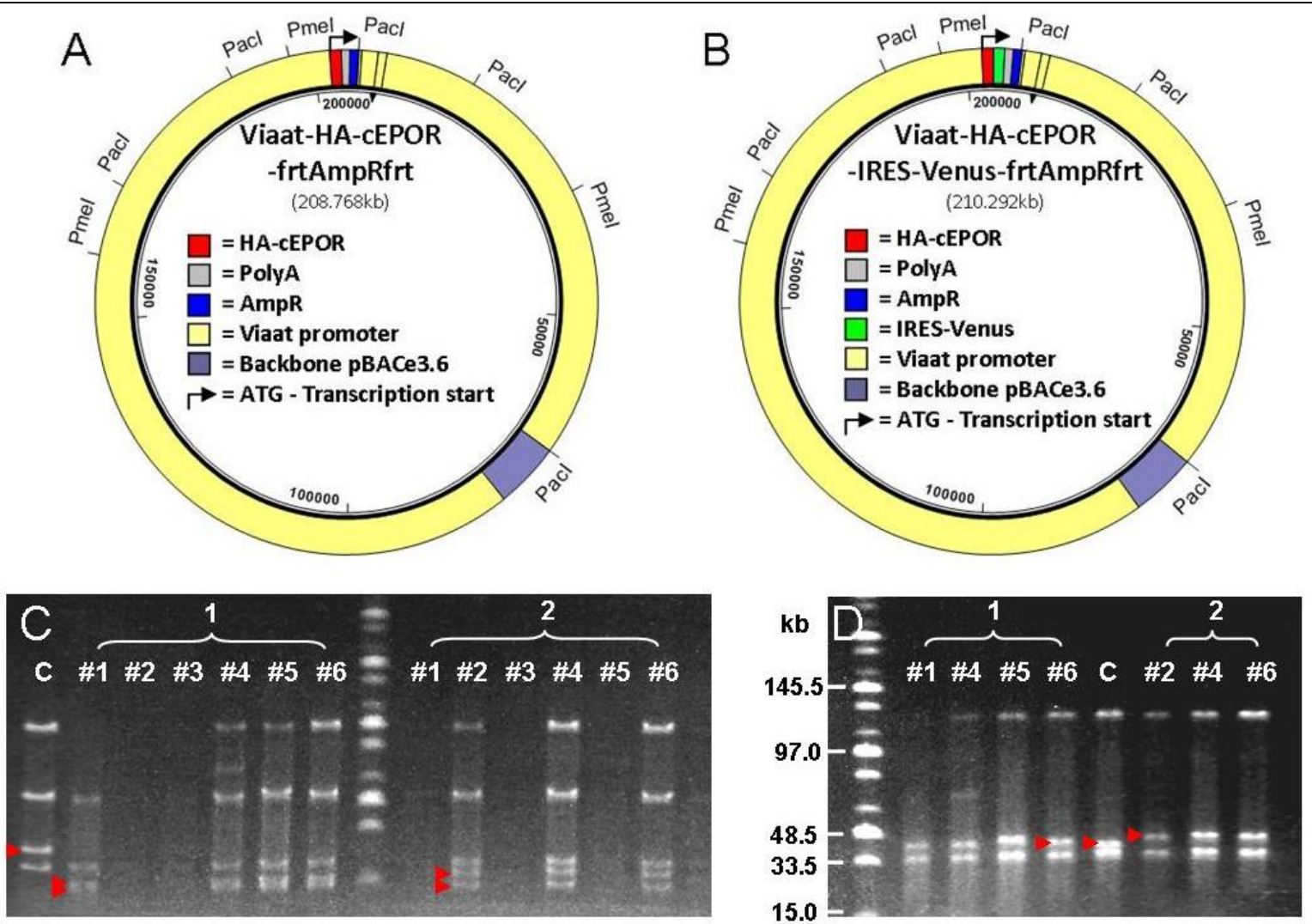

E

\begin{tabular}{|l|l|l|c|l|}
\hline & BAC & Enzyme & Frequency & Fragment size (kb) \\
\hline C (C) & RP23-392P11 & Pacl & 4 & $99.001,55.747,29.233,20.900$ \\
\hline C (1) & Viaat-HA-cEPOR-frtAmpRfrt & Pacl & 5 & $99.001,55.747,20.900,17.211,15.909$ \\
\hline C(2) & Viaat-HA-cEPOR-IRES-Venus-frtAmpRfrt & Pacl & 5 & $99.001,55.747,20.900,18.735,15.909$ \\
\hline D (C) & RP23-392P11 & Pmel & 3 & $125.657,40.823,38.401$ \\
\hline D (1) & Viaat-HA-cEPOR-frtAmpRfrt & Pmel & 3 & $125.657,44.710,38.401$ \\
\hline D (2) & Viaat-HA-cEPOR-IRES-Venus-frtAmpRfrt & Pmel & 3 & $125.657,46.234,38.401$ \\
\hline
\end{tabular}

Figure 25: Cloning Step 10 - Recombineering. (A,B) Circular illustration of Viaat-HA-CEPOR-frtAmpRfrt and Viaat-HA-CEPOR-IRES-Venus-frtAmpRfrt. (C) PFGE visualizing the restriction fragments of 6 clones (\#1-6) of Viaat-HA-CEPOR-frtAmpRfrt (1) and Viaat-HA-CEPOR-IRES-Venus-frtAmpRfrt (2) after digestion with Pacl. The BAC RP23-392P11 (C) serves as a control to compare the new fragment sizes. Fragment sizes that change through recombineering are marked with a red arrowhead. (D) PFGE of the restrictions fragments of 6 clones (\#1-6) of Viaat-HA-CEPOR-frtAmpRfrt (1) and Viaat-HA-cEPOR-IRES-Venus-frtAmpRfrt (2) after digestion with Pmel. The BAC RP23-392P11 (C) serves as a control to compare the new fragment sizes. (E) Table presenting construct and fragment sizes after cutting with the respective restriction enzymes. Fragment sizes, which have changed by successful recombineering, are marked in red. Midrange I PFG Marker was used as size standard. 


\subsubsection{Step 11 - Excision of the AmpR gene}

The last modifying step of the BAC was the excision of the AmpR gene. For this, clone \#5 and \#6 of Viaat-HA-CEPOR-frtAmpRfrt and clone \#2 and \#4 of Viaat-HA-CEPOR-IRES-VenusfrtAmpRfrt were amplified and grown in the presence of arabinose to induce the excision. The new BACs were digested with Pacl and separated by PFGE (Figure 26A). With a successful excision, the fragment $17.211 \mathrm{~kb}$ is reduced to $16.049 \mathrm{~kb}$ in the case of Viaat-HACEPOR, and the fragment $18.735 \mathrm{~kb}$ is reduced to $17.573 \mathrm{~kb}$ in the case of Viaat-HA-CEPORIRES-Venus (Figure 26A and D, in red). All clones showed the predicted fragment sizes.
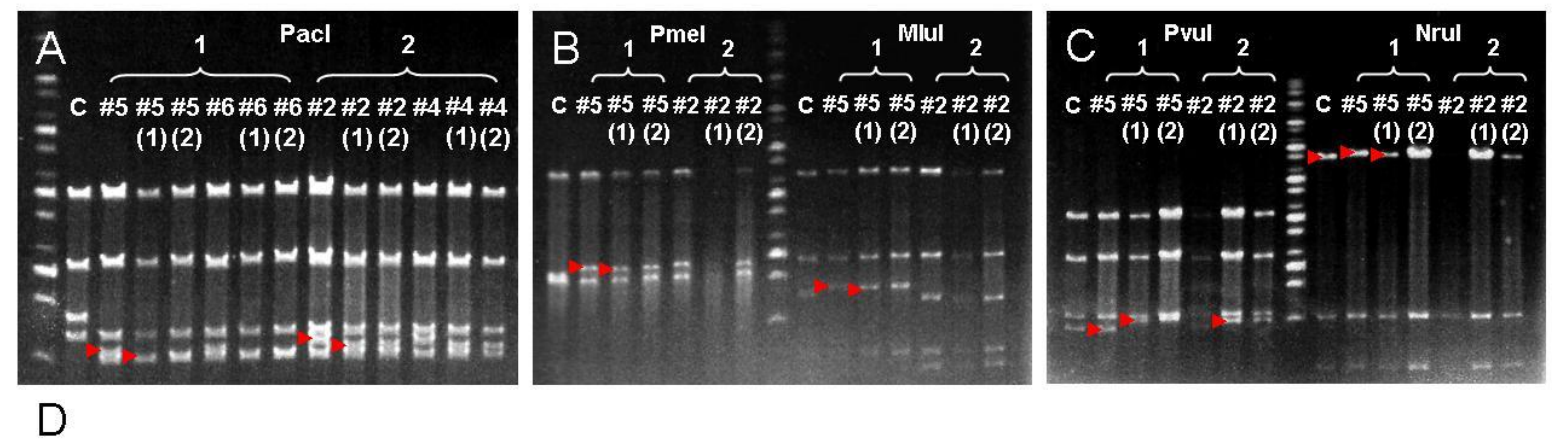

\begin{tabular}{|c|c|c|c|c|}
\hline & BAC & Enzyme & Frequency & Fragment size (kb) \\
\hline$A \# 5, \# 6(1,2)$ & Viaat-HA-CEPOR & Pacl & 5 & $99.001,55.747,20.900,>16.049,15.909$ \\
\hline$A \# 2, \# 4(1,2)$ & Viaat-HA-CEPOR-IRES-VenUS & Pacl & 5 & $99.001,55.747,20.900,>17.573,15.909$ \\
\hline $\mathrm{B}(\mathrm{C})$ & $R P 23-392 P 11$ & Pmel & 3 & $125.657,40.823,38.401$ \\
\hline $\mathrm{B} \# 5$ & Viaat-HA-cEPOR-frtAmpRfit & Pmel & 3 & $125.657,-44.710,38.401$ \\
\hline $\mathrm{B} \# 2(1,2)$ & Viaat-HA-CEPOR-IRES-Venus & Pmel & 3 & $125.657,45.072,38.401$ \\
\hline $\mathrm{B}(\mathrm{C})$ & $R P 23-392 P 11$ & Mlul & 4 & $121.026,48.781,25.106,9.968$ \\
\hline $\mathrm{B} \# 5$ & Viaat-HA-CEPOR-frtAmpRfrt & Mlul & 4 & $121.026,48.781,>28.993,9.968$ \\
\hline $\mathrm{B} \# 5(1,2)$ & Viaat-HA-CEPOR & Mlul & 4 & $121.026,48.781,>27.831,9.968$ \\
\hline $\mathrm{B} \# 2$ & Viaat-HA-CEPOR-IRES-Venus-frtAmpRfrt & Mlul & 5 & $121.026,48.781,22.037,9.968,8.480$ \\
\hline $\mathrm{C} \# 2$ & Viaat-HA-CEPOR-IRES-Venus-frtAmpRfrt & Pvul & 8 & $107.659,62.229,17.399,14.678,4.148,3.069,2.655,2.603$ \\
\hline $\mathrm{C} \# 2(1,2)$ & Viaat-HA-CEPOR-IRES-VenUS & Pvul & 7 & $107.659,62.229,17.399,>16.119,4.148,3.069,2.655$ \\
\hline$C(C)$ & $R P 23-392 P 11$ & Nrul & 3 & $181.421,16.187,7.273$ \\
\hline $\mathrm{C} \# 5$ & Viaat-HA-CEPOR-frtAmpRfit & Nrul & 3 & $185.308,16.187,7.273$ \\
\hline$C \# 5(1,2)$ & Viaat-HA-CEPOR & Nrul & 3 & $>184.146,16.187,7.273$ \\
\hline $\mathrm{C} \# 2$ & Viaat-HA-CEPOR-IRES-Venus-frtAmpRfrt & Nrul & 3 & $186.832,16.187,7.273$ \\
\hline $\mathrm{C} \# 2(1,2)$ & Viaat-HA-CEPOR-IRES-Venus & Nrul & 3 & $185.670,16.187,7.273$ \\
\hline
\end{tabular}

Figure 26: Cloning Step 11 - Excision of the AmpR gene. (A) PFGE of the restriction fragments of Viaat-HAcEPOR clones \#5 $(1,2)$ and \#6 $(1,2)$ and Viaat-HA-cEPOR-IRES-Venus clones \#2 $(1,2)$ and \#4 $(1,2)$ after digestion with Pacl. The BAC RP23-392P11 (C) and the clones before excision (\#5, \#6, \#2, \#4) serve as controls to compare the new fragment sizes. (B) PFGE of the restriction fragments of Viaat-HA-cEPOR clones \#5 $(1,2)$ and Viaat-HA-CEPOR-IRES-Venus clones \#2 $(1,2)$ after digestion with Pmel and Mlul. The BAC RP23-392P11 (C) and the clones before excision $(\# 5, \# 2)$ serve as controls to compare the new fragment sizes. (C) PFGE showing the restriction fragments of Viaat-HA-CEPOR clones \#5 $(1,2)$ and Viaat-HA-CEPOR-IRES-Venus clones \#2 $(1,2)$ after digestion with Pvul and Nrul. The BAC RP23-392P11 (C) and the clones before excision (\#5, \#2) serve as controls to compare the new fragment sizes. (D) Table presenting the constructs and their fragment sizes after cutting with the respective restriction enzymes. Fragment sizes, which have changed by successful recombineering, are marked in red. Midrange I PFG Marker was used as size standard. 
The correct configuration of the BAC clones was confirmed by additional diagnostic digests before using them for microinjection. The digestions with Pacl and Mlul (Figure 26B, D, in red) gave no clearly visible differences of the fragment sizes before and after excision).

In contrast, the Pvul digest showed a clear difference in fragment sizes (Figure 26C and D). By excision of $A m p R$ the BAC one cutting site for Pvul is lost and the fragment of $14.678 \mathrm{~kb}$ increases to $17.644 \mathrm{~kb}$ for Viaat-HA-CEPOR and the fragment of $14.678 \mathrm{~kb}$ increases to $16.119 \mathrm{~kb}$ for Viaat-HA-CEPOR-IRES-Venus (Figure 26C and D, highlighted in red). The last digestion was the digestion with Nrul (Figure 26C and D), which was to be used in the next step to linearize the BAC for microinjection. The digestion also showed correct fragment numbers and sizes for clone \#5(1) for Viaat-HA-EPOR and for clone \#2(1) for Viaat-HA-EPORIRES-Venus. These clones were chosen and prepared for pronuclear injection.

\subsubsection{Step 12 - Linearization and purification of the BAC for pronuclear injection}

The BACs Viaat-HA-EPOR clone \#5(1) and Viaat-HA-EPOR-IRES-Venus clone \#2(1) were amplified, isolated, and digested with Nrul. Nrul does not only linearize the constructs, but also releases the backbone pBACe3.6. The linearized construct was separated and purified on a self-made sepharose column. Fractions of approximately $200 \mu \mathrm{l}$ were collected and $25 \mu \mathrm{l}$ of the fractions with the highest DNA amount were separated by PFGE (Figure 27). The early fractions 13 - 19 of Viaat-HA-EPOR and fractions 9 - 15 of Viaat-HA-EPOR-IRES-Venus contained visible amounts of the backbone (Figure 27A and B, red arrowheads) and were not used for microinjection. Fraction 20 of Viaat-HA-EPOR and fraction 16 of Viaat-HA-EPORIRES-Venus showed clean bands of $184.146 \mathrm{~kb}$ or $185.670 \mathrm{~kb}$ (Figure 27, framed fractions) and no visible backbone contamination.

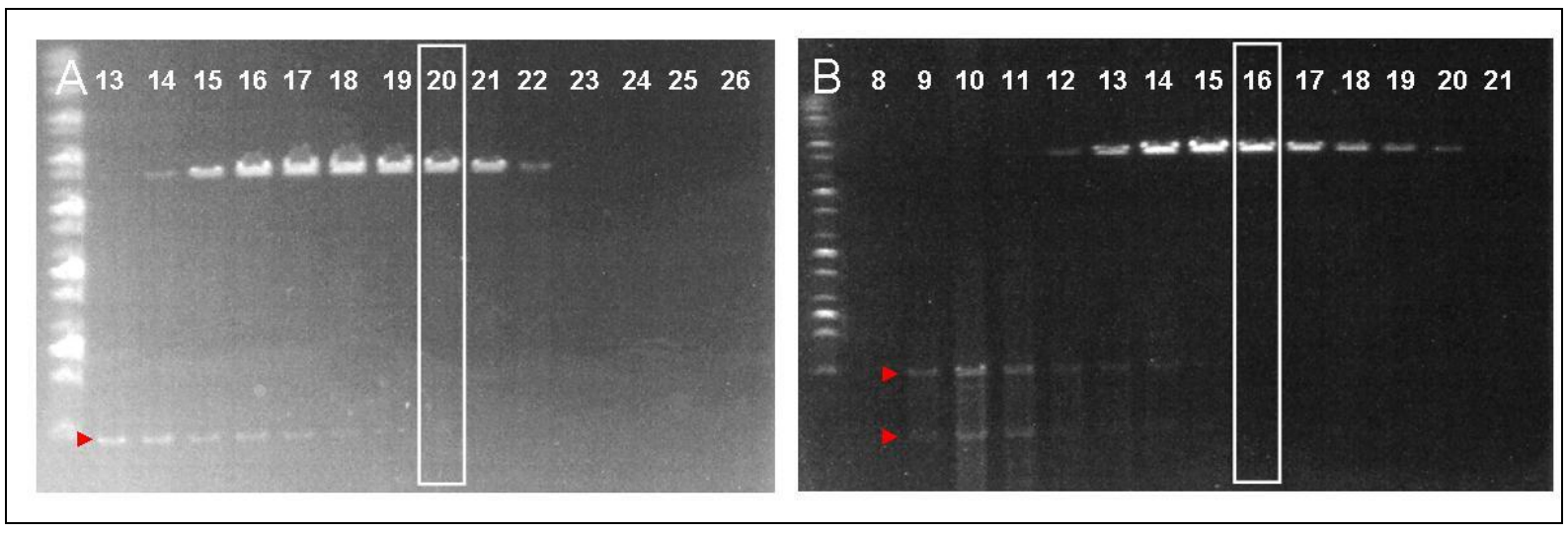

Figure 27: Cloning Step 12 - Linearization and purification of the BAC for pronuclear injection. (A) PFGE showing fraction 13-26 of Nrul linearized Viaat-HA-EPOR. (B) PFGE showing fraction 8-21 of Nrul linearized Viaat-HA-EPOR-IRES-Venus. Framed are the fractions chosen for pronuclear injection. Midrange I PFG Marker was used as size standard. 
These fractions were spectrophotometically analyzed and they passed the quality requirements with concentrations of $5.1 \mu \mathrm{g} / \mathrm{ml}$ and $5.4 \mu \mathrm{g} / \mathrm{ml}$ and $\mathrm{OD}_{260 / 280}$ ratios of 1.73 and 1.82. The fractions were diluted to $1 \mu \mathrm{g} / \mathrm{ml}$ and used for pronuclear injection. Step 12 was repeated three times to deliver fresh DNA for the different injection dates (pictures and data not shown). The DNA was injected into fertilized eggs that were re-implanted into the oviducts of pseudopregnant females (foster mothers). The offspring was genotyped to identify transgenic animals. 


\section{Results part II}

\subsection{Analysis of Viaat-HA-cEPOR \pm IRES-Venus mouse lines}

\subsubsection{Identification of transgenic offspring by genotyping PCR - F0 generation}

The offspring of all foster mothers were genotyped with the primer pair 25763/25764, which binds in the polyA signal sequence of the construct (Figure 28), and a primer pair for IL-2 as internal control. The animals positive for the transgene were then genotyped with three additional primer pairs. Primer pair 26857/26958 is located in the $5^{\prime}$ UTR and provides information if the complete Viaat promoter has integrated. Primer pair 2521/24016 is located in the IRES-Venus sequence and can be used to distinguish between the two types of transgenic animals. Primer pair 26859/26860 is located in the bacterial backbone pBACe3.6, which should have been removed by the Nrul digestion, and if this was successful, the PCR result would be negative.

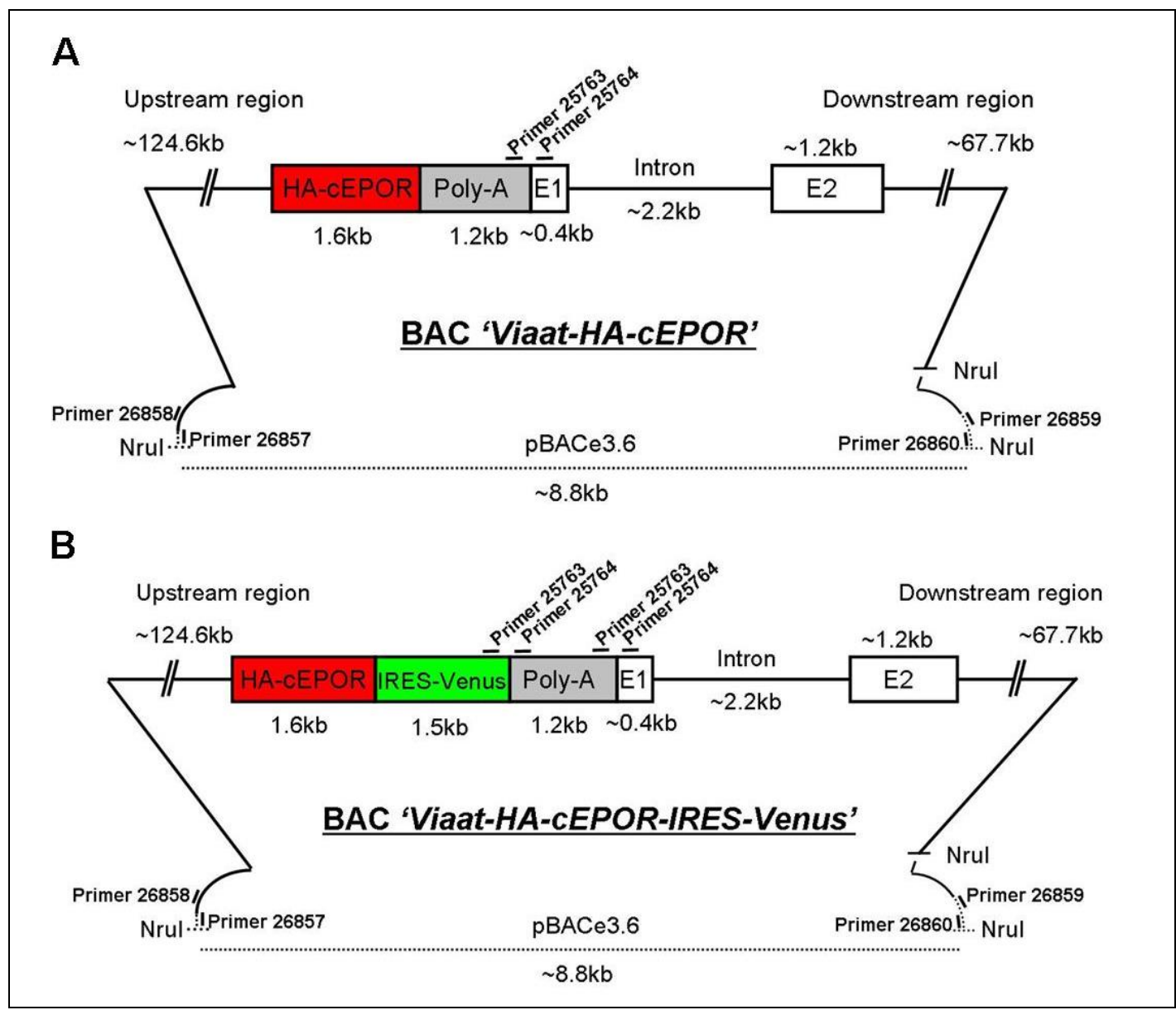

Figure 28: Illustration of the BAC constructs used for pronuclear injection. (A) Viaat-HA-CEPOR (B) Viaat-HACEPOR-IRES-Venus. Bacterial backbone pBACe3.6, which should have been removed by Nrul digestion, illustrated by dotted line. 
From 57 Viaat-HA-cEPOR pubs, six animals carried the transgene and showed a PCR product of $410 \mathrm{bp}$ with the primer pair $25763 / 25764$ (Figure 29). The mouse identification numbers (IDs) were D14-0023, D14-0028, D14-0034, D14-0044, D14-0053 and D14-0055. From 87 Viaat-HA-cEPOR-IRES-Venus pubs, another six animals were positive for the transgene with the following mouse IDs D13-0062, D13-0069, D13-0085, D13-0091, D13-0096 and D130099. All founders ( $F_{0}$ animals positive for the transgene) included the complete $5^{\prime}$ Viaat promoter, as shown by the PCR product of $751 \mathrm{bp}$ with the primer pair $26857 / 26958$. As expected, all Viaat-HA-CEPOR transgenic animals were negative for IRES-Venus, whereas all transgenic Viaat-HA-CEPOR-IRES-Venus animals contained the gene for the fluorescent marker, as indicated by the PCR product of 615 bp with the primer pair $2521 / 24016$. Some founders were not only positive for the construct but also for the bacterial backbone pBACe3.6, as demonstrated by the PCR product of 260 bp with the primer pair 26859/26860.

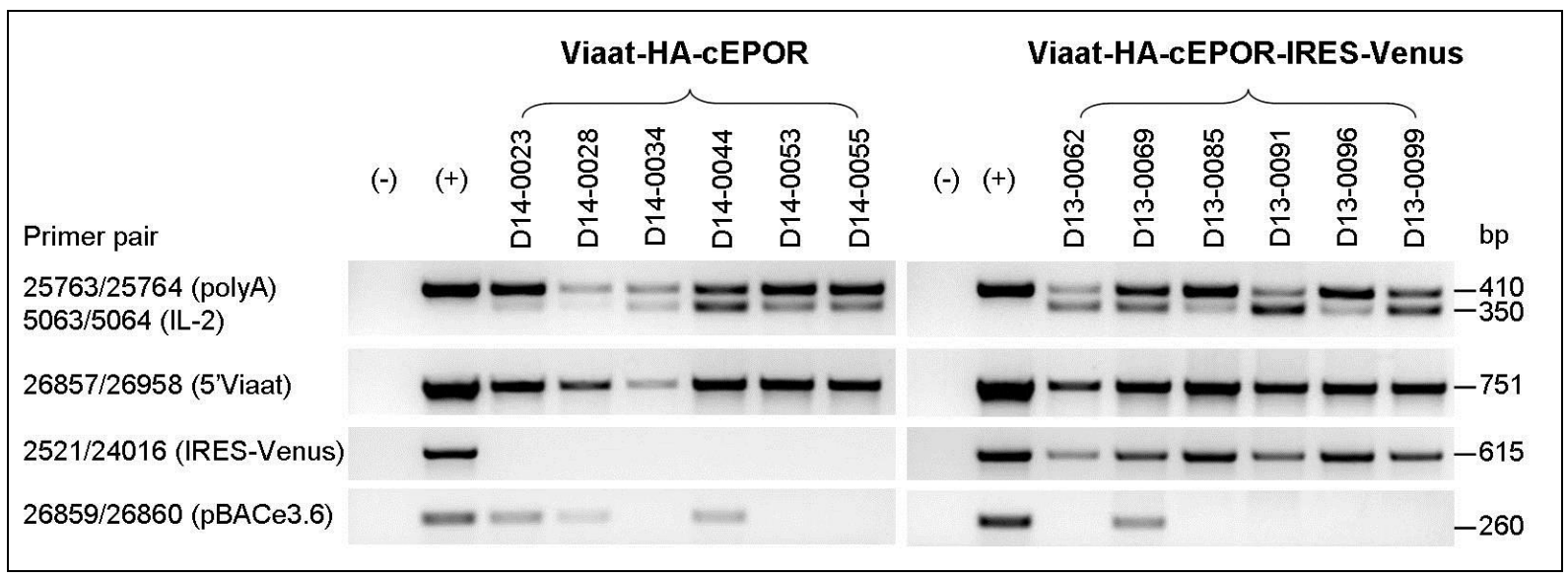

Figure 29: Inverted agarose gel pictures showing the products of the genotyping PCR of the transgenic $F_{0}$ generation (founders).

It is well known that the generation of transgenic animals with pronuclear injection has some limitations (Ohtsuka et al., 2012). The injected DNA gets integrated at random locations into the genome, is integrated with different copy numbers, and may even be integrated at multiple sites into the genome. The first hint of different copy numbers integrated, was given by the genotyping PCR with the primer pairs 25763/25764 and 5063/5064 (Figure 29). Compared to the PCR product of IL-2, which can be seen as an endogenous housekeeper, the transgenic PCR product varies; e.g. founder D14-0023 showed for example a much higher amount of the transgenic product compared to the PCR product of IL-2, and D14-0044 had approximately equal amounts of the PCR products. The product intensities were further evaluated densitometrically using Fiji and the ratios are shown in Figure 30. Thus, founder D14-0023, D14-0028, D13-0085 and D13-0096 seemed to have the 
highest copy number and D13-0062, D13-0091 and D13-0099 only a low copy number integrated. All mice with lower or comparable band strength compared to IL-2 were marked with one $\operatorname{star}\left({ }^{*}\right)$, mice with stronger construct PCR products compared to IL-2 were marked

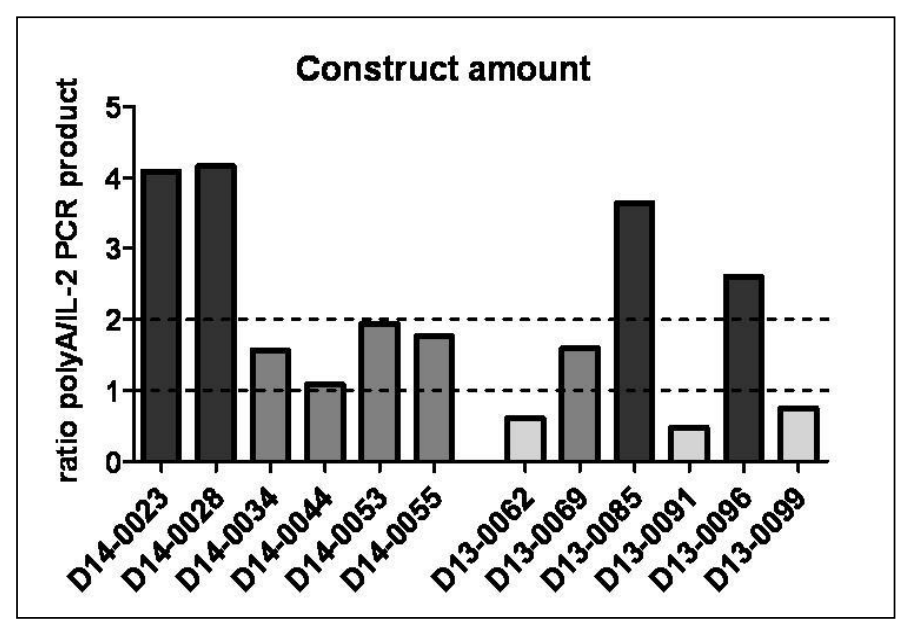
with two stars $(* *)$. However, copy number is not the only factor that influences the amount of transgene expression. In addition, the integration location plays a role and can result in varying transgene expression levels.

Figure 30: Ratio of PCR products (polyA/IL-2) of the transgenic $F_{0}$ generation.

These variations highlight, why it is important to analyze each founder separately. All founders were bred with C57BL/6N mice to start 12 separate mouse lines. 9 different lines could successfully be established: founder D14-0034 was not fertile, D14-0044 had not enough transgenic offspring to establish a mouse line and D13-0069 had no transgenic offspring at all. From all other founders, it was possible to create a small mouse cohort, which was genotyped and further analyzed. In one mouse line (D14-0023) the $F_{1}$ generation had a very unusual, conspicuously high number of transgenic offspring ( $72 \%$ out of 64 animals). Additionally, their polyA/IL-2 ratio was split into two distinct groups. An exemplary genotyping gel is shown in Figure 31A. Some offspring showed a very strong upper band like the founder animal D14-0023, but there were also some animals having equal intensities compared to IL-2. The relative numbers of these offspring groups are shown in Figure 31B.

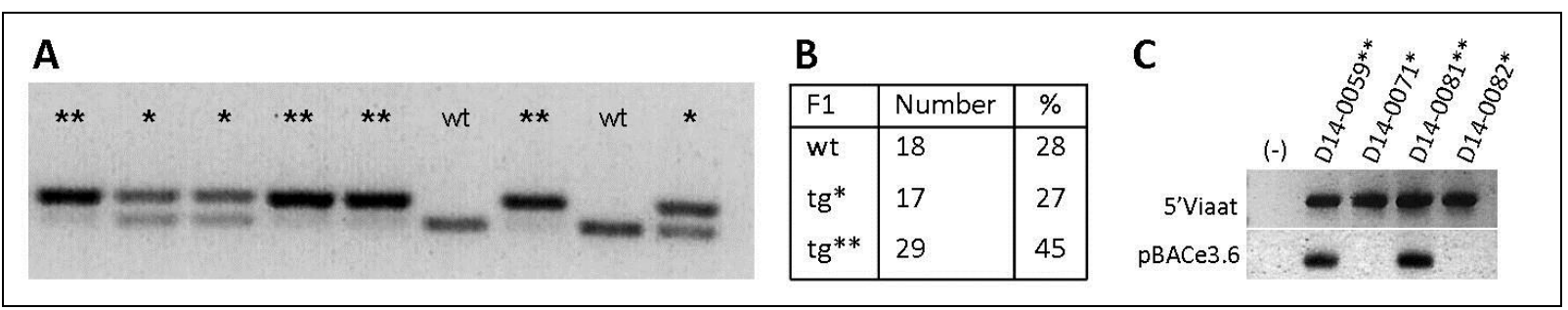

Figure 31: Genotyping of the F1-Generation of the mouse line D14-0023. (A) Inverted agarose gel picture visualizing the genotyping PCR products with the primers 25763/25764 and 5063/5064. Animals with the strong transgenic product are labeled with two stars; animals with equal amounts of both products are labeled with one star. (B) Table of the number and percentages of the $F_{1}$-generation groups. (C) Agarose gel of genotyping with the $5^{\prime}$ Viaat and pBACe 3.6 primers for $\operatorname{tg}^{*}$ and $\operatorname{tg}^{* *}$ animals. 
These results led to the conclusion that the construct had been integrated into two different chromosomes (for illustration see Figure 32). Next it was important to know if both chromosomes had integrated the complete 5' promoter region. Animals with high and low copy numbers were genotyped with the 5' Viaat primer pair 26857/26958 and both groups had the complete 5' Viaat promoter integrated (Figure 31C). Additionally, all animals were genotyped for the backbone with the primer pair 26859/26860. Interestingly, the animals with the low copy number showed no band for the backbone (Figure 31C). Therefore, it is possible to distinguish between animals with the low copy number $\left({ }^{*}\right)$ and with the high copy number $\left({ }^{* *}\right)$ via PCR. Unfortunately, it is not possible to detect if high copy number animals are also carrier of the low copy number chromosome.

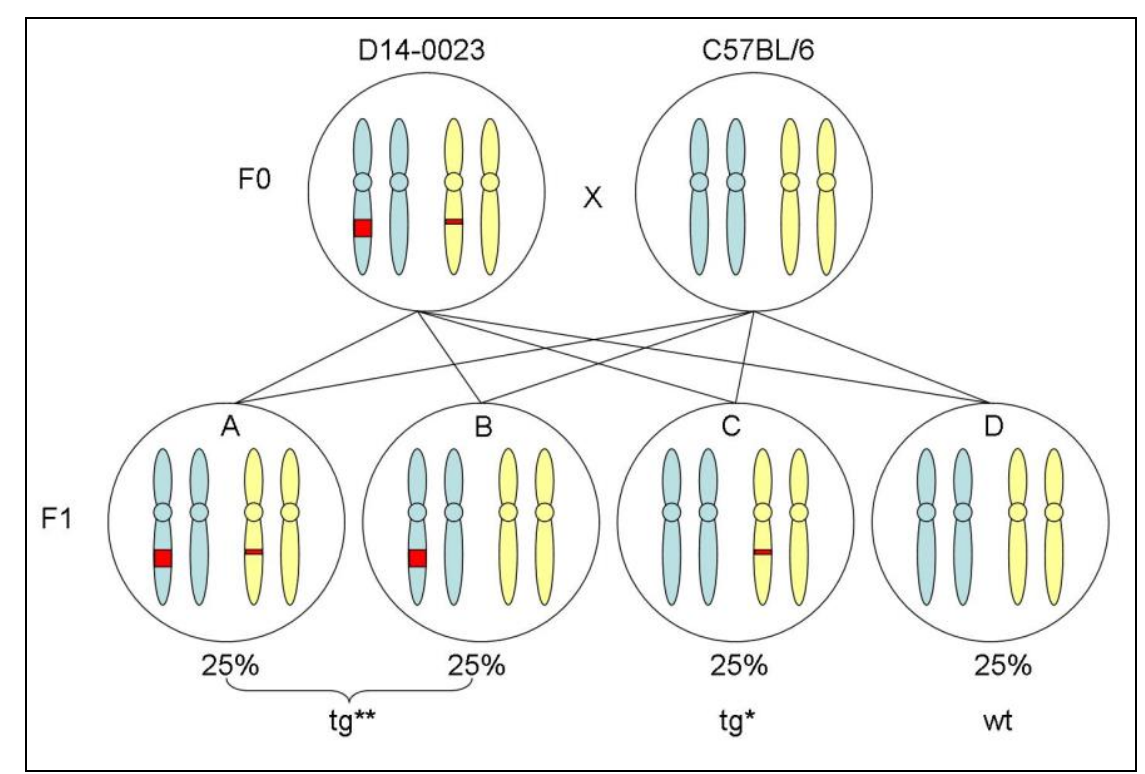

Figure 32: Illustration of the construct integration in 2 chromosomes (line D14-0023) and the $F_{1}$ segregation when $\mathrm{F}_{0}$ is bred to wt $\mathrm{C57BL/6N}$.

\subsubsection{Analysis of the construct expression by immunohistochemistry}

As for the alpha-CaMKII-HA-cEPOR mice, the detection of the construct expression by immunohistochemistry was rather difficult. Three different staining methods were tested in the mouse line D13-0085 with primary antibodies against HA and GFP (IRES-Venus). The methods used were (I) a common indirect fluorescent staining method, (II) a biotinstreptavidin enhanced indirect fluorescent staining method, and (III) an ABC/TSA enhanced indirect fluorescent staining method. With the primary anti-GFP antibody, weakly positive cells were found by methods I and II (Figure 33A', B'). 


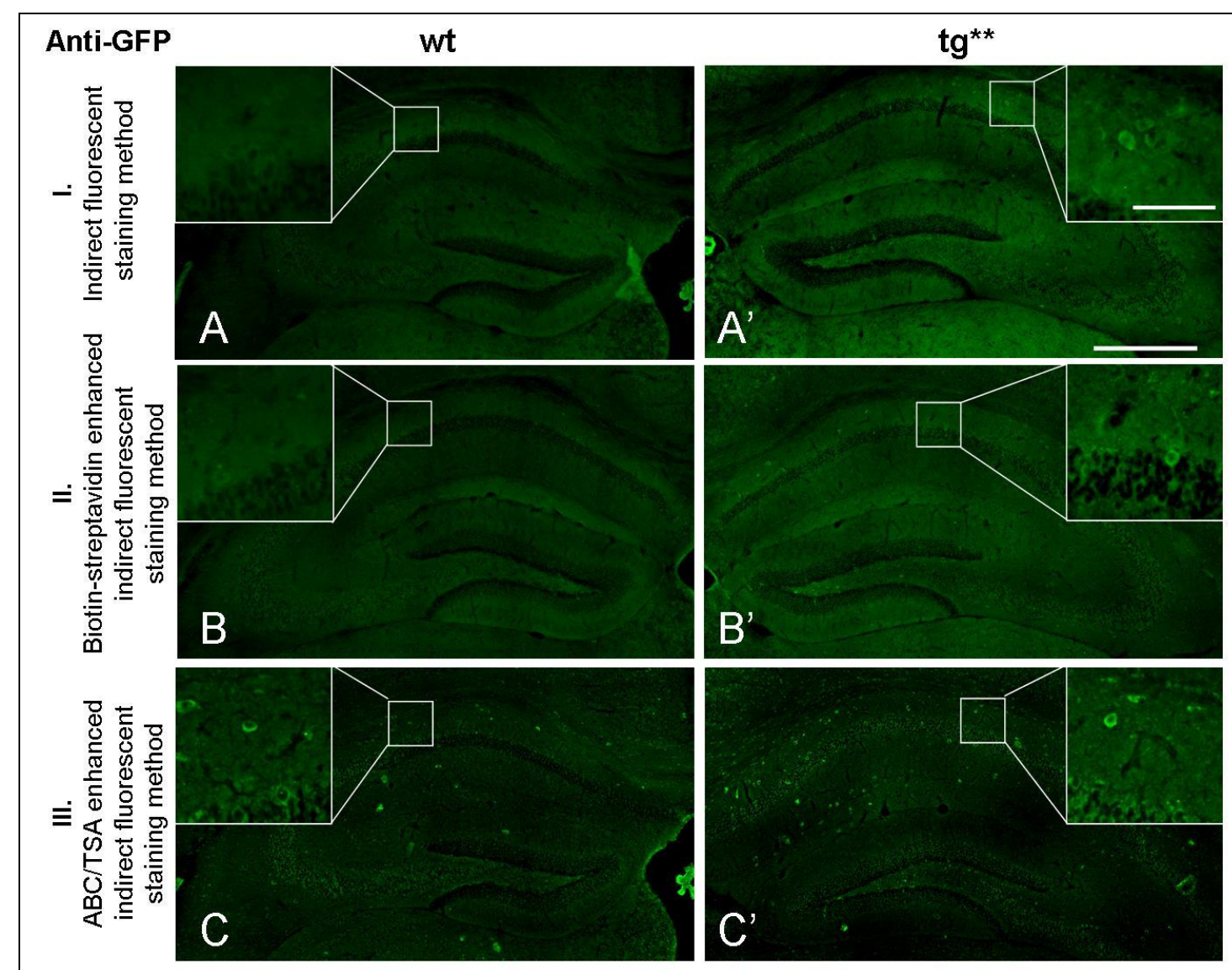

\section{Anti-HA}
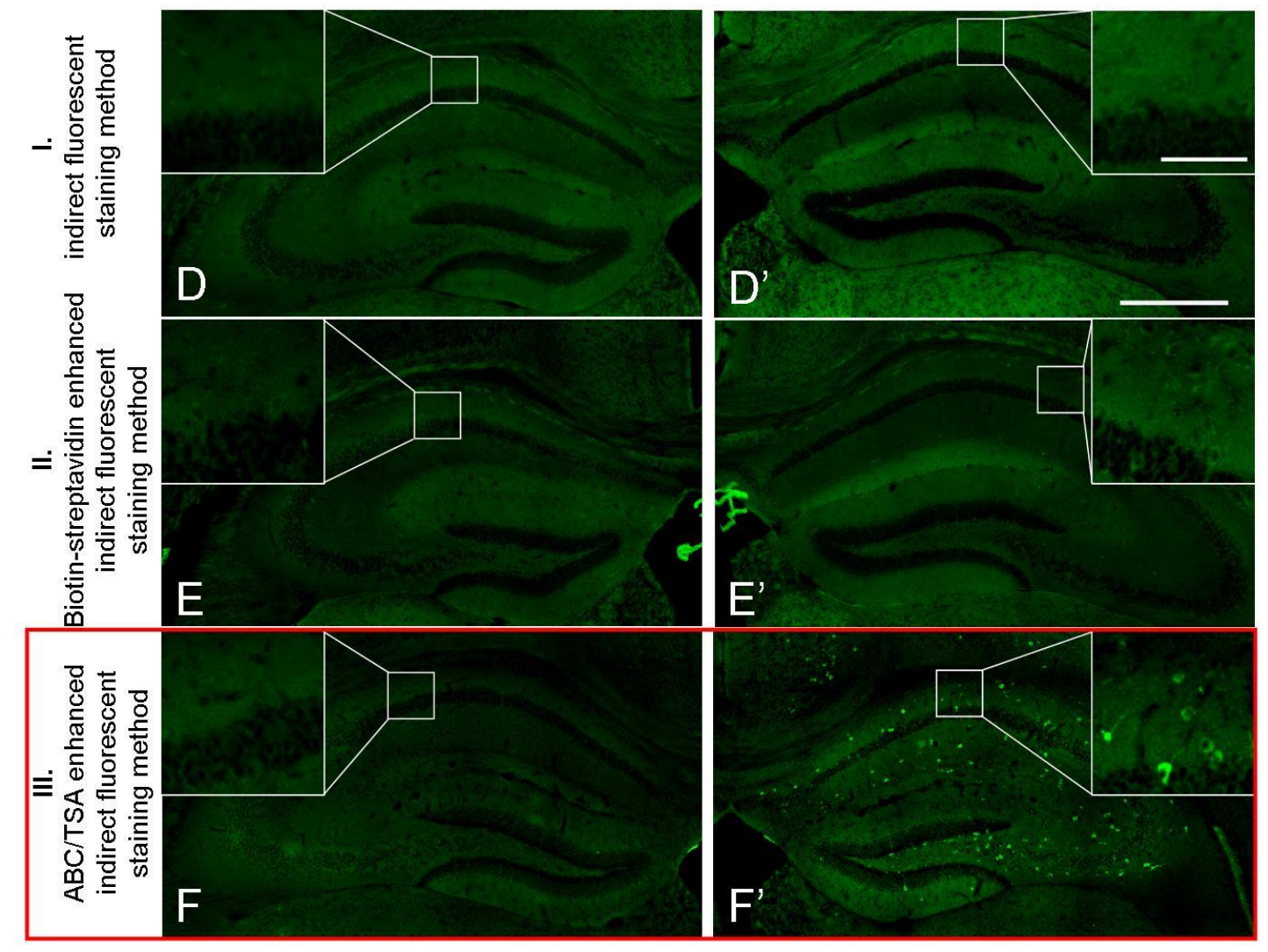

Figure 33: Fluorescent immunohistochemistry of the mouse line D14-0085 with the primary antibodies antiGFP (A-C) and anti-HA (D-F) using different staining methods. The staining method giving the best result is framed in red (F, $\left.F^{\prime}\right)$ and was used for the following experiments. Scale bar: $500 \mu \mathrm{m}$ (insert: $100 \mu \mathrm{m}$ ). 
The staining increased if method III was used with the anti-GFP antibody, but there were also false positive cells in the wt animal (Figure $33 \mathrm{C}, \mathrm{C}^{\prime}$ ). In contrast, the primary antibody against HA showed no false positive cells in all three staining methods (Figure 33D, E, F) and with the $A B C / T S A$ enhanced staining method many positive cells could be visualized (Figure 33F'). Therefore this method was used for the following experiments.

To compare the expression in the different mouse lines, coronal sections of 4-6 week old animals were double stained against the HA-tag and the GABAergic marker parvalbumin. Parvalbumin is expressed in a subpopulation of interneurons and was used to confirm the expression in the correct cell type. For illustration, the CA3 area of the hippocampus was chosen. In the first run, the wt, $\operatorname{tg}^{*}$ and $\operatorname{tg}^{* *}$ animals of line D14-0023 were stained against the HA-tag (red) and parvalbumin (green) (Figure 34). The tg* animal showed less HA-tag positive cells compared to $\mathrm{tg}^{* *}$ animal. In both mice, colocalization of HA and parvalbumin could be shown (arrows). In the wt, no HA-tag positive cells were detectable, confirming again the specificity of the antibody.

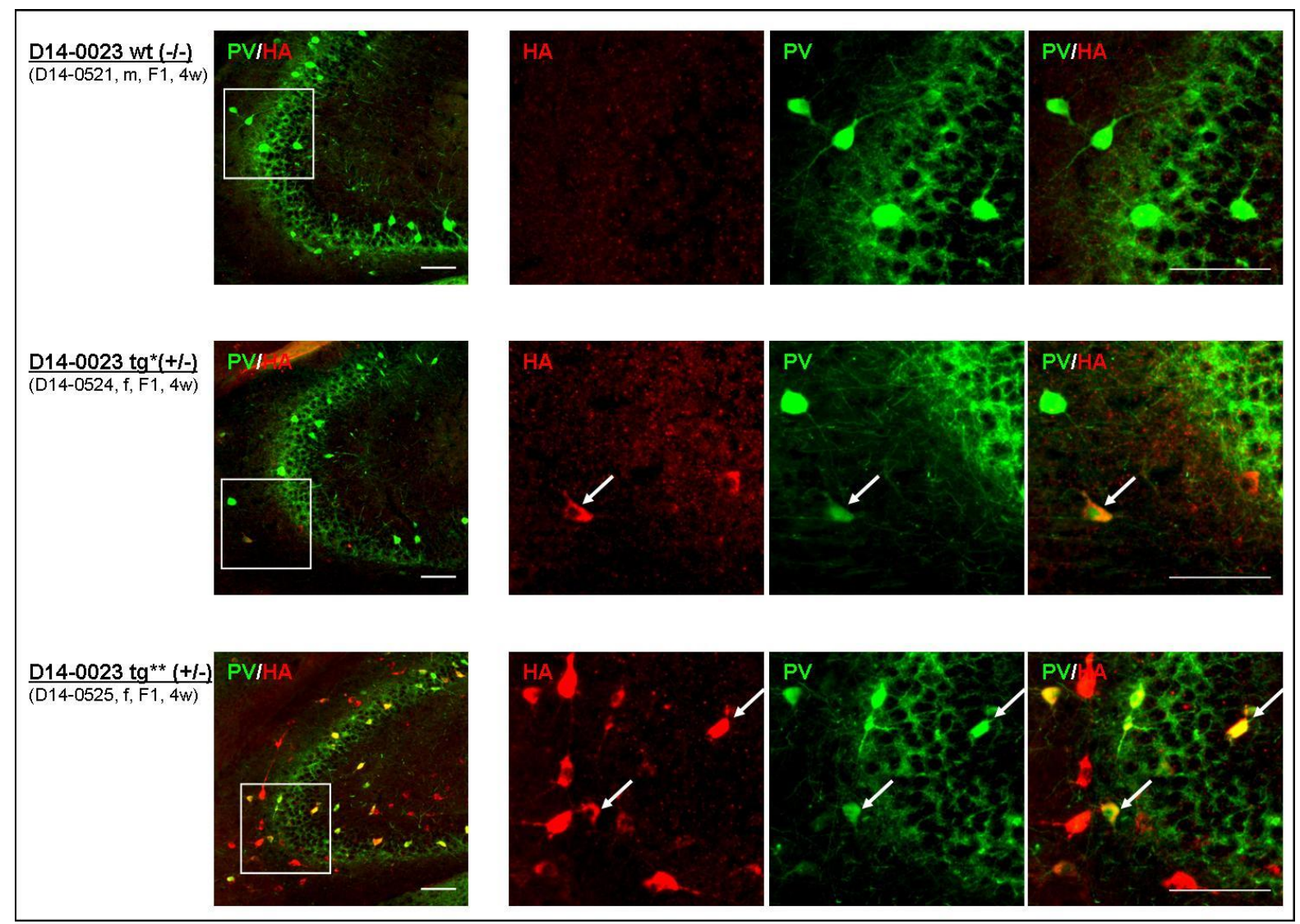

Figure 34: Fluorescent immunohistochemistry of the mouse line D14-0023 showing interneurons in the CA3 region of the hippocampus positive for the construct (HA-tag in red) and parvalbumin (green). Colocalized cells appear in yellow (arrows). Scale bar: $100 \mu \mathrm{m}$. 
Even though we were especially interested in mouse line D14-0023, all other mouse lines were also analyzed by immunohistochemistry for construct expression (Figure 35, Figure 36). In the second run, the Viaat-HA-CEPOR lines D14-0028, D14-0053, and D14-0055 were analyzed (Figure 35). All three mouse lines showed a robust transgene expression and positive cells were colocalized with parvalbumin positive cells. Although the strongest transgene expression had been observed in mouse line D14-0055, this mouse line was excluded from further analysis because of poor breeding performance.

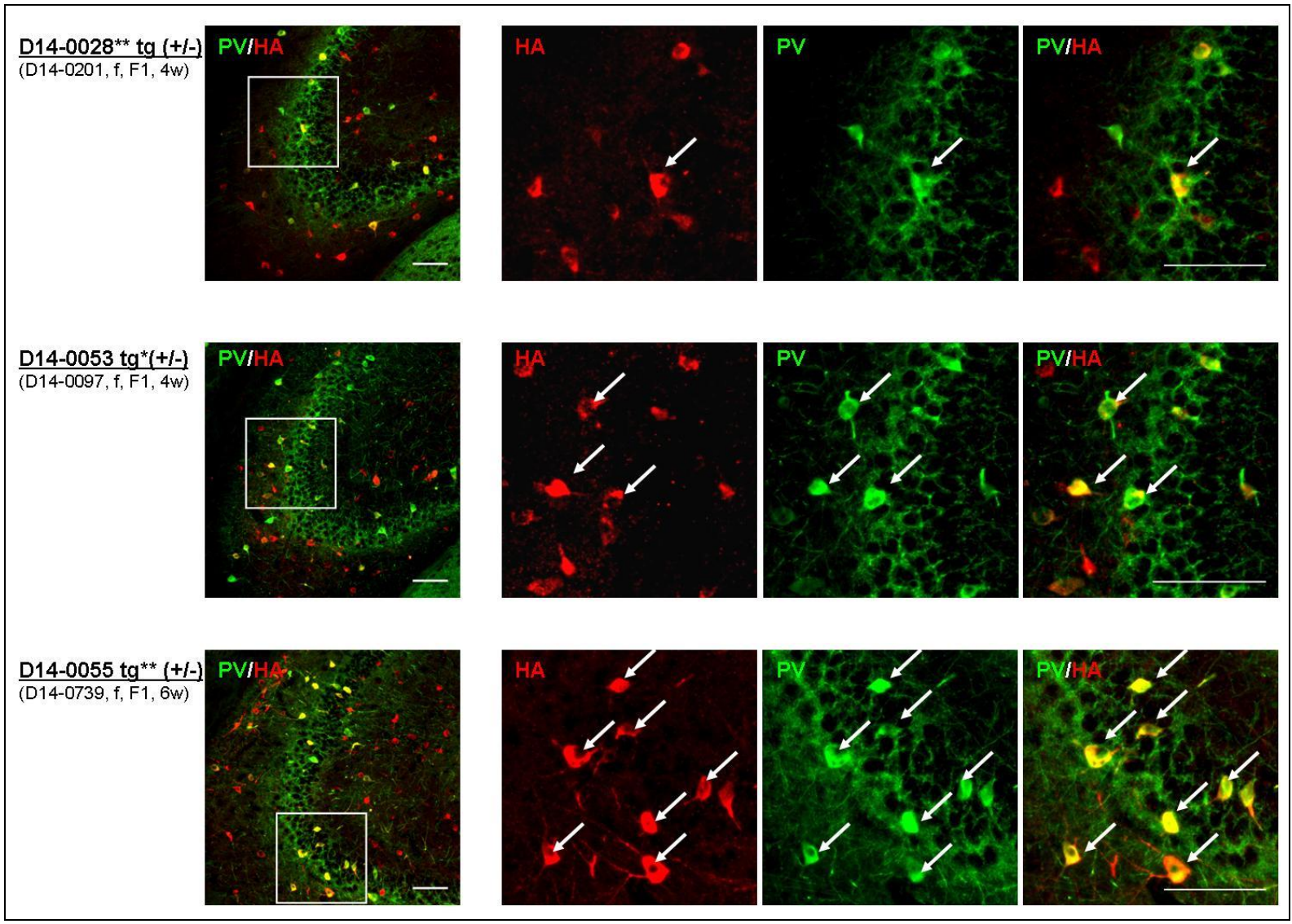

Figure 35: Fluorescent immunohistochemistry of the mouse lines D14-0028, D14-0053, and D15-0055 showing interneurons in the CA3 region of the hippocampus positive for the construct (HA-tag in red) and parvalbumin (green). Colocalized cells appear in yellow (arrows). Scale bar: $100 \mu \mathrm{m}$.

In the third run, the Viaat-HA-CEPOR-IRES-Venus mouse lines were analyzed. The transgene expression varied considerably in these mouse lines. For mouse line D13-0062, it was not possible to detect any construct expression (two transgenic animals analyzed). Mouse lines D13-0085 and D13-0096 had a robust transgene expression, D13-0091 showed a weaker expression, and D13-0099 had only a few weakly stained positive cells and almost no colocalization with parvalbumin positive cells. All together, the staining against the HA-tag was in accordance with the copy number analysis by PCR. On average, the tg* lines showed 
less positive cells and a lower expression compared to $\mathrm{tg}^{* *}$ lines. However, it is not clear if the $\mathrm{tg}^{*}$ lines have truly less cells expressing the construct or if the expression is below the detection limit of the used staining procedure.

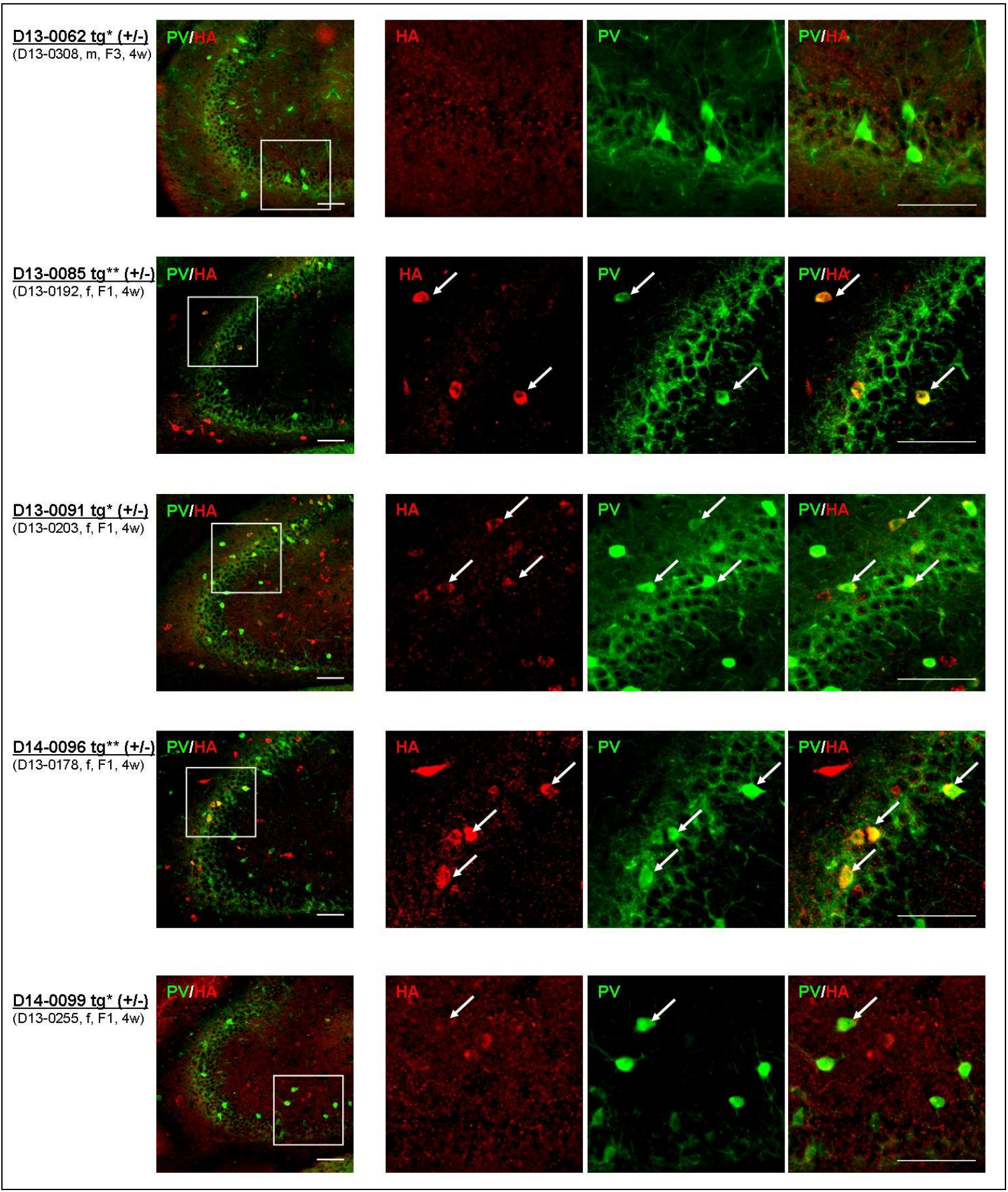

Figure 36: Fluorescent immunohistochemistry of the mouse lines D13-0062, D13-0085, D13-0091, D13-0096, and D13-0099 showing interneurons in the CA3 region of the hippocampus that are positive for the construct (HA-tag in red) and parvalbumin (green). Colocalized cells appear in yellow (arrows). Scale bar: $100 \mu \mathrm{m}$. 


\subsubsection{Summary of all mouse lines}

The characterization of all mouse lines is summarized in Table 3 . This table includes the breeding performance, the relative amount of integrated construct copy number, the integration of the backbone, the construct expression and the information on whether the line was preserved via cryoconservation (sperm freezing). Line D14-0023 was chosen for further analysis, because of its special feature of having the construct integrated in two different chromosomes with different copy numbers. This allows the analysis of expression level dependent effects of cEPOR. Line D14-0053 would be the second line of choice. This mouse line had a good breeding performance, no backbone integrated, and a robust construct expression. Mouse line D14-0053 could be analyzed to reproduce the most important findings of mouse line D14-0023, however, this is not part of this thesis.

Table 3: Summary of all mouse lines

\begin{tabular}{|c|c|c|c|c|c|c|}
\hline Construct & $\begin{array}{l}\text { Mouse ID } \\
\text { (founder) }\end{array}$ & $\begin{array}{c}\text { Breeding } \\
\text { performance }\end{array}$ & $\begin{array}{c}\text { PCR integration } \\
\text { level }\end{array}$ & $\begin{array}{c}\text { backbone } \\
\text { (pBACe3.6) }\end{array}$ & $\begin{array}{c}\text { Construct expression } \\
\left(\mathrm{F}_{1} \text { generation }\right)\end{array}$ & Cryoconservation \\
\hline Viaat-HA-CEPOR & D14-0023 & good & $* * / *$ & $+/-$ & $* * / *$ & + \\
\hline Viaat-HA-CEPOR & D14-0028 & good & $* *$ & + & $* *$ & + \\
\hline Viaat-HA-CEPOR & D14-0034 & no offspring & * & - & no animals & - \\
\hline Viaat-HA-cEPOR & D14-0044 & very poor & * & + & no animals & - \\
\hline Viaat-HA-CEPOR & D14-0053 & good & *** & - & $* *$ & + \\
\hline Viaat-HA-CEPOR & D14-0055 & poor & $* *$ & - & ** & + \\
\hline Viaat-HA-CEPOR-IRES-Venus & D13-0062 & good & * & - & no positive staining & - \\
\hline Viaat-HA-CEPOR-IRES-Venus & D13-0069 & no tg offspring & *** & + & no animals & - \\
\hline Viaat-HA-CEPOR-IRES-Venus & D13-0085 & good & *** & - & $* *$ & + \\
\hline Viaat-HA-CEPOR-IRES-Venus & D13-0091 & good & * & - & * & + \\
\hline Viaat-HA-cEPOR-IRES-Venus & D13-0096 & good & $* *$ & - & ** & + \\
\hline Viaat-HA-cEPOR-IRES-Venus & D13-0099 & good & * & - & * & + \\
\hline
\end{tabular}




\subsection{Analysis of mouse line D14-0023 (Viaat-HA-cEPOR)}

\subsubsection{EPOR expression in the brain of D14-0023}

For further analysis of the $F_{2}$ generation, mouse line D14-0023 was used. First the mRNA expression of total EPOR was analyzed by qPCR. The used primer pair cannot distinguish between the endogenous EPOR and the transgenic CEPOR. Therefore, the amount of EPOR as well as cEPOR was detected. Three different brain areas, the hippocampus (HP), the cortex (CX), and the cerebellum (CB) were investigated. As expected, the EPOR (CEPOR) expression was significantly increased in the transgenic mice (Figure 37A). In the CX of $\operatorname{tg}^{*}$ female mice, the expression did not reach significance with $n=3$. In all investigated brain areas, the analysis of the female animals confirmed that the $\operatorname{tg}^{* *}$ mice have a significantly higher construct expression than the tg* mice. In the male animals, the pattern looked similar (Figure 37B).

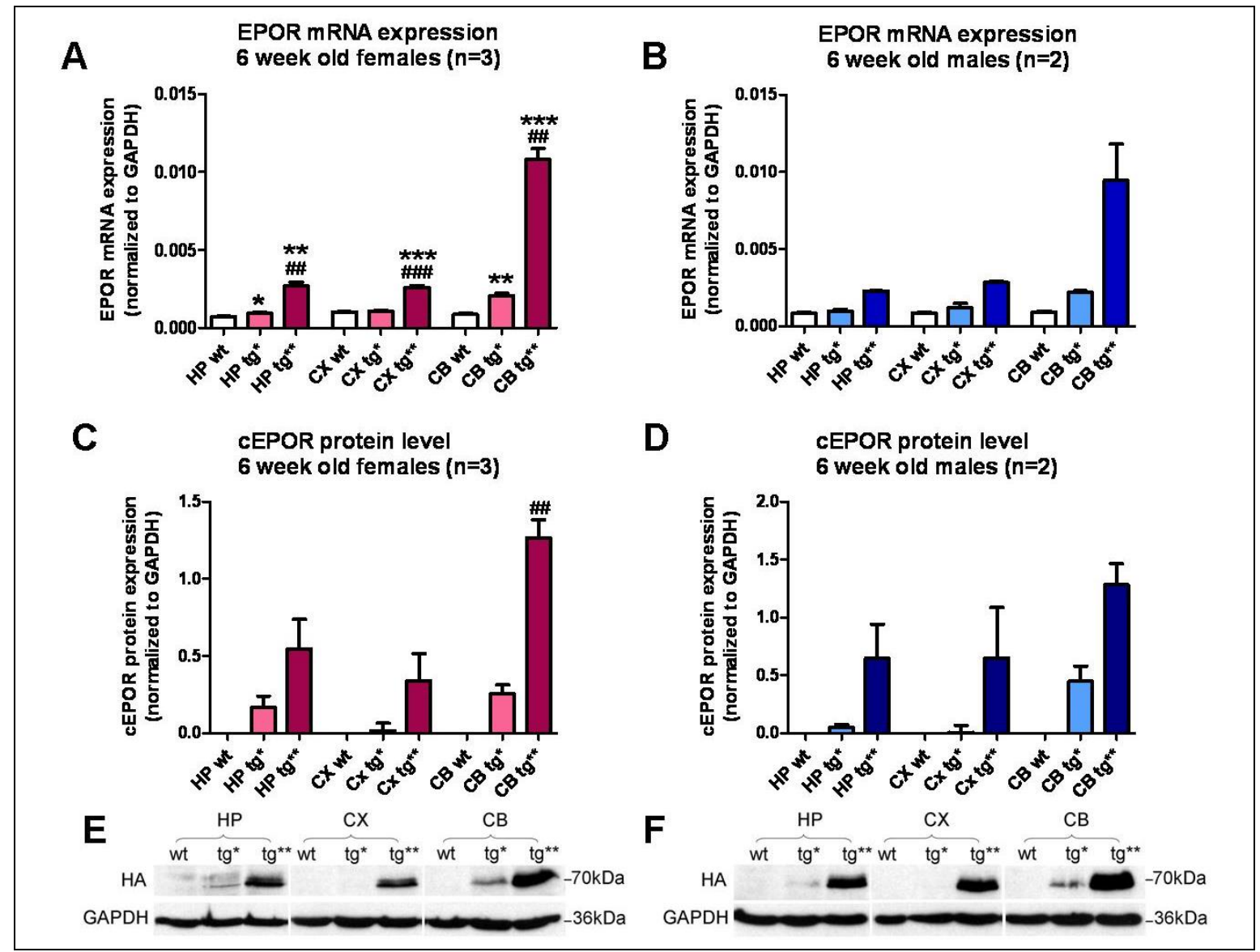

Figure 37: Expression of cEPOR in the hippocampus (HP), cortex (CX) and cerebellum (CB). (A) Bar graph of EPOR mRNA expression in females $(n=3)$. (B) Bar graph of EPOR mRNA expression in males $(n=2)$. (C) Bar graph of cEPOR protein amount in females $(n=3)$. (D) Bar graph of cEPOR protein amount in males $(n=2)$. (E) Example Western blot of cEPOR and GAPDH (female). (F) Example Western blot of cEPOR and GAPDH (male). Mean $\pm S E M$ presented; ${ }^{*} P \leq 0.05,{ }^{*} P \leq 0.01, * * * P \leq 0.001$ (unpaired $t$-test) $\operatorname{tg}^{*}$ and $\mathrm{tg}^{* *}$ of each brain area compared to the respective wt area; ${ }^{\#} \leq 0.05,{ }^{\# \#} \mathrm{P} \leq 0.01,{ }^{\# \#} \mathrm{P} \leq 0.001$ (unpaired $t$-test) tg* of each brain area compared to respective $\operatorname{tg}^{* *}$ are area. 
Additionally, the cEPOR expression was analyzed on the protein level by Western blot (Figure 37C-F). In contrast to the GPCR, the Western blot was specific for CEPOR by using an antibody against the HA-tag. As for the qPCR results, the cEPOR was detectable in the HP, $\mathrm{CX}$, and strongest in the $\mathrm{CB}$ of the $\mathrm{tg}^{* *}$ mice. In the $\mathrm{tg}^{*}$ mice, it was hardly detectable in the $\mathrm{HP}$, not in the $\mathrm{CX}$, and relatively strong in the $\mathrm{CB}$.

\subsubsection{Hematocrit}

To exclude that the expression of cEPOR in GABAergic and glycinergic neurons affects the proliferation and differentiation of erythrocyte precursor cells, the hematocrit was

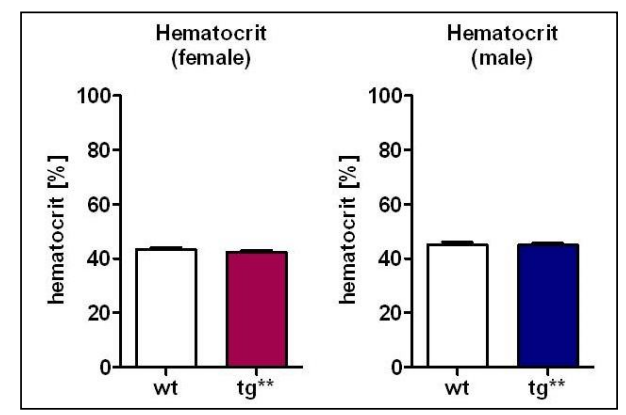

measured. As demonstrated in Figure 38, the hematocrit level of the $\operatorname{tg}^{* *}$ animals does not differ from wt mice.

Figure 38: Level of hematocrit of 6-12 week old female and male mice. Number of animals: female $w t=10, \mathrm{tg}^{* *}=10$; male $\mathrm{wt}=2$, $\operatorname{tg}^{* *}=6$. Mean \pm SEM shown.

\subsubsection{Body weight}

During the behavioral analyses, the body weight was measured regularly (Figure 39). After combining two mouse cohorts, $\operatorname{tg}^{* *}$ females showed a significantly reduced body weight at an age of 28 - 31 weeks (Figure 39C). However, neither the tg* female and male nor the $\mathrm{tg}^{* *}$ male mice showed a significant difference at that age (Figure 39C, F).

\subsubsection{Behavior analysis}

Male and female mice of the $F_{2}$ generation were first analyzed for anxiety-related behavior by elevated plus maze (Figure 40A-C). Laboratory mice exhibit an innate fear of open, unsheltered, and elevated spaces and thus avoid the open arms of an elevated plus-maze. Neither the $\operatorname{tg}^{*}$ nor the $\operatorname{tg}^{* *}$ mice showed differences in the time they spent in the open or closed arm as compared to the wt mice. After the elevated-plus maze, the animals were subjected to the open field test (Figure 40D-F). In this test, the overall activity of the mice is represented by the distance traveled. There were no differences between $\operatorname{tg}^{*}, \mathrm{tg}^{* *}$, and $\mathrm{wt}$ mice. Additionally, anxiety-like behavior (center avoidance) was measured by analyzing the time spent in the center zone of the open field arena. Again, no differences between genotypes could be observed. Furthermore, no differences were observed for the intermediate and peripheral zones. 

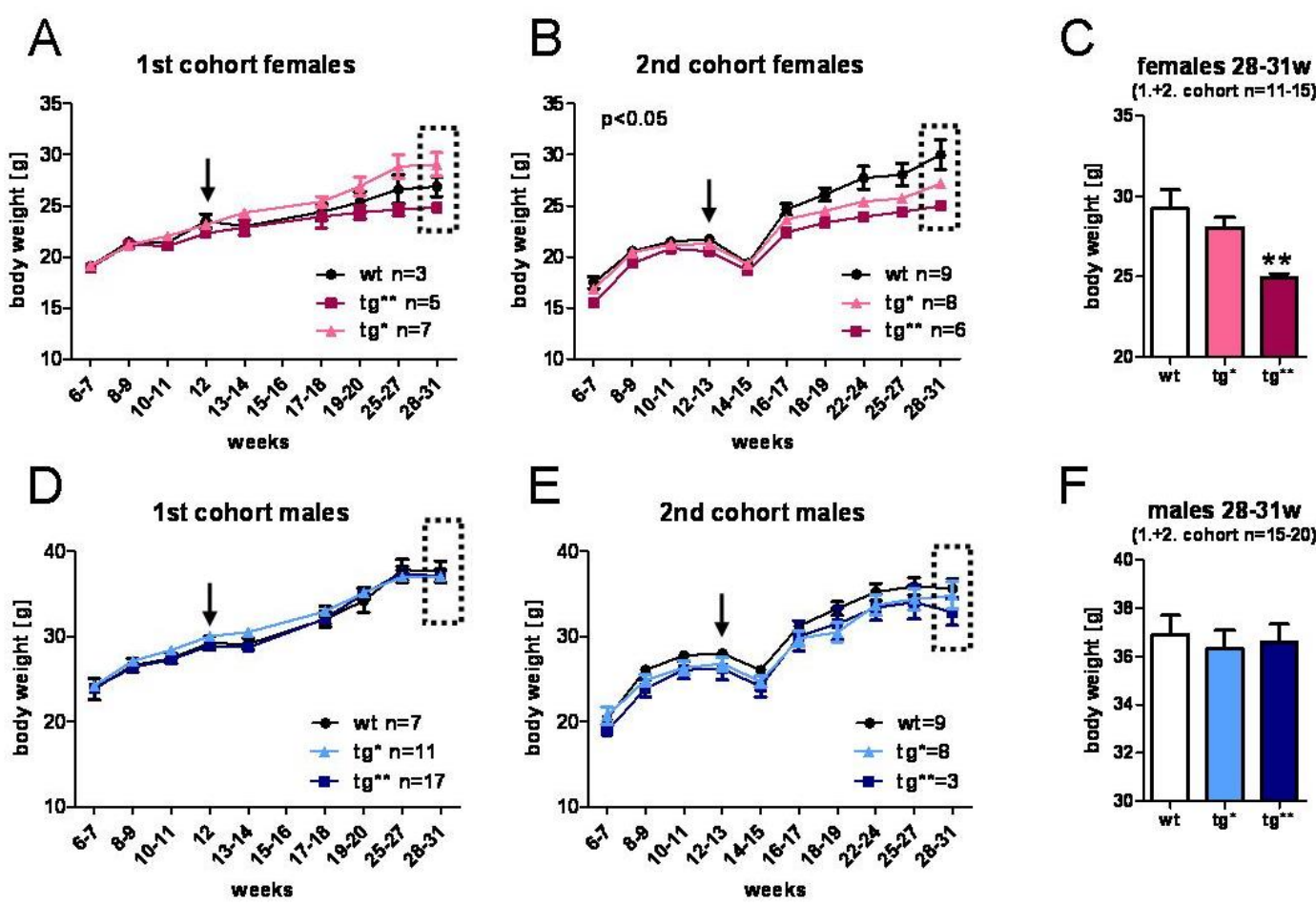

Figure 39: Body weight of two cohorts of mice (female and male). (A) First cohort of female mice. (B) Second cohort of female mice. (C) Bar graph of both cohorts of female mice at the age of 28-31 weeks. (D) First cohort of male mice. (E) Second cohort of male mice. (F) Bar graph of both cohorts of male mice at the age of 28-31 weeks. Mean \pm SEM shown; ${ }^{* * P} \leq 0.01$ (unpaired $t$-test) tg** compared to wt.

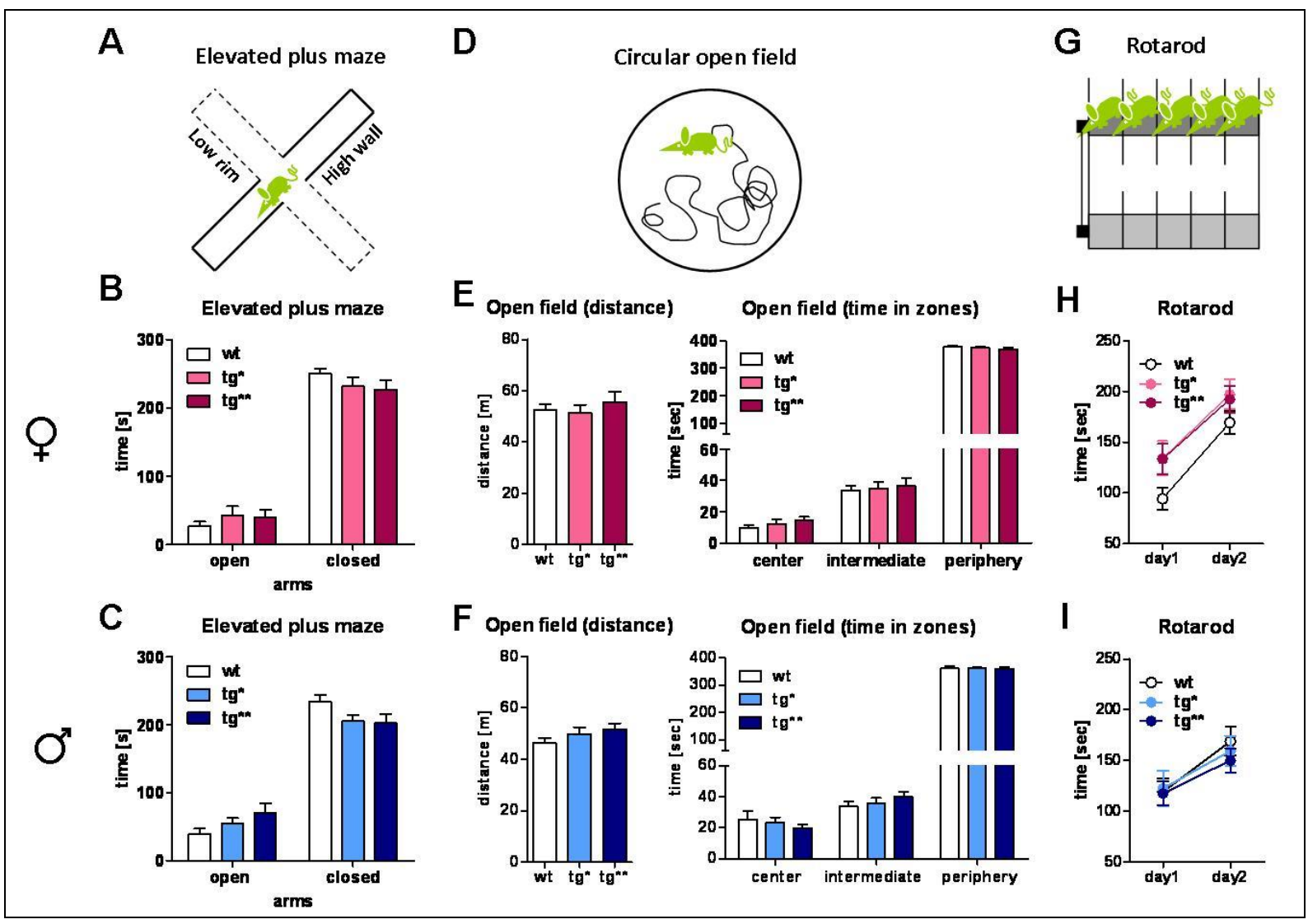

Figure 40: Transgenic female and male mice show normal behavior in basic tasks such as elevated plus maze $(A-C)$, open field (D-F), and rotarod (G-I). For all tests, animal numbers were as follows: female wt $=12, \operatorname{tg}^{*}=15$, $\operatorname{tg}^{* *}=11$ and male $\mathrm{wt}=15, \operatorname{tg}^{*}=19, \operatorname{tg}^{* *}=20$; mean \pm SEM. 
The rotarod was used to measure motor coordination and balancing performance. There were no differences between groups. Summarizing the first set of tests, one can conclude that the transgenic mice do not show significant differences in tasks measuring basic behaviors such as anxiety-like behavior, overall activity, or motor performance.

Next, the mice were evaluated for sensorimotor gating by prepulse inhibition (PPI). PPI is the phenomenon of the reduction of the acoustic startle response to a test stimulus if a less intense stimulus precedes the test stimulus. It has been proposed that PPI is mediated by a circuit of a fast excitatory and a slower inhibitory pathway that are activated in parallel (Larrauri and Schmajuk, 2006). In principle, an activation of the inhibitory neurons would result in a stronger pre-pulse inhibition. However, female and male mice showed no significant difference in PPI (Figure 41A, B). In addition, the startle response itself can also be used as a hearing test. For this purpose, a tone of $10 \mathrm{kHz}$ was applied randomly at different intensities. Again, no difference was found between wt and transgenic mice (Figure 41C, D). After having tested the hearing capability of the transgenic mice, olfaction and pain perception were analyzed. Olfaction was measured as the latency to find buried food. As a test for pain perception the hot plate test was performed. Both tests showed no differences of the tg mice compared to wt (Figure 41E-H).

To summarize, all basic behavior tests show results for tg mice that are indistinguishable from wt. Therefore, the prerequisite for sophisticated cognitive testing is provided.

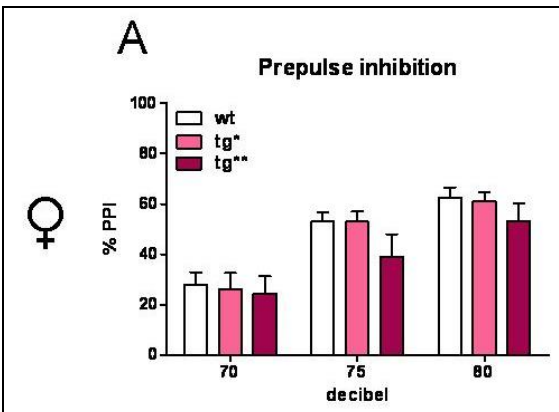

$\mathrm{B}$

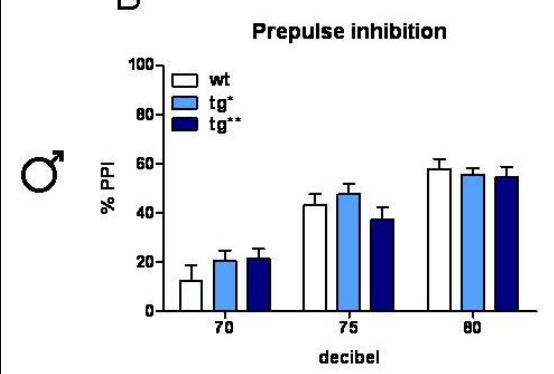

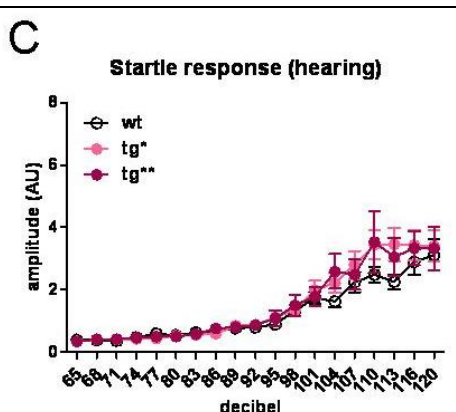

D

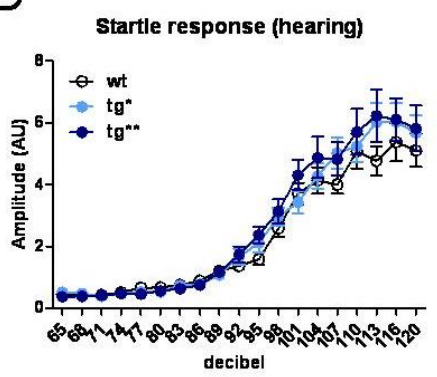

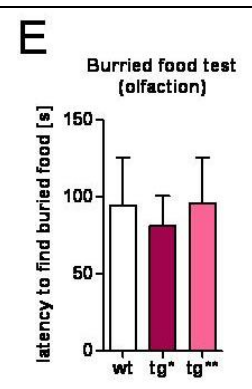

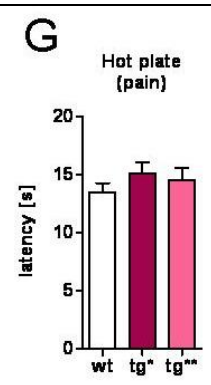

F

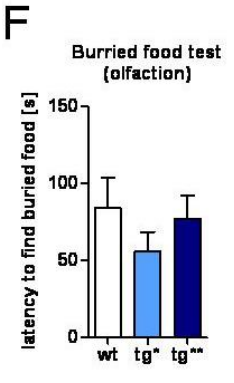

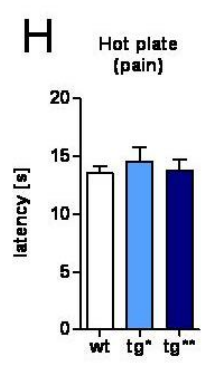

Figure 41: Transgenic female and male mice are normal in prepulse inhibition (PPI) (A, B), hearing (C, D), olfaction $(E, F)$, and pain perceptions $(G, H)$. For all tests, animal numbers were as the follows: female wt=12, $\operatorname{tg}^{*}=15, \operatorname{tg}^{* *}=11$ and male $\mathrm{wt}=15, \operatorname{tg}^{*}=19, \operatorname{tg}^{* *}=20 ;$ mean \pm SEM. 


\section{Spatial reference and working memory (hole board)}

A comprehensive cognitive test, which was used to analyze learning and memory, is the hole board test. The test includes the following phases: habituation, acquisition, long-term retention, and reversal learning. During habituation, the mice were trained with sucrose solution to investigate each of the 16 holes. In the second phase, the acquisition stage, only 4 out of the 16 holes were baited with the sucrose solution. The mice were tested with two trials per day for 6 days and had to learn and remember the location of the baited holes. In the test, two forms of spatial memory can be discriminated: 1. spatial reference memory (rule learning; remembering which holes are baited) and 2. spatial working memory (which holes have been already visited). The transgenic mice showed no differences in reference memory and spatial working memory when analyzed with ANOVA for repeated measures over all trials (Figure $42 \mathrm{~A}, \mathrm{~B}$ ).

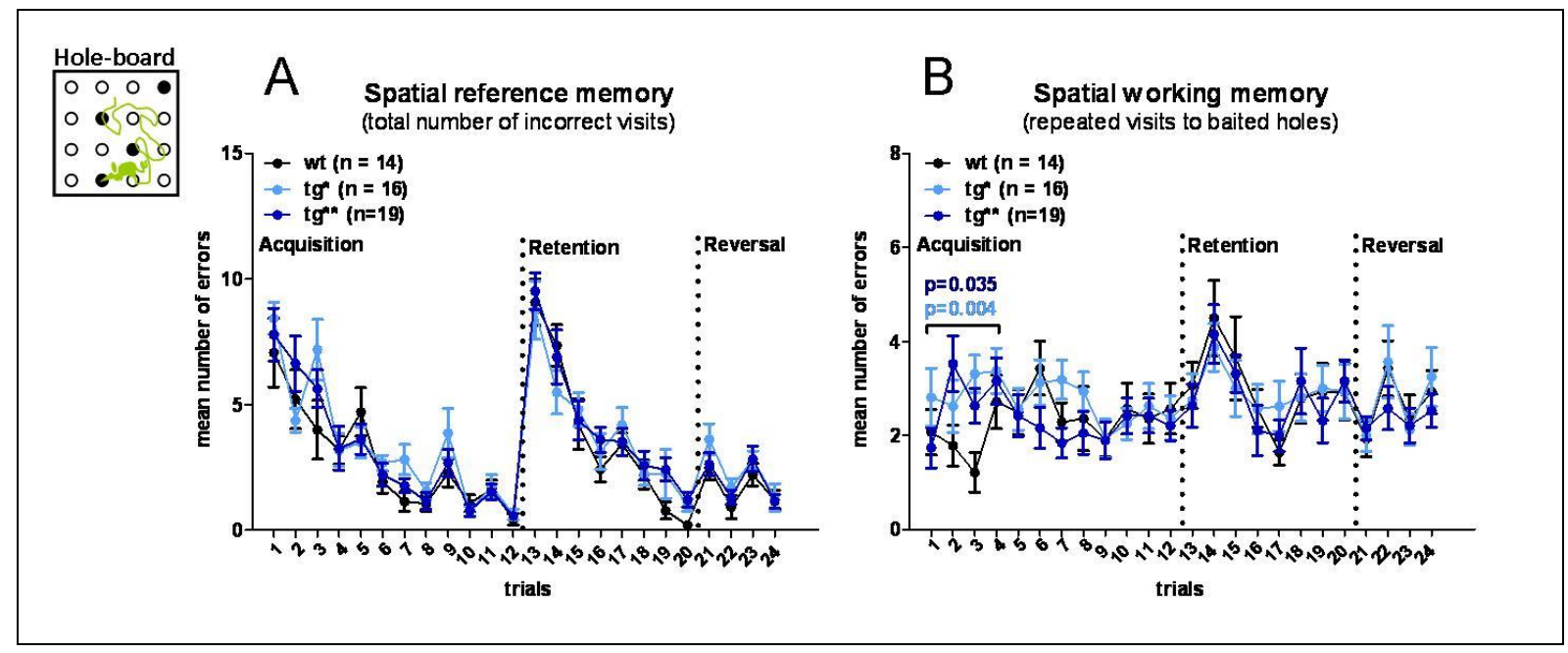

Figure 42: Transgenic male mice showed no difference in reference memory but in working memory in the hole board test. (A) Line graph of spatial reference memory. (B) Line graph of spatial working memory. Two trials were performed per day with an inter-trial interval of 2.5h. Data were analyzed with repeated measures ANOVA. Data are presented as mean \pm SEM.

The transition from the habituation phase to the acquisition phase involves changes in the general procedure as well as the reinforcement contingencies, including a reduction in the number of rewards available (16 during habituation and 4 during acquisition), a change in the maximal trial duration ( $15 \mathrm{~min}$ vs. $5 \mathrm{~min}$ ), and the number of trials per day (1 vs. 2 ). Therefore, the acquisition phase is composed of a procedural and rule learning stage (day 1 and 2, trial 1-4), where the animals have to learn that the task requirements have been changed, followed by the acquisition of the spatial relations between extra-maze cues and the location of baited holes. 
In these first two days of acquisition, the transgenic animals performed significantly worse in working memory (tg** vs. wt $p=0.035$, $\operatorname{tg}^{*}$ vs. wt $p=0.004$; repeated measures ANOVA). Here, no difference between the low $\mathrm{tg}^{*}$ and high $\mathrm{tg}^{* *}$ expressers was detected. In contrast, in the long-term retention and reversal phase of the test no differences were found in $\mathrm{tg}$ mice compared to wt. These findings indicate that cEPOR expression in inhibitory interneurons (Viaat) influences discrete aspects of higher cognitive function, best described as procedural or rule learning capacity.

\subsubsection{Electrophysiology - kainate induced gamma oscillation}

GABAergic and glycinergic interneurons are the main source of inhibition in the central nervous system and play a major role in neuronal network stabilization and oscillation. Gamma oscillations, with frequencies of $30-80 \mathrm{~Hz}$, are known to be associated with higher brain functions (Fries et al., 2007; Jensen et al., 2007) and were therefore a very interesting readout of the study. Gamma oscillations were induced by the addition of kainate in acute hippocampal slices of 6 week old male $\mathrm{tg}^{* *}$ and wt mice.

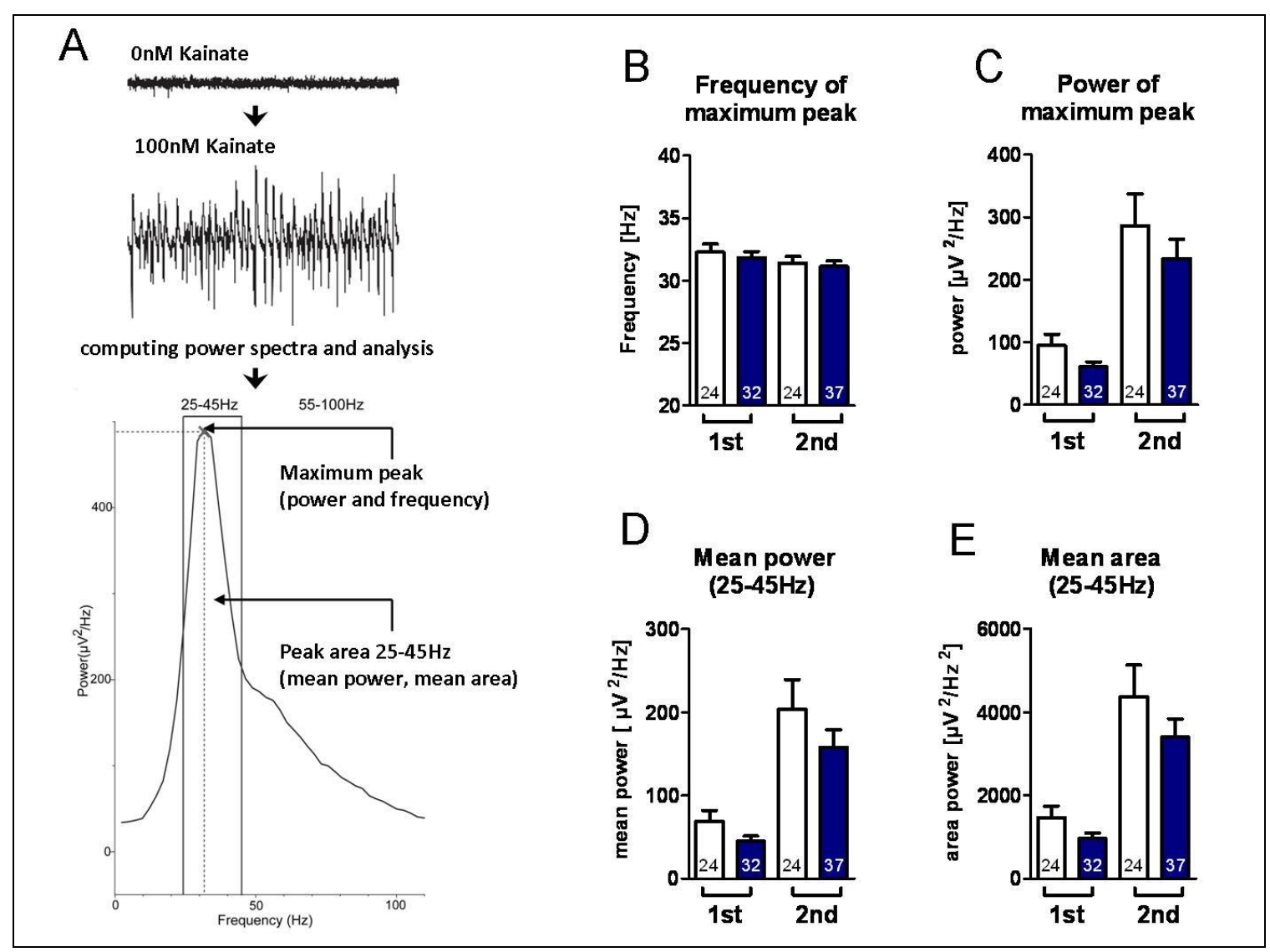

Figure 43: Kainate induced gamma oscillations in transgenic $\mathrm{tg}^{* *}$ male mice do not differ from wt. (A) Illustration of kainate induced oscillations, computed power spectrum as well as the analyzed parameters. (B-E) Bar graphs presenting the frequency and the power of the maximum peak and the mean power and area in the peak area of the $25-45 \mathrm{~Hz}$ interval in wt and $\mathrm{tg}^{* *}$ males in the $1^{\text {st }}$ and $2^{\text {nd }} 20 \mathrm{~min}$ of measured field potentials. Animal numbers: $\mathrm{wt}^{=7}$; $\mathrm{tg}^{* *}=10$; slice numbers $\mathrm{n}=24-37$ as indicated in columns. Mean \pm SEM presented. 
Baseline field-potentials were recorded in the CA3 region for 20 min before the addition of kainate and 2 times 20 min $\left(1^{\text {st }}\right.$ and $\left.2^{\text {nd }}\right)$ with addition of $100 \mathrm{nM}$ kainate in ACSF buffer. The power spectrum was computed and analyzed (for illustration see Figure 43A). The analyzed parameters were the power and frequency of the maximum peak and the mean power and area of the $25-45 \mathrm{~Hz}$ frequency interval. The $\operatorname{tg}^{* *}$ male mice showed no significant differences compared to wt animals (Figure 43B-E).

\subsubsection{Electrophysiology - short and long term potentiation (STP and LTP)}

Long term potentiation (LTP) is accepted as an electrophysiological correlate for synaptic plasticity and memory consolidation (Bliss and Collingridge, 1993; Cooke and Bliss, 2006) and was measured in the Schaffer collateral CA1 pathway of the hippocampus. As for the gamma oscillations, we used $\operatorname{tg}^{* *}$ male mice for STP and LTP determinations. The basal synaptic function in the transgenic $\operatorname{tg}^{* *}$ male mice was judged on the basis of the input-output curves and was comparable to wt mice (Figure 44A). The LTP was induced by applying 3 tetanic stimuli of $100 \mathrm{~Hz}$ for $1 \mathrm{~s}$ every $5 \mathrm{~min}$ and calculated by averaging the normalized fEPSP amplitude collected over $60 \mathrm{~min}$ after the last tetanic stimulus. STP was defined as the response in the first $10 \mathrm{~min}$ after the last titanic stimuli and was found to be significantly increased in the $\operatorname{tg}^{* *}$ mice compared to wt (tg** vs. wt, 1-10 min, genotype effect $p=0.023$, 1-way ANOVA for repeated measures; Figure 44B). The LTP showed comparable significances measured 10-60 min or 50-60 min after the last titanic stimulus. (tg** vs. wt, 10-60 min, genotype effect $p=0.030$; $\mathrm{tg}^{* *}$ vs. wt, 50-60 min, genotype effect $\mathrm{p}=0.025$; 1 -way ANOVA for repeated measures; Figure 44B).

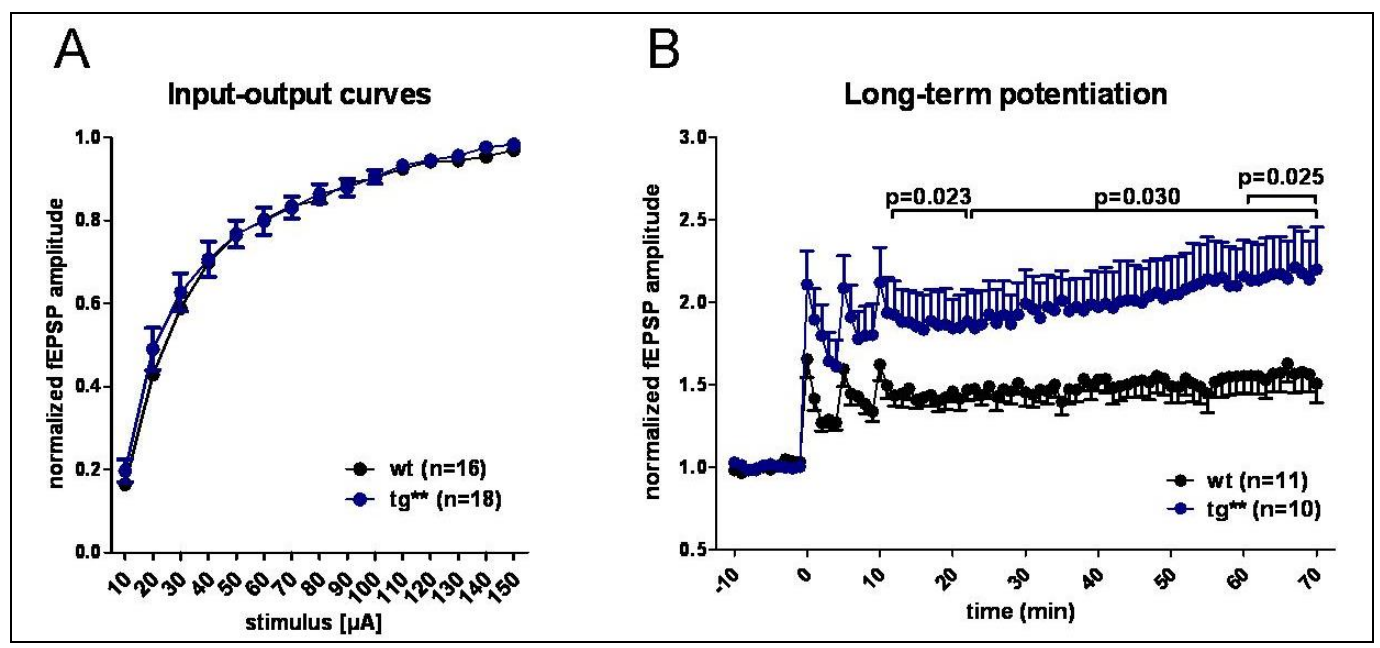

Figure 44: Electrophysiological analysis of the $\mathrm{tg}^{* *}$ male mice showed $(\mathrm{A})$ no differences in the input-output curves; animals numbers: $\mathrm{wt}^{\mathrm{t}}=7, \mathrm{tg} \mathrm{g}^{* *}=7$; slices numbers $\mathrm{wt}=16, \mathrm{tg}^{* *}=18$. (B) However, a significant increase was observed in LTP compared to wt mice; animals numbers: $w t=7, \operatorname{tg}^{* *}=6$; slices numbers $w_{t}=11, \operatorname{tg}^{* *}=10$. Data were analyzed with ANOVA for repeated measures. Data are presented as mean \pm SEM. 


\section{Discussion}

In this work, a transgenic mouse line expressing a constitutively active EPOR (CEPOR) in inhibitory interneurons was generated to provide further insight into the role of the EPO/EPOR system and the relative contribution of distinct neuronal subpopulations to EPOmediated effects on cognitive functions.

The project was based on results showing that systemically administered EPO is able to increase cognitive performance in mouse (Adamcio et al., 2008; El-Kordi et al., 2009) and man (Bartels et al., 2008; Ehrenreich et al., 2007b; Miskowiak et al., 2008). However, none of these studies focused on the underlying mechanisms or the cell type specific contribution to this phenomenon. Since EPO and EPOR are expressed in various cell types of the brain, including different subpopulations of neurons, oligodendrocytes and microglia, it is of interest to dissect the particular impact of these different cell types on the networks of cellular interactions and how they contribute to cognitive performance. For this, the EPO/EPOR system would have to be activated or inactivated in specific cell types. The first study, where the EPO/EPOR system was activated in a subpopulation of neurons, was published in 2011 (Sargin et al., 2011). There, a transgenic mouse line was generated that expresses the CEPOR in excitatory neurons under the alpha-CaMKII promoter. This transgenic mouse line showed increased hippocampal-dependent learning, social memory, attention and LTP compared to wt. However, the mouse showed also hyperactivity and impulsivity, which was not observed under systemically administered EPO (Table 1). This was discussed to result from a continuous stimulation of the EPO system exclusively in cortical projection neurons, leading to a relative deficit of inhibitory input and a disturbance of the homeostatic balance of excitation and inhibition in the brain (Sargin et al., 2011). This thesis continued the analysis of the cell type specific effects of the EPO/EPOR system in the brain. This time, the cEPOR was specifically expressed in GABAergic and glycinergic interneurons to examine the effect of EPO/EPOR activation in an inhibitory subpopulation of neurons in the brain.

\subsection{Expression of cEPOR in inhibitory interneurons}

Inhibitory interneurons are a very heterogeneous neuronal population and are classified by marker expression profiles, electrophysiological properties and morphology (Markram et al., 
2004). One feature, which almost all inhibitory neurons in the brain have in common, is the expression of GABA, the main inhibitory transmitter of the brain. A shared property is therefore the commonly expressed vesicular GABA transporter (VGAT). Since the transporter shuttles not only GABA but also the inhibitory transmitter glycine, the revised name is vesicular inhibitory amino acid transporter (Viaat). We used the Viaat BAC RP23-392P11 as promoter to express CEPOR in the majority of inhibitory interneurons in the central nervous system. The BAC RP23-392P11 includes not only the Viaat gene, which is around $5 \mathrm{~kb}$ in size and consists of two exons and one intron, but also the upstream and downstream promoter region of $\sim 125 \mathrm{~kb}$ and $\sim 68 \mathrm{~kb}$. Using BACs in the generation of transgenic animals has the advantage of a relatively independent transgene expression in terms of the genetic integration site. In the case of the Viaat-HA-CEPOR \pm IRES-Venus mice, the usage of the BAC RP23-392P11 was successful. In eight out of nine analyzed transgenic mouse lines, the expression could be visualized and colocalized with parvalbumin. The differences found in the amount of transgene expression were mainly dependent on the inserted copy number and less on the site of integration.

One question, that could not be answered, is why the expression of the construct was relatively low. This was also observed for the cEPOR expression in alpha-CaMKII-HA-cEPOR mice. At that time, it was speculated that the HA-tag might be causing the problem. The HAtag is a very short peptide of nine amino acids that is widely assumed to have a low impact on the natural structure and bioactivity of the proteins. However, the short sequence causes difficulties in the development of specific antibodies and reduces the number of antibodies, able to bind to the epitope. Problems of specificity also became apparent in this study. From four antibodies tested (results not shown), only two were specific in immunohistochemistry: the monoclonal rabbit anti-HA from Cell Signaling and the monoclonal mouse anti-HA from Covance. The polyclonal rabbit anti-HA from Abcam and the monoclonal rat anti-HA from Roche showed false positive cells. In order to achieve a better detection rate in the newly generated transgenic mouse, an internal fluorescent marker (IRES-Venus) was additionally inserted. However, this did not result in an appreciable improvement of detection sensitivity. Therefore, the low abundance seems to be inherent to cEPOR rather than being caused by the method of detection. Since a regulation on the level of transcription can be excluded, cEPOR might be restricted on the translational level or by a fast internalization and degradation of the protein. 


\subsection{Analysis of the Viaat-HA-cEPOR line D14-0023}

It is well known that the generation of transgenic animals with pronuclear injection has some limitations (Ohtsuka et al., 2012) and that the injected DNA gets integrated randomly and with different copy numbers. Therefore, each founder is unique and can express the construct in different intensities and in variable percentages of cells. Thus, it is common to analyze the founder lines separately and crossbreeding is rather unusual. One challenge is the selection of one or two lines for further analysis, since it is in general not possible to characterize all lines in detail. In this study, nine mouse lines were established and analyzed for transgene expression. One line that was chosen for further analysis showed the rare event of an insertion of the construct in two different chromosomes, which resulted in two distinct groups of very high and very low expressers in the offspring. This line (D14-0023) was behaviorally examined in anxiety-like behavior, overall activity, motor performance, PPI, hearing, olfaction, pain, spatial reference memory, and working memory. In summary, the transgenic mice showed no significant differences in their basic behavior. This situation is actually an ideal prerequisite for testing higher cognitive functions, since most readouts used for judging cognition are dependent on e.g. normal motor performance and activity. The mice were then analyzed with the reference and working memory version of the hole board test. Here, the transgenic mice showed reduced performance in rule learning during the acquisition phase. This is the first indication that the activated EPO/EPOR system in inhibitory neurons influences higher brain functions. To get further mechanistic inside, the Viaat-HA-cEPOR mice were electrophysiologically examined. The kainate induced gamma oscillation showed a strong tendency to be reduced in their power, and more experiments are currently running to clarify whether this effect can be consolidated. Additionally, hippocampal slices of the animals were tested for STP and LTP, which had earlier been shown to be increased after systemically administered EPO as well as in alpha-CaMKII-HAcEPOR mice. Interestingly, the Viaat-HA-cEPOR mice showed comparable increased STP and LTP.

\subsubsection{Gamma oscillation and memory formation}

It is one of the most challenging tasks in the field of neuroscience to identify the cellular and molecular processes underlying cognitive performance and memory formation (Lynch, 2004). Two electrophysiological readouts, the measurement of gamma oscillation and LTP, 
have gained considerable attention in the field. Gamma oscillations are hypothesized to modulate cognitive processes and are altered in psychiatric diseases including schizophrenia, autism, and anxiety disorders (Sohal, 2012). The rhythmic network inhibition by gamma oscillations, also postulated as gamma cycle (Fries et al., 2007), is thought to synchronize the network activity and thereby to organize the brain processes necessary for cognitive function (Ward, 2003). As mentioned above, the transgenic mice showed an overall tendency of a decreased power of gamma oscillations. This may be consistent with the slight reduction found in initial rule learning in a working memory task. More tests of higher cognitive functions are currently under way.

\subsubsection{LTP and memory formation}

In contrast to the gamma oscillations, the transgenic mice showed increased STP and LTP compared to wt mice. On first thought, it is difficult to accommodate a reduced cognitive performance in spatial working memory with increased LTP, since LTP is the most popular cellular readout for learning and memory (Cooke and Bliss, 2006; Lynch, 2004). However, there are increasing numbers of publications discussing and questioning the causal role of LTP for memory formation (Gerlai, 2002). Some reviews conclude that LTP is necessary but might be not sufficient for learning and memory (Martin et al., 2000) and others pursue the question if there is a role of LTP in memory formation at all (Goda and Stevens, 1996; Stevens, 1998). The latter proposition was mainly formed after experiments showing that blocked or decreased LTP in the dentate gyrus, the Schaffer collateral pathway or the mossy fiber pathway had no effects on spatial memory (Huang et al., 1995; Nosten-Bertrand et al., 1996; Qi et al., 1996; Saucier and Cain, 1995). Later on, publications indicated that increased LTP did not equate with increased learning and memory. Moreover, it was even shown, that increased LTP can be found in mice with decreased spatial memory (Migaud et al., 1998; Pineda et al., 2004; Uetani et al., 2000). Summarizing these studies, only severe LTP defects seem to impair spatial memory and decreased spatial memory is also present in animal models with increased LTP. One explanation discussed (Migaud et al., 1998) is a model of synaptic plasticity that includes bidirectional modifications of synaptic strength (potentiation and depression). If too many synapses become strongly potentiated and not enough depressed, this might result in a degradation of information storage and recall capacity, which, in the end, manifests as a learning impairment (Migaud et al., 1998). 
Finally, it is not only the question of how increased LTP can be linked to decreased memory formation, but also the question of how cEPOR expression in interneurons is able to increase LTP, which is an extracellular measurement of the activity of excitatory neurons.

\subsubsection{Comparison with EPO treated and with alpha-CaMKII-HA-cEPOR mice}

Getting back to the analysis of the specific impact of the EPO/EPOR system in neuronal subtypes on cognition, the so far achieved results of the Viaat-HA-cEPOR mice were compared with the results of systemically administered EPO (Adamcio et al., 2008) and the alpha-CaMKII-HA-cEPOR mice (Sargin et al., 2011) (Table 4). Here, the systemically administered EPO was seen as a collective model representing the sum of EPO action in all types of cells expressing the EPOR (inside as well as outside the brain). Of interest would be how the different cell types in the brain add to this picture. The first readout that was analyzed in all three models was spontaneous activity, which was unchanged after systematically administered EPO, but increased in alpha-CaMKII-HA-cEPOR mice. This was discussed to be caused by an excitatory/inhibitory imbalance and a relative deficit of inhibition (Sargin et al., 2011). It was hypothesized that an expression of cEPOR in inhibitory interneurons might strengthen the inhibitory output leading to reverse effects and reduced activity. However, the first results showed no decrease of activity in the Viaat-HA-cEPOR mice.

\begin{tabular}{|l|c|c|c|}
\hline \multicolumn{1}{|c|}{ Readout } & $\begin{array}{l}\text { Systemically } \\
\text { administered EPO }\end{array}$ & $\begin{array}{l}\text { alpha-CaMKII- } \\
\text { HA-cEPOR mice }\end{array}$ & $\begin{array}{l}\text { Viaat-HA- } \\
\text { cEPOR mice }\end{array}$ \\
\hline Spontaneous activity (Behavior) & $=$ & $\boldsymbol{\uparrow}$ (Hyperactive) & $=$ \\
\hline Cognition (Behavior) & $\uparrow$ & $\uparrow$ & $\downarrow$ \\
\hline STP and LTP (Electrophysiology) & $\uparrow$ & $\uparrow$ & $\uparrow$ \\
\hline Input-output curves (Electrophysiology) & $=$ & $\downarrow$ & $=$ \\
\hline
\end{tabular}

Table 4: Comparison of the EPO effects, if systemically administered, constitutively active in excitatory pyramidal cells (alpha-CaMKII-HA-cEPOR-mice) or constitutively active in inhibitory interneurons (Viaat-HacEPOR mice). = no change, $\uparrow$ increased, $\downarrow$ decreased.

Furthermore, the kainate induced gamma oscillation result suggests that the interneurons are rather decreased in their power than increased. This was consistent with the first cognitive readout, which showed a mild cognitive impairment in the Viaat-HA-CEPOR mice. These results contrast the effect of EPO treatment as well as CEPOR expression in excitatory neurons, where a significant improvement of cognitive performance was observed. Further tests are planned to analyze the phenotype of a mild cognitive impairment in more detail. 
Comparing the electrophysiological readouts, it was interesting to find all three models sharing the phenotype of increased STP and LTP, demonstrating the role of the EPO/EPOR system on potentiation of the synaptic strength. However, EPO did not change the basal excitability of the neurons, as seen in the input-output curves, in the EPO treated and the Viaat-HA-cEPOR transgenic mice, whereas the alpha-CaMKII-HA-cEPOR mice showed a decreased basal excitability.

\subsubsection{Body weight and metabolism}

During this study, an inconspicuous but very interesting discovery was made. The female transgenic mice were significantly reduced in their body weight at an age of 28-31 weeks, suggesting a role of the EPO/EPOR system on energy homeostasis. In fact, the first indication of EPO influencing metabolism was found in end-stage renal disease patients, who were treated with EPO (Khedr et al., 2009; Rasic-Milutinovic et al., 2008; Tuzcu et al., 2004) and showed improved insulin sensitivity. Recent studies suggest EPO as a beneficial treatment for type 2 diabetes, and showed improved glucose tolerance and inhibition of gluconeogenesis (Meng et al., 2013). The effect of EPO on metabolism was also determined in the $\mathrm{EPOR}^{-/-}$knockout animals, which were rescued for the blood system (EPOR ${ }^{-1-} \mathrm{TgEPOR}_{\mathrm{E}}$ ). Initially, these mice developed normally to start with and were fertile, but developed obesity and insulin resistance later in their life (Teng et al., 2011). Interestingly, the effect was more obvious in female mice as compared to male mice. Therefore, in our case, it is remarkable that the opposite effect is present in a transgenic mouse line with CEPOR expression in interneurons. This allows at least two speculative hypotheses. First, cEPOR expression in the inhibitory interneurons of the hypothalamus influences energy homeostasis (decreased food uptake and/or increased energy expenditure). Second, EPO could increase glucose uptake in general. This would be supported by the expression pattern of EPOR. EPOR is expressed at high levels in precursor cells or during hypoxic stress conditions, and in both cases the cells have an increased need of energy. Future work will have to investigate these hypotheses. 


\section{Outlook}

In this study, a transgenic mouse line expressing cEPOR in inhibitory interneurons was generated and analyzed. First results indicate that the mouse is normal in its basic behavior, but has a mild cognitive impairment, which manifests in deficits in spatial working memory. Additionally, the mouse was electrophysiologically analyzed and showed an increase in STP and LTP. However, the analysis of the newly generated transgenic mouse line is not finalized yet, and more experiments are planned to describe the phenotype in more detail. The planned experiments can be divided into three categories:

1.) Behavior analysis

2.) Electrophysiological analysis

3.) Cellular and biochemical analysis

For the behavior analysis, we plan several further experiments. One is the analysis of the $\operatorname{tg}^{*}$ and $\operatorname{tg}^{* *}$ mice in the Morris water maze, which is another tests of spatial learning and memory. Furthermore, it is planned to use the touch screen task to test higher brain functions, fear conditioning as an additional readout for hippocampal learning and memory, and marble burring, which can be used to analyze repetitive behavior or impulsivity.

For the electrophysiological analysis we are currently collecting data of the paired pulse facilitation as readout of short term plasticity, and we are also increasing the number of acute slices measuring kainate induced gamma oscillation. Analyses of long and short term depression (STD, LTD), as well as of low frequency oscillations, are currently considered for further experiments. Those results might help to understand how cEPOR expression in inhibitory interneurons is able to increase the network activity in form of LTP, to modulate synaptic strength, and to decrease in the end the cognitive performance.

The third category includes the cellular and biochemical analysis of the transgenic mouse line. One aspect, which has not been considered so far, is the effect of EPO on the differentiation of neural precursor cells. This phenomenon is explained in detail in the manuscript of the appendix. Therefore, it cannot be ruled out that cEPOR influences the differentiation of interneurons during embryonic development, since the Viaat promoter activity starts as early as E10 (Oh et al., 2005). This might result in a change of the total number of interneurons and we have already started counting Viaat-positive interneurons in the transgenic mouse line compared to wt. For this, the $\operatorname{tg}^{* *}$ mice were crossbred with a 
VGAT-Venus transgenic mouse line (Wang et al., 2009), to fluorescently label all Viaatpositive cells. In the same experiment, the percentage of Viaat-positive cells expressing the HA-cEPOR construct will be evaluated.

One interesting aspect of EPO action is the hypothesized influence on energy homeostasis and metabolism. We will analyze the protein turnover as metabolic readout, which can be measured by multi-isotope imaging mass spectrometry (MIMS) (Zhang et al., 2012). For this method, the mice are fed with food containing $L\left[{ }^{15} \mathrm{~N}\right]$ leucine, an amino acid labeled with a stable isotope. Newly synthesized protein will accumulate the isotope and will be become detectable with MIMS. If cEPOR is indeed increasing the protein turnover, the interneurons should then show a more pronounced ${ }^{15} \mathrm{~N}$ signal.

In summary, a new transgenic mouse line has been created in the current study. This line expresses the constitutively active EPOR in inhibitory interneurons. The already conducted initial analyses show very promising results but further experiments are necessary to complete the project. 


\section{References}

Adamcio, B., et al., 2008. Erythropoietin enhances hippocampal long-term potentiation and memory. BMC Biol. 6, 37.

Bartels, C., et al., 2008. Recombinant Human Erythropoietin: Novel Strategies for Neuroprotective/Neuro-regenerative Treatment of Multiple Sclerosis. Ther Adv Neurol Disord. 1, 193-206.

Baudin, A., et al., 1993. A simple and efficient method for direct gene deletion in Saccharomyces cerevisiae. Nucleic Acids Res. 21, 3329-30.

Berg JM, T. J., Stryer L. Biochemistry. W H Freeman, New York, 2002.

Bernaudin, M., et al., 1999. A potential role for erythropoietin in focal permanent cerebral ischemia in mice. J Cereb Blood Flow Metab. 19, 643-51.

Bickle, T. A., Kruger, D. H., 1993. Biology of DNA restriction. Microbiol Rev. 57, 434-50.

Bliss, T. V., Collingridge, G. L., 1993. A synaptic model of memory: long-term potentiation in the hippocampus. Nature. 361, 31-9.

Branda, C. S., Dymecki, S. M., 2004. Talking about a revolution: The impact of site-specific recombinases on genetic analyses in mice. Dev Cell. 6, 7-28.

Brines, M., Cerami, A., 2005. Emerging biological roles for erythropoietin in the nervous system. Nat Rev Neurosci. 6, 484-94.

Brines, M. L., et al., 2000. Erythropoietin crosses the blood-brain barrier to protect against experimental brain injury. Proc Natl Acad Sci U S A. 97, 10526-31.

Chomczynski, P., Sacchi, N., 1987. Single-step method of RNA isolation by acid guanidinium thiocyanate-phenol-chloroform extraction. Anal Biochem. 162, 156-9.

Chomczynski, P., Sacchi, N., 2006. The single-step method of RNA isolation by acid guanidinium thiocyanate-phenol-chloroform extraction: twenty-something years on. Nat Protoc. 1, 581-5.

Constantinescu, S. N., et al., 1999a. The Erythropoietin Receptor: Structure, Activation and Intracellular Signal Transduction. Trends Endocrinol Metab. 10, 18-23.

Constantinescu, S. N., et al., 1999b. Activation of the erythropoietin receptor by the gp55-P viral envelope protein is determined by a single amino acid in its transmembrane domain. EMBO J. 18, 3334-47.

Cooke, S. F., Bliss, T. V., 2006. Plasticity in the human central nervous system. Brain. 129, 1659-73.

Copeland, N. G., et al., 2001. Recombineering: a powerful new tool for mouse functional genomics. Nat Rev Genet. 2, 769-79.

D'Andrea, A. D., et al., 1989. Expression cloning of the murine erythropoietin receptor. Cell. 57, 277-85.

D'Andrea, A. D., et al., 1991. The cytoplasmic region of the erythropoietin receptor contains nonoverlapping positive and negative growth-regulatory domains. Mol Cell Biol. 11, 1980-7.

Davis, J. M., et al., 1987. Characterization of recombinant human erythropoietin produced in Chinese hamster ovary cells. Biochemistry. 26, 2633-8.

de la Chapelle, A., et al., 1993. Truncated erythropoietin receptor causes dominantly inherited benign human erythrocytosis. Proc Natl Acad Sci U S A. 90, 4495-9.

Digicaylioglu, M., et al., 1995. Localization of specific erythropoietin binding sites in defined areas of the mouse brain. Proc Natl Acad Sci U S A. 92, 3717-20. 
Digicaylioglu, M., Lipton, S. A., 2001. Erythropoietin-mediated neuroprotection involves cross-talk between Jak2 and NF-kappaB signalling cascades. Nature. 412, 641-7.

Divoky, V., et al., 2001. Mouse model of congenital polycythemia: Homologous replacement of murine gene by mutant human erythropoietin receptor gene. Proc Natl Acad Sci U S A. 98, 986-91.

Ebert, B. L., Bunn, H. F., 1999. Regulation of the erythropoietin gene. Blood. 94, 1864-77.

Ehrenreich, H., et al., 2004. Erythropoietin: a candidate compound for neuroprotection in schizophrenia. Mol Psychiatry. 9, 42-54.

Ehrenreich, H., et al., 2007a. Exploring recombinant human erythropoietin in chronic progressive multiple sclerosis. Brain. 130, 2577-88.

Ehrenreich, H., et al., 2002. Erythropoietin therapy for acute stroke is both safe and beneficial. Mol Med. 8, 495-505.

Ehrenreich, H., et al., 2007b. Improvement of cognitive functions in chronic schizophrenic patients by recombinant human erythropoietin. Mol Psychiatry. 12, 206-20.

Ehrenreich, H., et al., 2011. Circulating damage marker profiles support a neuroprotective effect of erythropoietin in ischemic stroke patients. Mol Med. 17, 1306-10.

Ehrenreich, H., et al., 2009. Recombinant human erythropoietin in the treatment of acute ischemic stroke. Stroke. 40, e647-56.

El-Kordi, A., et al., 2009. Erythropoietin improves operant conditioning and stability of cognitive performance in mice. BMC Biol. 7, 37.

Elliott, S., et al., 2006. Anti-Epo receptor antibodies do not predict Epo receptor expression. Blood. 107, 1892-5.

Eschbach, J. W., et al., 1987. Correction of the anemia of end-stage renal disease with recombinant human erythropoietin. Results of a combined phase I and II clinical trial. N Engl J Med. 316, 73-8.

Finney, M., 2001. Pulsed-field gel electrophoresis. Curr Protoc Mol Biol. Chapter 2, Unit2 5B. Fisher, J. W., 2003. Erythropoietin: physiology and pharmacology update. Exp Biol Med (Maywood). 228, 1-14.

Fisher, J. W., 2010. Landmark advances in the development of erythropoietin. Exp Biol Med (Maywood). 235, 1398-411.

Fries, P., et al., 2007. The gamma cycle. Trends Neurosci. 30, 309-16.

Gerlai, R., 2002. Hippocampal LTP and memory in mouse strains: is there evidence for a causal relationship? Hippocampus. 12, 657-66.

Goda, Y., Stevens, C. F., 1996. Synaptic plasticity: the basis of particular types of learning. Curr Biol. 6, 375-8.

Haase, V. H., 2010. Hypoxic regulation of erythropoiesis and iron metabolism. Am J Physiol Renal Physiol. 299, F1-13.

Higuchi, R., et al., 1992. Simultaneous amplification and detection of specific DNA sequences. Biotechnology (N Y). 10, 413-7.

Huang, L. J., et al., 2010. Advances in understanding the pathogenesis of primary familial and congenital polycythaemia. Br J Haematol. 148, 844-52.

Huang, Y. Y., et al., 1995. A genetic test of the effects of mutations in PKA on mossy fiber LTP and its relation to spatial and contextual learning. Cell. 83, 1211-22.

Jacobs, K., et al., 1985. Isolation and characterization of genomic and cDNA clones of human erythropoietin. Nature. 313, 806-10.

Jelkmann, W., 1992. Erythropoietin: structure, control of production, and function. Physiol Rev. 72, 449-89.

Jelkmann, W., 2004. Molecular biology of erythropoietin. Intern Med. 43, 649-59. 
Jelkmann, W., Metzen, E., 1996. Erythropoietin in the control of red cell production. Ann Anat. 178, 391-403.

Jensen, O., et al., 2007. Human gamma-frequency oscillations associated with attention and memory. Trends Neurosci. 30, 317-24.

Jones, S. S., et al., 1990. Human erythropoietin receptor: cloning, expression, and biologic characterization. Blood. 76, 31-5.

Juvonen, E., et al., 1991. Autosomal dominant erythrocytosis caused by increased sensitivity to erythropoietin. Blood. 78, 3066-9.

Kästner, A., et al., 2012. Common variants of the genes encoding erythropoietin and its receptor modulate cognitive performance in schizophrenia. Mol Med. 18, 1029-40.

Khedr, E., et al., 2009. Effect of recombinant human erythropoietin on insulin resistance in hemodialysis patients. Hemodial Int. 13, 340-6.

Kieran, M. W., et al., 1996. Thrombopoietin rescues in vitro erythroid colony formation from mouse embryos lacking the erythropoietin receptor. Proc Natl Acad Sci U S A. 93, 9126-31.

Kirkeby, A., et al., 2007. Functional and immunochemical characterisation of different antibodies against the erythropoietin receptor. J Neurosci Methods. 164, 50-8.

Klingmüller, U., 1997. The role of tyrosine phosphorylation in proliferation and maturation of erythroid progenitor cells--signals emanating from the erythropoietin receptor. Eur J Biochem. 249, 637-47.

Klingmüller, U., et al., 1995. Specific recruitment of SH-PTP1 to the erythropoietin receptor causes inactivation of JAK2 and termination of proliferative signals. Cell. 80, 729-38.

Konishi, Y., et al., 1993. Trophic effect of erythropoietin and other hematopoietic factors on central cholinergic neurons in vitro and in vivo. Brain Res. 609, 29-35.

Kuc, K. A., et al., 2006. Holeboard discrimination learning in mice. Genes Brain Behav. 5, 35563.

Kurien, B. T., Scofield, R. H., 2006. Western blotting. Methods. 38, 283-93.

Lacroix, C., et al., 2011. FLP/FRT-mediated conditional mutagenesis in pre-erythrocytic stages of Plasmodium berghei. Nat Protoc. 6, 1412-28.

Laemmli, U. K., 1970. Cleavage of structural proteins during the assembly of the head of bacteriophage T4. Nature. 227, 680-5.

Larrauri, J., Schmajuk, N., 2006. Prepulse inhibition mechanisms and cognitive processes: a review and model. EXS. 98, 245-78.

Lewczuk, P., et al., 2000. Survival of hippocampal neurons in culture upon hypoxia: effect of erythropoietin. Neuroreport. 11, 3485-8.

Lin, C. S., et al., 1996. Differential effects of an erythropoietin receptor gene disruption on primitive and definitive erythropoiesis. Genes Dev. 10, 154-64.

Lin, F. K., et al., 1985. Cloning and expression of the human erythropoietin gene. Proc Natl Acad Sci U S A. 82, 7580-4.

Liu, C., et al., 1997. Regulated human erythropoietin receptor expression in mouse brain. J Biol Chem. 272, 32395-400.

Liu, P., et al., 2003. A highly efficient recombineering-based method for generating conditional knockout mutations. Genome Res. 13, 476-84.

Liu, Z. Y., et al., 1994. Tissue specific expression of human erythropoietin receptor in transgenic mice. Dev Biol. 166, 159-69.

Livnah, O., et al., 1999. Crystallographic evidence for preformed dimers of erythropoietin receptor before ligand activation. Science. 283, 987-90. 
Longmore, G. D., 1993. Erythropoietin receptor mutations and Olympic glory. Nat Genet. 4, 108-10.

Lowry, O. H., et al., 1951. Protein measurement with the Folin phenol reagent. J Biol Chem. 193, 265-75.

Lynch, M. A., 2004. Long-term potentiation and memory. Physiol Rev. 84, 87-136.

Malatesta, P., et al., 2003. Neuronal or glial progeny: regional differences in radial glia fate. Neuron. 37, 751-64.

Markram, H., et al., 2004. Interneurons of the neocortical inhibitory system. Nat Rev Neurosci. 5, 793-807.

Marti, H. H., et al., 1996. Erythropoietin gene expression in human, monkey and murine brain. Eur J Neurosci. 8, 666-76.

Martin, S. J., et al., 2000. Synaptic plasticity and memory: an evaluation of the hypothesis. Annu Rev Neurosci. 23, 649-711.

Masuda, S., et al., 1993. Functional erythropoietin receptor of the cells with neural characteristics. Comparison with receptor properties of erythroid cells. J Biol Chem. $268,11208-16$.

Masuda, S., et al., 1994. A novel site of erythropoietin production. Oxygen-dependent production in cultured rat astrocytes. J Biol Chem. 269, 19488-93.

Meng, R., et al., 2013. Erythropoietin inhibits gluconeogenesis and inflammation in the liver and improves glucose intolerance in high-fat diet-fed mice. PLoS One. 8, e53557.

Migaud, M., et al., 1998. Enhanced long-term potentiation and impaired learning in mice with mutant postsynaptic density-95 protein. Nature. 396, 433-9.

Miskowiak, K., et al., 2008. Differential effects of erythropoietin on neural and cognitive measures of executive function 3 and 7 days post-administration. Exp Brain Res. 184, 313-21.

Miskowiak, K., et al., 2007. Erythropoietin reduces neural and cognitive processing of fear in human models of antidepressant drug action. Biol Psychiatry. 62, 1244-50.

Miskowiak, K. W., et al., 2012. Erythropoietin: a candidate treatment for mood symptoms and memory dysfunction in depression. Psychopharmacology (Berl). 219, 687-98.

Miura, O., et al., 1991. Induction of tyrosine phosphorylation by the erythropoietin receptor correlates with mitogenesis. Mol Cell Biol. 11, 4895-902.

Miyake, T., et al., 1977. Purification of human erythropoietin. J Biol Chem. 252, 5558-64.

Moore, D., et al., 2002. Isolation and purification of large DNA restriction fragments from agarose gels. Curr Protoc Mol Biol. Chapter 2, Unit 26.

Morishita, E., et al., 1997. Erythropoietin receptor is expressed in rat hippocampal and cerebral cortical neurons, and erythropoietin prevents in vitro glutamate-induced neuronal death. Neuroscience. 76, 105-16.

Nagai, A., et al., 2001. Erythropoietin and erythropoietin receptors in human CNS neurons, astrocytes, microglia, and oligodendrocytes grown in culture. J Neuropathol Exp Neurol. 60, 386-92.

Noguchi, C. T., et al., 2007. Role of erythropoietin in the brain. Crit Rev Oncol Hematol. 64, 159-71.

Noguchi, C. T., et al., 2008. Survival and proliferative roles of erythropoietin beyond the erythroid lineage. Expert Rev Mol Med. 10, e36.

Nosten-Bertrand, M., et al., 1996. Normal spatial learning despite regional inhibition of LTP in mice lacking Thy-1. Nature. 379, 826-9. 
Oh, W. J., et al., 2005. The mouse vesicular inhibitory amino acid transporter gene: expression during embryogenesis, analysis of its core promoter in neural stem cells and a reconsideration of its alternate splicing. Gene. 351, 39-49.

Ohtsuka, M., et al., 2012. PITT: pronuclear injection-based targeted transgenesis, a reliable transgene expression method in mice. Exp Anim. 61, 489-502.

Pineda, V. V., et al., 2004. Removal of G(ialpha1) constraints on adenylyl cyclase in the hippocampus enhances LTP and impairs memory formation. Neuron. 41, 153-63.

Qi, M., et al., 1996. Impaired hippocampal plasticity in mice lacking the Cbeta1 catalytic subunit of cAMP-dependent protein kinase. Proc Natl Acad Sci U S A. 93, 1571-6.

Rasic-Milutinovic, Z., et al., 2008. The effect of recombinant human erythropoietin treatment on insulin resistance and inflammatory markers in non-diabetic patients on maintenance hemodialysis. Hippokratia. 12, 157-61.

Sakanaka, M., et al., 1998. In vivo evidence that erythropoietin protects neurons from ischemic damage. Proc Natl Acad Sci U S A. 95, 4635-40.

Sargin, D., et al., 2011. Expression of constitutively active erythropoietin receptor in pyramidal neurons of cortex and hippocampus boosts higher cognitive functions in mice. BMC Biol. 9, 27.

Sargin, D., et al., 2010. Erythropoietin as neuroprotective and neuroregenerative treatment strategy: comprehensive overview of 12 years of preclinical and clinical research. Best Pract Res Clin Anaesthesiol. 24, 573-94.

Sasaki, H., et al., 1987. Carbohydrate structure of erythropoietin expressed in Chinese hamster ovary cells by a human erythropoietin cDNA. J Biol Chem. 262, 12059-76.

Saucier, D., Cain, D. P., 1995. Spatial learning without NMDA receptor-dependent long-term potentiation. Nature. 378, 186-9.

Sawitzke, J. A., et al., 2007. Recombineering: in vivo genetic engineering in E. coli, S. enterica, and beyond. Methods Enzymol. 421, 171-99.

Sawyer, S. T., et al., 1987. Identification of the receptor for erythropoietin by cross-linking to Friend virus-infected erythroid cells. Proc Natl Acad Sci U S A. 84, 3690-4.

Schleif, R., 2003. AraC protein: a love-hate relationship. Bioessays. 25, 274-82.

Semenza, G. L., Wang, G. L., 1992. A nuclear factor induced by hypoxia via de novo protein synthesis binds to the human erythropoietin gene enhancer at a site required for transcriptional activation. Mol Cell Biol. 12, 5447-54.

Sharan, S. K., et al., 2009. Recombineering: a homologous recombination-based method of genetic engineering. Nat Protoc. 4, 206-23.

Sinclair, A. M., et al., 2010. Functional erythropoietin receptor is undetectable in endothelial, cardiac, neuronal, and renal cells. Blood. 115, 4264-72.

Sirén, A. L., et al., 2001. Erythropoietin prevents neuronal apoptosis after cerebral ischemia and metabolic stress. Proc Natl Acad Sci U S A. 98, 4044-9.

Sohal, V. S., 2012. Insights into cortical oscillations arising from optogenetic studies. Biol Psychiatry. 71, 1039-45.

Stevens, C. F., 1998. A million dollar question: does LTP = memory? Neuron. 20, 1-2.

Sugawa, M., et al., 2002. Effects of erythropoietin on glial cell development; oligodendrocyte maturation and astrocyte proliferation. Neurosci Res. 44, 391-403.

Suzuki, N., et al., 2002. Erythroid-specific expression of the erythropoietin receptor rescued its null mutant mice from lethality. Blood. 100, 2279-88.

Tan, C. C., et al., 1992. Feedback modulation of renal and hepatic erythropoietin mRNA in response to graded anemia and hypoxia. Am J Physiol. 263, F474-81. 
Teng, R., et al., 2011. Disrupted erythropoietin signalling promotes obesity and alters hypothalamus proopiomelanocortin production. Nat Commun. 2, 520.

Tilbrook, P. A., Klinken, S. P., 1999. The erythropoietin receptor. Int J Biochem Cell Biol. 31, 1001-5.

Tsai, P. T., et al., 2006. A critical role of erythropoietin receptor in neurogenesis and poststroke recovery. J Neurosci. 26, 1269-74.

Tuzcu, A., et al., 2004. The comparison of insulin sensitivity in non-diabetic hemodialysis patients treated with and without recombinant human erythropoietin. Horm Metab Res. 36, 716-20.

Uetani, N., et al., 2000. Impaired learning with enhanced hippocampal long-term potentiation in PTPdelta-deficient mice. EMBO J. 19, 2775-85.

Voytas, D., 2001. Agarose gel electrophoresis. Curr Protoc Immunol. Chapter 10, Unit 104.

Wang, Y., et al., 2009. Fluorescent labeling of both GABAergic and glycinergic neurons in vesicular GABA transporter (VGAT)-venus transgenic mouse. Neuroscience. 164, 1031-43.

Ward, L. M., 2003. Synchronous neural oscillations and cognitive processes. Trends Cogn Sci. 7, 553-9.

Watowich, S. S., et al., 1992. Homodimerization and constitutive activation of the erythropoietin receptor. Proc Natl Acad Sci U S A. 89, 2140-4.

Watson, R. E., Jr., et al., 1986. Use of cryoprotectant to maintain long-term peptide immunoreactivity and tissue morphology. Peptides. 7, 155-9.

Witthuhn, B. A., et al., 1993. JAK2 associates with the erythropoietin receptor and is tyrosine phosphorylated and activated following stimulation with erythropoietin. Cell. 74, 227-36.

Wu, H., et al., 1999. Inactivation of erythropoietin leads to defects in cardiac morphogenesis. Development. 126, 3597-605.

Wu, H., et al., 1995. Generation of committed erythroid BFU-E and CFU-E progenitors does not require erythropoietin or the erythropoietin receptor. Cell. 83, 59-67.

Wüstenberg, T., et al., 2011. Recombinant human erythropoietin delays loss of gray matter in chronic schizophrenia. Mol Psychiatry. 16, 26-36, 1.

Yoshimura, A., et al., 1990. Point mutation in the exoplasmic domain of the erythropoietin receptor resulting in hormone-independent activation and tumorigenicity. Nature. $348,647-9$.

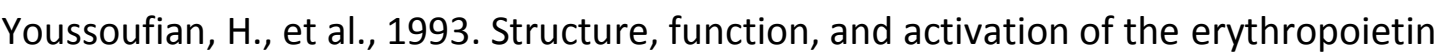
receptor. Blood. 81, 2223-36.

Youssoufian, H., et al., 1990. Structure and transcription of the mouse erythropoietin receptor gene. Mol Cell Biol. 10, 3675-82.

$\mathrm{Yu}, \mathrm{X}$., et al., 2002. Erythropoietin receptor signalling is required for normal brain development. Development. 129, 505-16.

Zeller, R., 2001. Fixation, embedding, and sectioning of tissues, embryos, and single cells. Curr Protoc Mol Biol. Chapter 14, Unit 141.

Zhang, D. S., et al., 2012. Multi-isotope imaging mass spectrometry reveals slow protein turnover in hair-cell stereocilia. Nature. 481, 520-4.

Zhuo, L., et al., 2001. hGFAP-cre transgenic mice for manipulation of glial and neuronal function in vivo. Genesis. 31, 85-94.

Zon, L. I., et al., 1991. Activation of the erythropoietin receptor promoter by transcription factor GATA-1. Proc Natl Acad Sci U S A. 88, 10638-41. 


\section{Appendix}

In agreement with the first reviewer, Prof. Dr. Dr. Hannelore Ehrenreich, the second reviewer, Prof. Dr. Klaus-Armin Nave, and the speaker of the doctoral program (Center for Systems Neuroscience), Prof. Dr. Stefan Treue, the appendix with the manuscript draft of thesis project 1 , is not published in the official version of the thesis. Its publication as an original paper will follow as soon as the manuscript (which is presently in revision) is accepted. 


\section{Curriculum Vitae}

\section{$\underline{\text { Personal data }}$}

$\begin{array}{ll}\text { Name } & \text { Liane Valerie Dahm } \\ \text { E-mail } & \text { dahm@em.mpg.de } \\ \text { Date of birth } & \text { August 8, 1981 } \\ \text { Place of birth } & \text { Wiesbaden, Germany } \\ \text { Nationality } & \text { German }\end{array}$

\section{Education}

04/2009 - present Georg-August-University (Göttingen, Germany) Doctoral student in the research group of Clinical Neuroscience at the Max Planck Institute of Experimental medicine, (PhD program - Center for Systems Neuroscience, Graduate School for Neuroscience and Molecular Biosciences)

03/2008 - 03/2009 Georg-August-University (Göttingen, Germany) Doctoral student in the research group of Neuroanatomy at the Center of Anatomy

10/2003-04/2007 Friedrich-Schiller-University (Jena, Germany) Diploma in biochemistry

10/2001 - 09/2003 Martin-Luther-University (Halle-Wittenberg, Germany) Intermediate diploma in biochemistry

06/2001 Jakob-Grimm-Schule (Rotenburg, Germany) Abitur

\section{Teaching}

2010, 2011, 2012 Junior lecturer at the yearly interdisciplinary workshop Translational Neuroscience, Block: Schizophrenia,

2009/2010/2011 Junior lecturer at the yearly interdisciplinary workshop Translational Neuroscience, Block: Multiple Sclerosis 


\section{Attended conferences and symposia}

October 29-30, 2012

(Jerusalem, Israel)

July 13-15, 2012

(Lübeck, Germany)

July 14-18, 2011

(Florenz, Italy)

September 17, 2010

(Göttingen, Germany)

July 30 - August 1, 2009

(Lübeck, Germany)
Workshop - From genes to intervention

'The molecular basis of neurological disorders'

Oral presentation

$9^{\text {th }}$ International Lübeck Conference on the Pathophysiology

and Pharmacology of Erythropoietin and other Hematopoietic

Growth factors

Poster presentation

$8^{\text {th }}$ IBRO World Congress of Neuroscience

Poster presentation

$4^{\text {th }}$ International Symposium on Schizophrenia of the Göttingen

Research Association for Schizophrenia

$8^{\text {th }}$ International Lübeck Conference on the Pathophysiology and Pharmacology of Erythropoietin and other Hematopoietic Growth factors

Poster presentation

March 25-29, 2009

$8^{\text {th }}$ Göttingen Meeting of the German Neuroscience Society Poster presentation

GBM-Meeting, Young Scientists meet Experience

Oral presentation

SfN Neuroscience meeting 2007

Poster presentation

(San Diego, USA)

\section{Publications}

Dahm L., Klugmann F., Gonzales-Algaba A., Reuss B. (2010) Tamoxifen and raloxifene modulate gap junction coupling during early phases of retinoic acid-dependent neuronal differentiation of NTera2/D1 cells. Cell Biol Toxicol. 26, 579-91. 